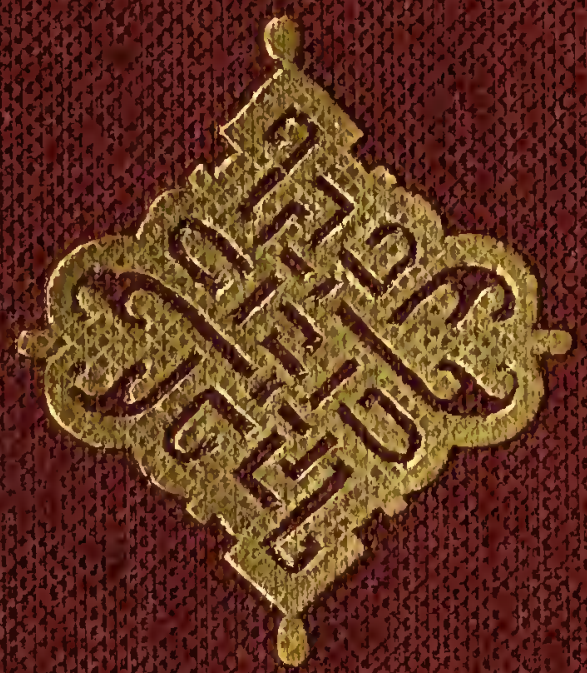




\section{PRI 38253}

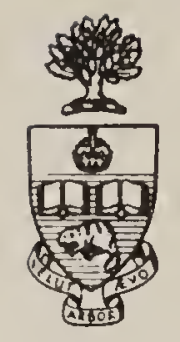

Presented to the

LIBRARY of the

UNIVERSITY OF TORONTO

by

Mrs. Andrew Kellogg 


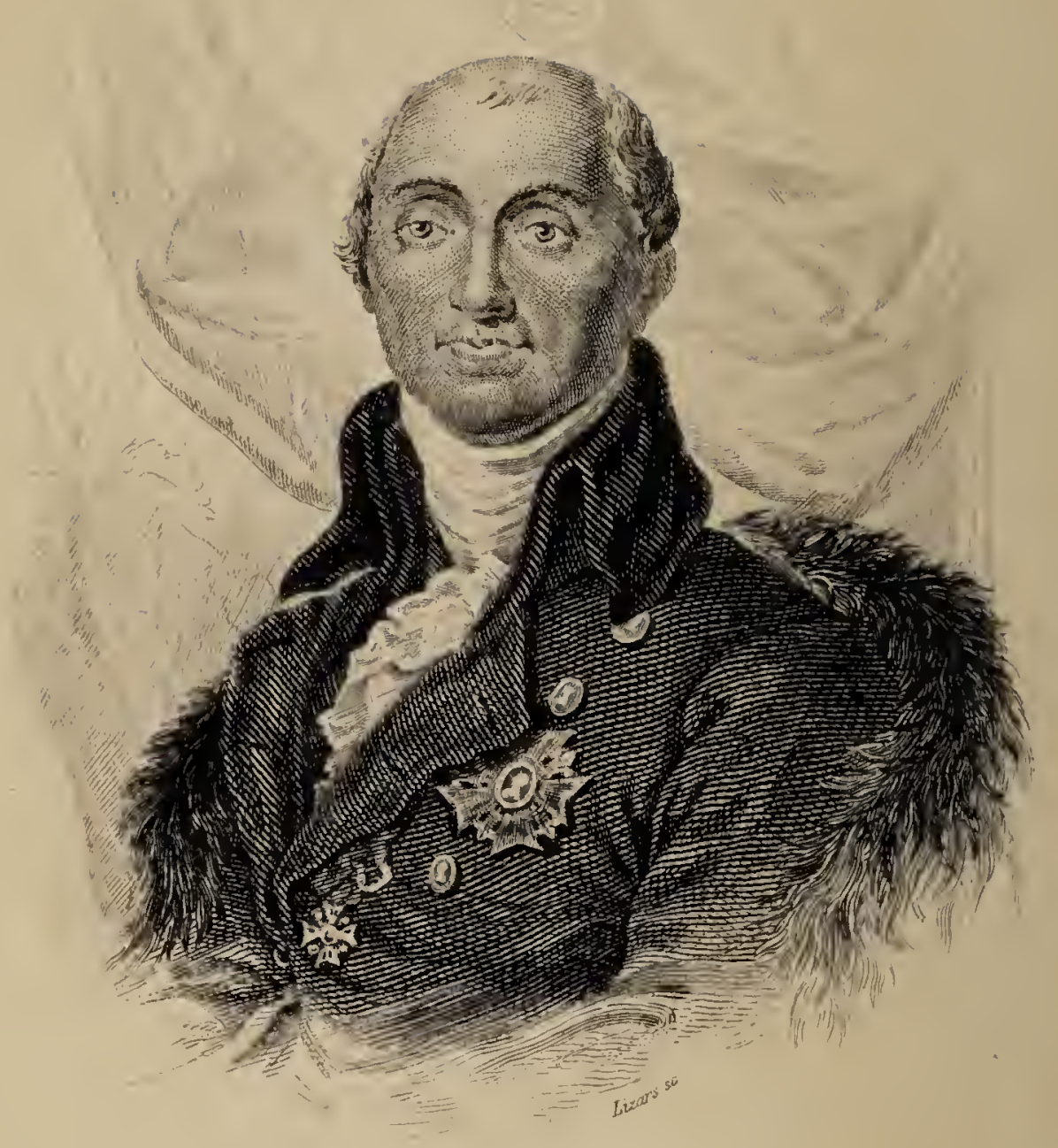

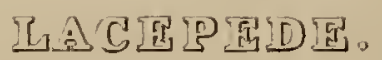


"T' HIT

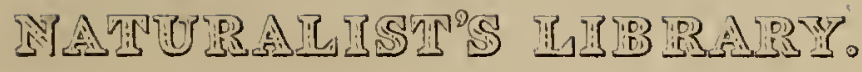

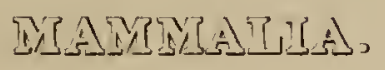

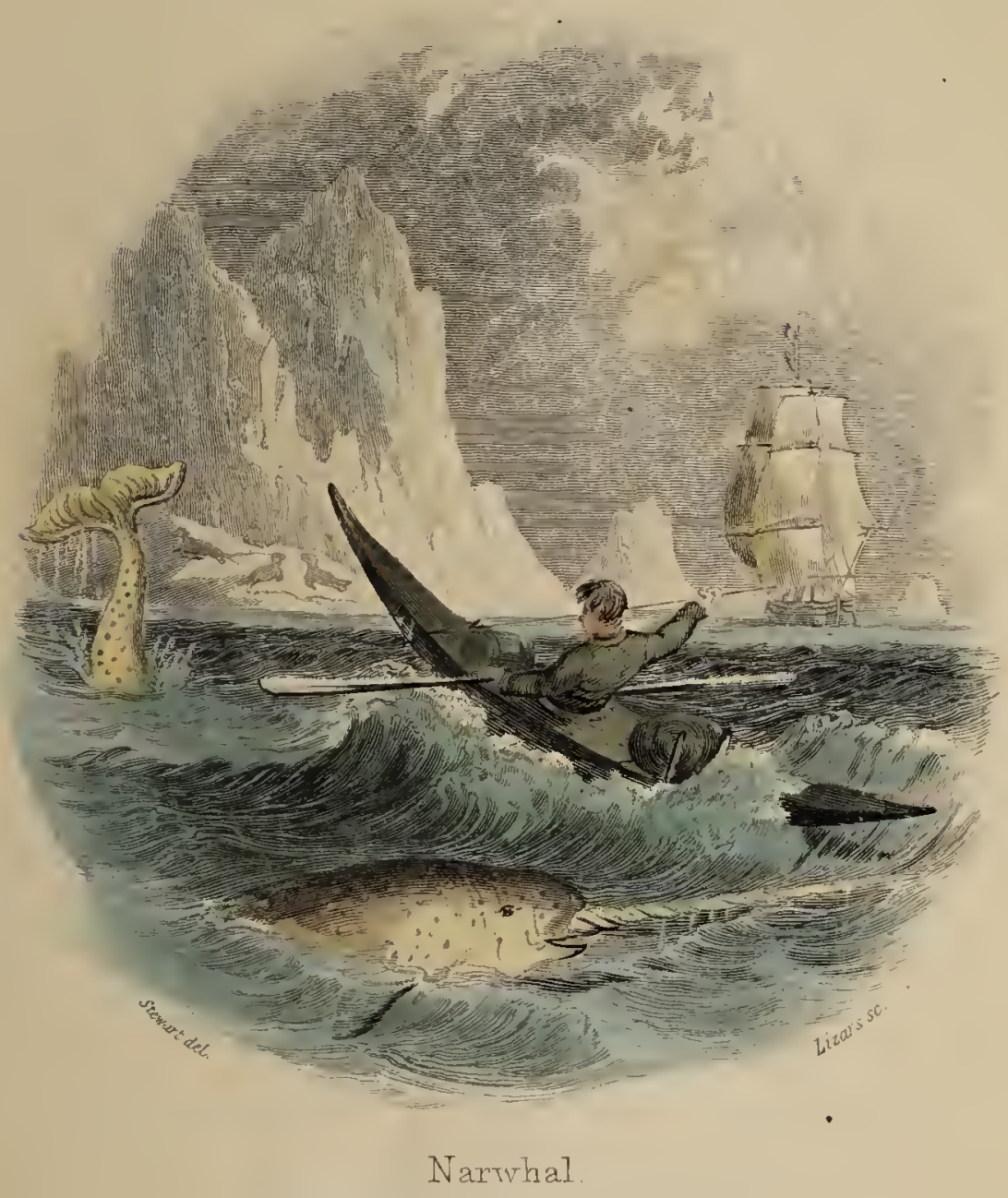

- LONDON. HENEY Q U:H

YORK STREET. COVEVT - LEN 



\title{
THE
}

\section{NATURALIST'S LIBRARY.}

\author{
IDITED BY
}

SIR WILLIAM JARDINE, BART.,

F.R.S.E., F.L.S., ETC., ETC.

VOL。XXVI.

\author{
M A M M A L I A. \\ WHALES, ETC. \\ BY ROBERT HAMILTON, ESQ., M.D. \\ F.R.S.B., H.W.S., ETC.
}

EDINBURGH :

W. H. LIZARS, 3, ST. JAMES' SQUARE.

LONDON :

HENRY G. BOHN, YORK ST., COVENT GARDEN. 



\section{CONTENTS.}

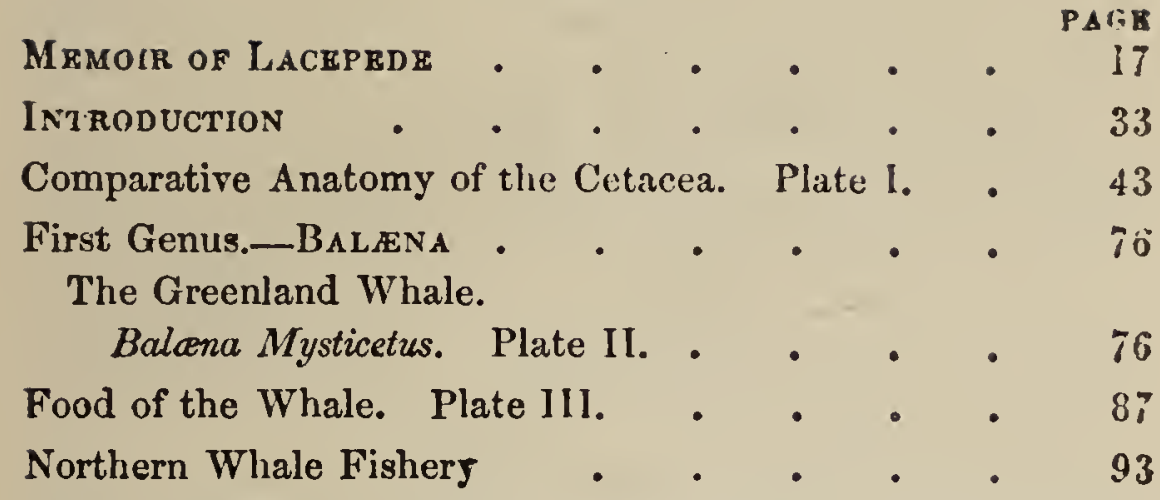

Whale breaching, or leaping out of the water. Plate IV. 113

Whale upsetting a boat. Plate IV*. . . . 115

Whale of the Southern Seas.

Balana Australis . . . . . . 122

Second Genus.-Rorqualus . . . . . 125

Great Northern Rorqual.

Rorqualus Borealis. Plate V. . . . . 125

Skeleton of the Great Northern Rorqual. Plate VI. 139

The Lesser Rorqual.

Rorqualus Rostratus. Plate VII. • . . 142

Rorqual of the Southern Seas.

Rorqualus Australis . • . . . 146

Fossile Rorquals, \&c. $\quad$ • $\quad$ • $\quad$ • $\quad$. 150

Third Genu8.-САсна LOT • . . . . 154

The Spermaceti Whale from Frith of Fortl. Pl. VIII. 154

The Spermaceti Whale of Southern Ocean. Plate IX. 1.58

The South Sea Fishery $\quad$ • . . . 169

Dying Struggles of the Spermaceti Whale. Plate X. 1;1

The Hzrerodons (with few and beterogeneous teeth) 181 
CONTENTS.

Fourth Genus.-Narwhalus - . . . 182

The Narwhal, or Sea Unicorn. Plate XI. . . 182

Fiftl Genus.-Drodons, or Two-teethed Whales . 191

Two-teethed Whale of Desmarest.

Diodon Desmaresti . $\quad$ • $\quad$ • $\quad$. $\quad$. 191

Two-teethed Whale of sowerby.

Diodon Souerbi. Plate XII. • • • • • 192

Sixth Genus.-Hyperoodontes • • • • 194

Buttle-nosed Whale of Hunter.

Hyperoodon Honfloriensis. Plate XIII. • • 194

Seventh Genus.-Aodons. Foochless Whales • 398

Toothless Whale of Havre.

A. Dalei. Plate XIV. • . . . . . 198

Eighth Genus._Ziphius (Fossile) • . • 201

Ziphius Planirostris . . . . . . 201

The DelPhinia (with teeth in both jaws) • • 202

Ninth Genus.-Beluga • . . . . 204

White Whale.

Beluga. Plate XV. • • • • . 204

Tenth Genus.-Denphinaprerus (Dolphin without dorsal fin) . $. \quad . \quad . \quad . \quad . \quad .210$

Delphinapterus Peronii. Plate XVI. . . . 210

Eleventh Genus.-GıobicephaLus • • • 212

The Deductor, or Ca'ing Whale.

Globicephalus Deductor or Melas. Plate XVII. • 212

The Globiceps of Risso.

Globicephalus Rissii. Plate XVIII. • . $\quad 219$

Fossile Globiceps . • • • • • 220

Twelfth Genus.-Phocana • • . • • 222

The Common Porpoise.

Phucana Communis. Plate XIX. Fig. 1. . . 222

The Porpoise of the Cape of Good Hope.

Phocana Capensis. Plate XIX. Fig. 2. • . 227

The Grampus.

Plocana Grampus. Plate XX. ․ . $\quad$ - 228 
CONTENTS.

The Grey Porpoise.

PAGE.

P. Griseus. Plate XXI. $\quad$ • . . $\quad 233$

The Striped Porpoise.

Phocena Bivittatus Plate XXII. Fig. 1. - 234

Thirteenth Genus._Delphinus . • • • 236

The Common Dolphin.

Delphinus Communis. Plate XXIII. • • 238

Pernetty's Dolphin.

D. Pernetti. Plate XXIV. : • . . 244

The Lead-coloured Dolphin.

D. Plumbeus. Plate XXV. Fig. 1. • . . 246 The Bridled Dolphin.

D. Fronatus. Plate XXV. Fig. 2. . . . 247

Dolphin with white mark over the Eye.

Delphinus Superciliosus. Plate XXVI. • . 248

Thic Funenas of the Chilians.

D. Lunutus. Plate XXII. Fig. 2. . . . 250

Delphinus Youngii (Fossile) . . . $\quad 251$

Fourteenth Genus.-Driphinorhyncus - • 252

Delphinorhyncus of Breda.

D. Bredunensis. Plate XXVII. • . • 252

Fifteenth Genus._Soosoo - . • • • 254

Soosoo of the Ganges.

S. Gangeticus Plate XXVIII. • . $\quad \mathbf{8 4}$

The Soosoo of M. De Borda (Fossile).

S. Bordaii

Sixtenth Genus._Inia $\quad$ • . . • • 259

I. of Bolivia.

I. Boliviensis. Plate XXIX. • • • $\quad 259$

Seventeenth Genus._Oxyptrerus . • • • 262

Rhinoceros Whale.

Oxypterus Rhinoceros $\quad$ • $\quad$ • $\quad$ • $\quad$ • $\quad 262$

Portrait of M. Le Comte de Lacépède • • • 2

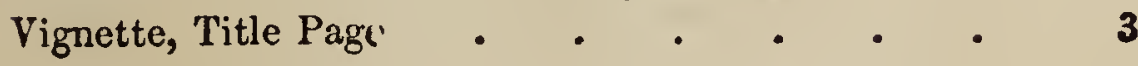

In all, Thirty-Two Plates in this Volume. 



\section{MEMOIR OF LACEPEDE.}


$\backslash$ 


\section{MEMUIR}

\section{OF \\ M. LE COMTE DE LACÉPĖDE.}

As Le Comte DE LACEPEDe was the author of that elegant and classical work on the Cetacea, which for so many years has been the most popular treatise on the subject, we have thought that we could not submit to the attention of our readers a more appropriate biographical memoir than a brief sketch of this very illustrious and most amiable man.

Bernard-Germain-Etienne de La Ville was born at Agen on December 26, 1756. He was descended from a long line of honourable ancestors ; and his father, Jean Joseph de La Ville, was lieutenant-general of Senechausée. Lacépède, however, did not value himself on his extraction, but entered life with the determination of exhibiting his birth only by the urbanity of his manners and the uprightness of his conduct. This resolution he maintained with the most scrupulous uniformity throughout his chequered history: his politeness was proverbial, 
whilst it was universally acknowledged that he was as obliging as he was polished, and that he did not more indulge in compliment than in rendering important services, and in bestowing substantial favours. His father superintended his education with great care, and received valuable assistance from M. de Chabannes, the Bishop of Agen; and it was remarked that during his younger years the idea of a bad author or of a wicked man scarcely presented itself to his mind. When twelve years of age, as he himself stated, he imagined that all poets resembled Corneille and Racine, that all historians were like Bossuet, and all moralists like Fénélon. $\mathrm{He}$ had thus from his earliest years a great leaning to optimism, and would scarcely believe that any one was actuated by bad feelings or intentions, or that any one wished to deceive; and this prepossession had great influence over his conduct and writings, as well as on his social habits.

Buffon's Natural History was one of those books which was early put into his hands, and it instantly became a favourite; it was the companion of his walks, and that in one of the finest countries of the world. It was on the beautiful banks of the lovely valley of the Garonne, in the neighbourhood of those smiling hills which are so majestically terminated by the peaks of the Pyrenees that he studied the eloquent pictures of this great writer: his passion for the beauties of Nature thus originated at the same time with his admiration for that great painter who pointed them out to his contemplation, and these 
two sentiments always remained united in his mind. He took Buffon for his master and his model, and read him till he almost knew him by heart.

About this time the love and cultivation of music not less strongly took possession of his mind. His father and many of his near relatives were musicians, and he often joined their concerts. This art afforded him inexpressible delight, and became to him a second language, which he could write and speak with equal facility. Both the airs which he composed, and the mode of his execution generally, were greatly admired. He was often requested to compose, and ere long he engaged in the laborious task of an opera; this introduced him to the acquaintance of the celebrated Gluck, who greatly admired and cherished his genius.

Natural philosophy also, at this time, formed an object of his pursuit. At the age of thirteen he formed, with some of his school-fellows, a juvenile society, several members of which subsequently became members of the Institute. Their investigations became more important as their years adranced; and electricity and magnetism, among other subjects, engaged their attention. Lacépède having made some experiments, and deduced conclusions, which appeared new to him, he transmitted them to Buffon, who noticed them in the supplements of his work.

At the age of twenty-one, Lacépède resorted to Paris, where, on his arrival, he made the formal acquaintance of his correspondents, Gluck and Buf- 
fon, by both of whom he was received in the most flattering manner. He closed the day, as he began it, in a kind of enchantment; he spent the evening with his relative, the Archbishop of Lyons, where he met with the elite of the academicians, and from that time he determined to devote himself to science and to music. This resolution was scarcely approved by his family, whose interest might have advanced him in the army, in the diplomatic line, or at the bar. In these circumstances, a German prince, whose acquaintance he made in Paris, offered to procure him the brevet rank of colonel in one of the smaller states. This appointment led him to pay two short visits about this time to Germany, where he acquired his nominal rank, with his uniform and epaulettes; and his friends being thus satisfied, he was allowed henceforward to follow the bent of his inclination.

Lacépède now devoted some years very assiduously to music. He composed an opera, which, after being on the eve of performance, was from some trifling occurrence suppressed. In 1785 he published a work, - in two octavo volumes, $L a$ Poetique de la Musique, which procured him many admirers, among whom the great king of Prussia, Frederick II. was one, and Sacchini another.

Shortly afterwards, Lacépède published two works on physics; one on Electricity, and the other entitled Physique Generale et Particuliere. Neither of them, though both written with eloquence, procured the commendation of competent judges : and, after 
the lapse of a few years, he was so convinced of their imperfection, that he used his best exertions to suppress them.

At this time, Buffon very opportunely opened up a way by which the Count might usefully exercise his talents. He proposed that he should continue that part of his work on Natural History which treated of animals; and that he might do so with the greater advantage, he offered him the situation of under-demonstrator of the Cabinet du Roi, which had been just vacated by the younger Daubenton. Lacépède gladly accepted these proposals, and though some of the attendant duties were somewhat menial, he discharged them with the greatest assiduity. He attended in the museum on public days, and with his accustomed politeness answered the inquiries of the curious, whether poor or rich. To many this task might have been disagreeable, but he did it to please a beloved master, and to fit himself for being his successor, and these ideas ennobled every thing.

In 1788, some months before the death of Buffon, Lacépède published the first volume of his History of Reptiles, which comprehended the oviparous quadrupeds ; and the following year, the second, which treated of Serpents. These quartos, by the elegance of their style, and the interest of the numerous facts they embodied, were judged worthy of the great work of which they formed the continuation. $\mathrm{He}$ established classes, orders, and genera, and accurately characterized these divisions; he enumerated 
and named the species with care, and as methodically, though not so philosophically, as Linnæus himself. He also described a great number of new species, raising the number to two hundred and eighty-eight.

But at this epoch, a great change took place in the prospects of the young Naturalist, by the occurrence of those great events, which overturned every thing in France at the Revolution. Power then became the daily product of popular farour, and every month saw some great reputation fall, and some unknown and worthless person start from obscurity. Many of the celebrated men in France were at that time invited and drawn in to take a part in those agitating transactions, and Lacépède, from his great popularity, had peculiar difficulty in avoiding them. He was successively chosen president of his section, commander of the national guard, extraordinary deputy of Agen to the Assemblée Constituante, member of the general council of the department of Paris, president of the electors, deputy of the first legislature, and president of that assembly. In all these situations he attempted to act with his habitual kindness ; but that was a sentiment with which, ere long, there was no general sympathy. One morning, Lacépède saw his name at the head of an article in the newspaper entitled, " list of the Scelerats who vote against the people." He had been, and still was slow in thinking that matters would come to extremities, or that there was any general risk of personal safety; and the good 
opinion he entertained of mankind was too deeply rooted to allow him to suspect that truth and justice would not immediately resume the ascendancy. But, in waiting their return, his friends saw he was exposing himself to imminent danger; and, almost by main force, they removed him from the capital. He had not been long in the country till he longed to return, and he imagined that nothing would be more simple than to demand permission from Robespierre. Happily the monster had that day a spark of humanity about him, "He's in the country? -he demanded: Tell him to stay there." It is certain, an hour's residence in the metropolis would have been fatal to him; his retreat was searched for; and he could not venture to return to Paris till after the 9 th of Thermidor.

He returned with a singular title for a man of forty, who was already known by so many eminent works; it was that of a scholar of the Normal school. The convention, at last giving up its cruelties, imagined it might create as speedily as it had destroyed; and that, for the re-establishment of general education, it might in a few weeks educate masters with the help of a few celebrated men, who would only require to point out to them the best methods of proceeding. Fifteen hundred individuals were sent, with this object in view, from the departments. M. Lacépède found himself on the same bench with the celebrated Bougainville, a septuaginarian, and a general officer, equally famous as a writer and a mathematician; with the grammarian, 
Wailly, who had been esteemed as a classical author for forty years, and with Fourrier. La Place himself, and this is saying much, appeared in this strange scene as a scholar; and it was by the side of such men as these, that there were seated peasants who could scarcely read. The influence of these great men was soon felt in society, and was highly useful in the metropolis.

Lacépède, after his retirement, was not legally a member of the establishment of the Jardin des Plants, but scarcely was his name allowed to be pronounced in Paris, when those who had been appointed in his absence, urgently invited him to associate himself with them. For this purpose a new chair was appointed for him, connected with the history of Reptiles and Fishes. His lectures were most successful. A crowd of young men flocked round him, who, for three or four years, had been deprived of all instruction, and who were thus as it were famished. The politeness of the professor, the elegance of his language, the variety of the ideas and knowledge which he displayed, after so long an interval of barbarism, introduced as it were another and a better age. Then it was especially that Lacépède assumed, in the public estimation, the rank of the successor of Buffon; as in him, in truth, were found many of his distinguishing characteristics : he possessed the same art of giving interest to the driest details; and when Daubenton was approaching the termination of his career, the new professor remained the only re- 
presentative of that great association which had laboured so successfully in the popular field of $\mathrm{Na}$ tural History. It was on these accounts he was called upon to form a part of the nucleus of the Institute, and was thus one of those who were charged with the restoration of the Academie des Sciences. He was also one of its first secretaries, and his beautiful éloge on Dolomier makes it a matter of regret that he was raised to higher posts, from a situation which he would have filled better than any one else. This statement comes at least with as much grace as truth from the lips of Cuvier; who, in the discharge of the duties of the same office, pronounced the éloge of his predecessor.

Of all the occupations in which M. de Lacépède had been induced to engage, the sciences alone, as is usual, remained faithful to him in the time of misfortune, and it was with them he consoled himself in his retreat. Resuming the habits of his youth, passing the day in the midst of the woods or on the banks of the rivers, he traced his plan of his Natural History of Fishes, the most important of his works. Immediately after his return, he commenced its composition; and at the end of two years, in 1798, he found himself in a condition to publish the first volume. Five volumes appeared in succession, the last in 1803. All that he could collect regarding the organization of these animals, their habits, the wars which the human species wage against them, and the benefit derived from them, he has given in a pure and elegant style; he 
has even diffused a charm over his descriptions, whenever the beauties, which have been imparted to them in so high a degree, permitted their being presented to the admiration of naturalists. "And in fact," says Cuvier, "what can afford a greater subject of admiration, than those brilliant coloursthat glare of gold, steel, ruby, and emerald, profusely poured upon beings which man scarcely ever naturally meets with, and which are almost never seen in the obscure paths they frequent. Even at the present day (in 1826), there is no work on the history of fishes superior to Lacépède's, and he is always quoted on the subject: when the immense materials collected in these latter days shall have been put together in another work, the brilliant pieces of colouring, full of sensibilty and deep philosophy, with which he has enriched his Work, will not be forgotten. Science, from its nature, is every hour advancing; but the great writers will not remain the less immortal."

The Natural History of Fishes was followed, in 1804, by that of the Cetacea, which terminates the great system of vertebrate animals. M. de Lacépède considered it as the most perfect of his Works ; and in fact, he treated the historical and descriptive part, that referring to the organization and methodical characters, better than any one had done before him. His style also rises in some manner in proportion to the grandeur of his subject. He augments, by about a third, the number of the species. "This author," says Mr. Scorseby, " has published the most 
voluminous and pleasing account of cetaceous animals that has ever appeared from the press." He adds, " the style is animated and poetical, and his history is a most interesting work; but the interest, in many cases, is augmented at the expense of truth ; it is by no means accurate." (Artic. reg. i. 447-9.) Perfectly agreeing in this criticism, and ascribing the many inaccuracies to the imperfect state of this very difficult branch of science at the time of the publication, we deem these few words sufficient to put our readers on their guard, in their perusal of this interesting production.

After this time M. Lacépède undertook a work somewhat different in its character; more philosophical, and less liable to become antiquated by the rapid progress of science. $\mathrm{He}$ designated it a History of the Ages of Nature, in which he comprehended that of man,-considered in his individual developement, and in that of the race. The article Homme, in the Dict. des Sciences Naturelles, is a sort of programme of what he contemplated on the physical history of our race. The romances which he wrote,-Ellival and Caroline, and Charles dEllival et Alphonsine de Florentino, -and published about this time, were considered by him as studies upon man's moral history. But it was soon apparent that in the midst of these meditations the gradual developement of social life had the most especial charms for him, and the naturalist gradually merged into the historian; he dwelt chiefly upon the political and religious establishments 
which have appeared since the fall of the Western Empire. He left a history of them completed, and several volumes of this work have now been published.

Besides these greater works, we find that $M$. Lacépède transmitted no fewer than twenty-three memoirs to the several societies of which he was a member, and to the respectable periodicals of the day, principally between the years 1796 and 1808 ; the last, On the Cetacea of the Japanese Seas, was in the year 1818. He also published in 1799 a new edition of Buffon in fifty-two volumes duodecimo, and wrote the preface to the Menagerie, in folio, in 1801.

We must now add, that about this period he made another change from these active literary pursuits to equally active political engagements. Very soon after the new government was established, he was gradually replaced in all the high offices he had previously held. He was appointed senator in 1799 , president of the senate in 1801, chancellor of the legion of honour in 1803, and minister of state in 1804.

In the general administration of the legion $\alpha$ honour, M. Lacépède conducted himself with the greatest talent and address, and to the satisfaction of every one. He likewise exerted himself in establishing schools for the education of the orphans of those who had belonged to the legion, and procured comfortable accommodation for as many as nearly fourteen hundred of them. 
Lacépède conducted the multifarious affairs in which he was engaged with a facility and rapidity which astonished all who were cognizant of it. For him one or two hours were sufficient to determine every thing, and with a most intimate knowledge of all the circumstances. This amazing rapidity surprised even Napoleon, who himself was much celebrated for despatch of business. One day this great man asked him, by what secret he did so much? to which the other replied,- " I use the method employed by naturalists ;" an answer, which under the appearance of pleasantry contains much truth.

Another circumstance which much struck his imperial master, and which he but rarely witnessed, was the extreme disinterestedness of Lacépède. This servant of the public would at first receive no salary ; but, as his benevolence kept pace with his disinterestedness, his patrimony was soon exhausted, and much debt was contracted, which there was no progpect of his being able to pay. Under these circumstances, the head of the government insisted upon his taking a regular salary, and ordered that all his arrears should also be paid up. The sole advantage which he derived from this act of kindness and justice, was, that it enabled him to increase his donations. He considered himself accountable to the public for all that he received: and, as he every day had occasion to see poor legionaries, and many of their widows, without any means of subsistence, he had ever before him those who were 
objects of his bounty. His liberality usually anticipated their requests, and he often allowed them to suppose that his private charities flowed from the public funds. Much he bestowed without the recipients knowing whence it came. A gentleman who held a high office, having ruined. himself by speculation, abandoned his family, and Lacépède caused 500 francs per month to be regularly transmitted to his wife, till her son was old enough to support her; and this lady always imagined she received her income from her husband.

A young man who was employed in one of the offices under his controul, appeared depressed and ill. The Count supposed there was some latent cause of anxiety, and employed his physician to discover what it was. Having learned that the young man's circumstances were hopelessly embarrassed, he immediately sent him 10,000 francs: the gentleman hastened to him. with tears in his eyes, intreating him to fix the terms of reimbursement;"My friend," he replied, "I never receive any thing of that sort."

What rendered his disinterestedness in every degree conformable with his munificence, was the fact, that he had very few personal wants. He had no expenses but what were required by the situaations which he held. He never possessed more than one suit at a time. After dressing in the morning he never changed throughout the day. His diet was as simple as his clothing. From the age of seventeen he never drank wine, and a single and 
very slight repast was all he required. But what was most surprising, was the small quantity of sleep he took; he usually slept two or three hours, and the rest of the night was employed in composition, his memory retaining all the phrases and the very words; they were as if written in his brain, and early in the morning he dictated them to his secretary. He has stated, that in this way he could retain whole volumes; could change them as he saw fit in his mind, and remember what he had thus corrected, as accurately as the original text. It was thus that nearly the whole day was free for business, for his public duties, and especially for the sweets of the family circle: for his external life, so to speak, however brilliant, was to hirn nothing in comparison with his domestic enjoyments, in which he ever found a delightful solace for all his fatigues and trials. His attachment to his wife, Anne Caroline Jubé, was beyond all praise ; of which a satisfactory proof may be found in the impassioned language of the introduction to the Cetacea: "After I had commenced this work, misfortune felled me to the ground, and lacerated my heart; I lost my beloved companion. Grief without hope,-gratitude,--veneration,- -have inscribed the name of my Caroline on the dedication of my work on fishes; and again in this work; and they will consecrate all those I may undertake, till the end of my fearful banishment! Her name, which is dear to every virtuous and ten der heart, will recommend my feeble efforts to the lovers of nature." (Le 24 Nivose, An. 12-1804.) 
Many years afterwards he lost his only daughter, the wife of his adopted son; and immediately after this shock, he was hinself seized with the smallpox. In this last illness, almost the only one he had experienced during a life of seventy years, he continued remarkably to exhibit how much amiability and unalterable politeness were inherent in his nature. Not a word escaped him to show his sense of danger, though he apprehended death from the first moment of his seizure. He died on the 6th of October, 1825.

On the day of his funeral, the crowd, many of them unfortunate and miserable, who cume to weep over his tomb, was the best proof of his liberality and benevolence: and these virtues are not less distinctly proclaimed by the fact, that, after having long filled the most eminent situations, and having enjoyed, for ten years, the especial favour of the great Arbiter of Europe, the fortune which he left was much less than that which he had inherited from his father. 


\section{CETACEA.}

\section{INTRODUCTION.}

The present Volume of the Naturalist's Library is dedicated to an order of animals, which in point of interest yields to none presented to our contemplation in the whole range of animated nature.

The monarch of the deep is, in regard of dimensions at least, the monarch also of creation; the largest and most formidable of land animals shrinking into utter insignificance when brought into comparison with his prodigious bulk. The vast and expensive preparations which are made for the capture of the whale, and the excitement and perils attendant upon the adventure, not only render it an object of great commercial importance, but throw around it an air of something like chivalrous interest, in which every one must instinctively participate. But the main interest of our subject is to be found in its scientific investigation. If we pass from mere ignorant wonder to comprehensive and accurate observation, we shall find in this order of animals ample materials for exciting and gratifying 
the most enlightened curiosity, for expanding in no common degree, our conceptions of the harmony and beauty of the works of nature, and for raising to the highest pitch our admiration of the inexhaustible wisdom of the great Creator.

The very positjon which the Cetacea occupy in the animal kingdom, forms in itself a subject of the deepest wonder and astonishment.

Our readers are probably aware that of the four divisions into which Cuvier, the great master of natural science, has divided the animal kingdom, the first consists of the vertebrate. The vertebratæ, which include the animals of the most perfect structure, are again subdivided into four great classes, forming a natural descending series beautifully simple and complete; being 1st, Mammalia or Quadrupeds,-2dly, Birds,_-3dly, Reptiles,-and 4 thly, Fishes. Each of these classes is characterized by a diversity of locomotive powers, which depends on the quantity of inspiration, inasmuch as this is the grand source whence the muscular system derives its irritability and strength. The efficiency of respiration again, depends upon the relative amount of blood which is forced into the respiratory organs in a given space of time, and the relative amount of oxygen which operates upon the circulating fluid. Now, the respiratory organs in the first class of the vertebratx, viz. the Mammalia, are of the most perfect kind, and perform their functions under very favourable circumstances, - the circulating fluid, at each inspiration, being brought into im- 
mediate contact with the oxygen of the air. The same is true in a still higher degree respecting birds. But the case is widely different with the two remaining classes. In reptiles the respiratory organs are themselves greatly deficient, compared with the same organs in the two higher classes; and in fishes the difference. is still more conspicuous, inasmuch as they have no lungs at all, but gills, which execute their functions through the medium of water, their blood being thus acted upon only by the portion of oxygen which is contained in that fluid. From this diversity of structure results, in the words of Cuvier, "the four different kinds of motion for which the four classes of vertebrated animals are more particularly designed, quadrupeds, birds," \&c.

Many specific characters distinguish these four classes of the vertebratæ from each other, and especially the two which constitute the extremes, viz. quadrupeds and fishes. The former are viviparous in their mode of reproduction, and suckle their young; which circumstance being peculiar to this division, they hence derive their ordinary appellation of Mammalia; a distinction the surest, as well as the most apparent, of all external characters. The latter again are oviparous, and deposit the countless millions of their spawn in the sheltered creek or the shallow brook. Quadrupeds are warm-blooded animals, having lungs contained in a regular chest, and are more or less covered with hair or wool to protect them from change of 
temperature; but fishes are cold-blooded, and their respiration is effected by branchiæ, which consist of laminæ, suspended on arches, between the head and body, through which the water entering by the mouth is allowed to escape, and so purifies the blood for renewed circulation. On their surface scales almost invariably take the place of the warm and woolly covering: and finally, for it is unnecessary to carry the distinction farther, the former, as their name implies, move upon the earth with a firm tread, endowed with two limbs belonging to the anterior, and two to the posterior extremity; whilst fish are totally deprived of these, their only representatives being the fins, and they effect their movements through the liquid element mainly by means of their tail striking the water vertically and alternately from right to left.

These general observations will suffice to enable wur readers to understand distinctly the singular position which is occupied by the Cetacea in the classification of the animal kingdom. While they inhabit the water like fishes, and while in their mode of progression through their common element and in some of their more obvious external characters, they seem to claim kindred with the other inhabitants of the deep, yet, in every essential respect, they are unequivocally marked as members not of this the fourth and last class, but of the first and most remote class of the vertebratæ, viz. the Mammalia. Fish, as we have seen, are produced from spawn, and after the lapse of weeks or months, 
emerge from the gravel and the egg, where they had lain long neglected by the individuals who there deposited and deserted them; but the whales are brought alive into the world, and the cub is nourished for months by its mother's milk, and disports itself around her in playful affection, like the fawn or the lamb in the sunny glade. Fish are cold-blooded-their circulating fluid being only exposed to the water, in the gills; but the whale has no gills, nor any thing resembling them; on the contrary, it has true lungs, in a great bony chest, into which the air is freely admitted-no+ indeed by the mouth, but by a peculiar apparatus to be afterwards explained, and through which the animal breathes the pure air of heaven like other mammalia, and is thus enabled to maintain the warm temperature of its body even in the midst of the icy seas. Fish never breathe; and if removed from the water, and brought into the air, immediately die; whereas the Cetacea, if deprived of air and confined under water, are speedily and literally drowned.

The Cete, therefore, are not fishes, but true mammalia. Not only in their internal organization, but, to a great extent, in their osseous structure, they approximate to the quadrupeds or the mammalia of the land; and it is not a little interesting to trace the wonderful adaptations by which an animal of such a structure and habit of body is fitted to become the inhabitant of a different element Before we proceed, accordingly, to introduce the va- 
rious genera to the notice of our readers, we propose to devote a chapter to the comparative anatomy. of the order generally. By so doing we shall not only make our readers acquainted with the object of their study more effectually than it would be possible to do by any other means, but we shall prepare them for marking inteiligently the specific differences which we shall have occasion to point out as we advance in our survey.

The classification which we have adopted with the riew of exhibiting and treating the various species composing the Cetacea, will appear as we proceed. The series comprises a great variety of animals, descending from the greater whales to those. of smaller dimensions, down to the porpoises and dolphins, some of which are not more than two feet in length.

The fossile Cete which have been discovered form an interesting addition to the subject of our investigation. The examination and classification of these remains was one of the latest and most successful labours of the illustrious Cuvier, who informs us that the fossile marine mammalia, whose species it has been possible to characterise, are not less different from those which now inhabit our coasts, than are the terrestrial fossile mammiferæ distinct from those which now inhabit the land; and for some of them, he has been even under the neccessity of establishing entirely new genera. This, he adds, "only more and more confirms the proposition to which the examination of fossile shells 
had already led, that it is not land animals only which have undergone a change during the revolutions of the globe; but that the inhabitants of the ocean likewise, have not withstood their effects; and that when the sea formed on our continents those prodigious deposits filled with shells which are now almost unknown, the great mammalia which it nourished were not those which people it at present; and that in spite of the strength which the immensity of their size apparently conferred upon them, they had no more power to resist the catastrophies which disturbed their element, than had the elephant, the rhinoceroses, the hippopotami, \&c. to withstand those upon land; and that in the absence of the arts of man, which, of course, could not be brought to bear against them, their races must have been exterminated by the general revolutions of nature alone." (Oss. Foss. v. 398.) Many of the fossile varieties will be incorporated into our Survey, each being introduced in connexion with those genera and species with which it stands most nearly allied.

We must not conceal from our readers that the ascertainment and description of the existing Cetacea is a work of great difficulty and uncertainty."It is," says Cuvier, " concerning large animals that the greatest errors and confusion exists ; and for this reason, that we can know and distinguish only those species which we can examine under our eye and carefully compare with each other ; and this remark applies especially to the great Cetacea. They as- 
tonish every one by the immensity of their dimensions, and their capture has for ages given employment to unwearied efforts of activity and courage; but except under favourable circumstances, when occasionally stranded near some intelligent naturalist, they have scarcely ever been described with accuracy, and still less been minutely examined. Thousands of mariners have captured and cut up whales, who have never accurately examined one of them; and yet it is upon their vague descriptions and figures that zoologists have endeavoured to establish the natural history of these animals. The greater number of authors, moreover, have never endeavoured to exercise their critical powers in their compilations, inasmuch as they had but few ascertained facts as the basis of their reasonings. This is the true cause why the history of the Cetacea is so meagre, and yet so full of contradiction and repetition. It would be truly an easy matter, by availing ourselves of the extraordinary figures which have been depicted, but which are the mere creatures of imagination and recollection, and also of the many confused and mutilated descriptions which have been published, and by accumulating synonyms which are mere copies of each other, to display long lists of species, but they would have no real existence in nature, and would altogether vanish before the slightest breath of criticism."

It may tend in some degree to illustrate the difficulties which are here so ably noticed, and to demonstrate their almost incredible extent, to state what 
has long been asserted, and never denied, that notwithstanding thousands of the Greenland whale have been annually captured by the subjects of many different nations, there never was an accurate representation of this species till it was supplied in 1809 by our illustrious countryman, Scorseby ; and he, in his valuable work on the Arctic Regions, published in 1820, states that Lacépède's figure of the true whale has not its counterpart in nature; and that his common narwhal never had any real existence. It is worthy of remark, that Lacépède's interesting production has for long been the most popular treatise on the subject; and we regret to see that some of its worst errors of representation and description have been copied into more recent works. Some of the figures, in these popular treatises, are no more like the animals they are meant to represent, than a bull-dog is like a greyhound. Nor are the errors confined to the figure. They extend to whole genera. Loose and vague accounts of voyagers having been once incorporated into systematic works, an almost inextricable confusion has been introduced, which extorted from the capacious mind of Cuvier the exclamation,- "Toutes ces indications incomplète ne serve qu' à metre les naturalists à la torture ;" and a man must himself go over the ground before he can feel the full force of the sentiment Lesson gave utterance to his feelings on the point, in these words,- " What an impenetrable veil covers our knowledge of Cetacea! Groping in the dark, we advance in a field strewed with thorns." There 
is doubtless then, to use the words of Scorseby, no branch of zoology so much involved as that which is entitled Cetology. Some idea of its difficulties may be formed, by considering that although Desmaret, in his Mammalogie (1820-22), enumerated sixty-two species, yet he considered no fewer than twenty-nine of them as doubtful and not established; and that Lesson, in 1828, out of eighty-four species which he classified, can vouch for the accuracy and existence of not more than fifty.

We have thought it necessary to apprize the student, in these few words, of the difficulties in which the subject is even now involved, that he may perceive it is no easy matter at once to overcome them. From the great rarity of favourable opportunties for examination, we must be cautious even in getting right ; and must hesitate ere we finally reject what has previously been admitted even on insufficient and objectionable grounds. Having said this much, we entirely dismiss this part of the subject. We indulge the hope, that our little Volume may become a vade mecum to many a mariner and fisherman, and that beguiling over it the tedium of a sea voyage, he may thereby be excited to improve some of those opportunities which frequently present themselves to him, though not to us; and that by making pertinent and judicious observations, he may thus add to the stock of our interesting and important information.

We now proceed to the comparative anatomy of the Cetacea. 
PI.ATE I .
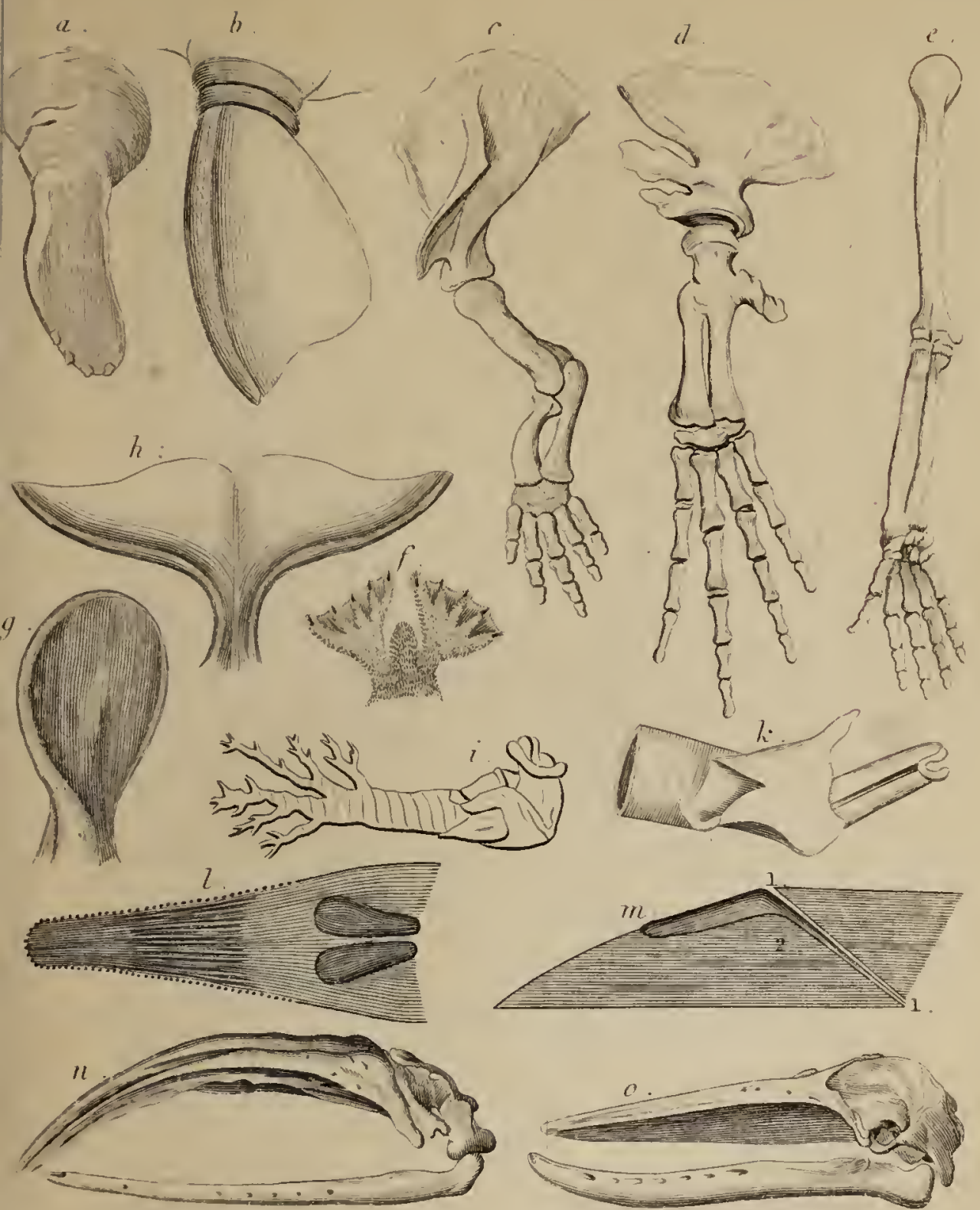

COMPARATIVE ANATOMY

OF THE

\section{CETACEA.}

IT has been well remarked, that the most useful and ennobling view of natural history is unquestionably that which gives the most exalted conception of the wisdom, goodness, and power of the Creator: and the branch of natural history best calculated to assist in tracing the works of nature up to nature's God, is probably the physiology of animals. When we bear in mind that the Cetacea are mammalia, and yet inhabitants of the mighty deep, we may safely conclude that the mechanism displayed in the adaptation of theur structure to their exigencies will superabound in ex. quisite design and infinite wisdom. Even externally, the changes which they undergo are interesting. The extremities are curiously and greatly modified. The upper is converted from an arm or fore foot into a fin, or swimming paw, as it is more accurately called; and though at first glance the difference between these two appears immense, yet when we examine their osseous structure, the real coincidence 
is truly striking. The sketches $a$ and $b$, in Plate I., exhibit this paw in one of the herbivorous and in one of the ordinary Cetacea, when covered with their usual integuments, and $c$ and $d$ exhibit the same part when deprived of these appurtenances; both of these can easily be compared with the human arm, $e$, and the simple unity of their structure, and the peculiar adaptation of each to its function, will, after this survey, scarcely require farther demonstration. We supply a sketch of the same part in the great whale of Greenland; and it is striking to observe, how much even this great fin supplies a representation of the osteology of the arm in man. And as with the anterior extremities, so

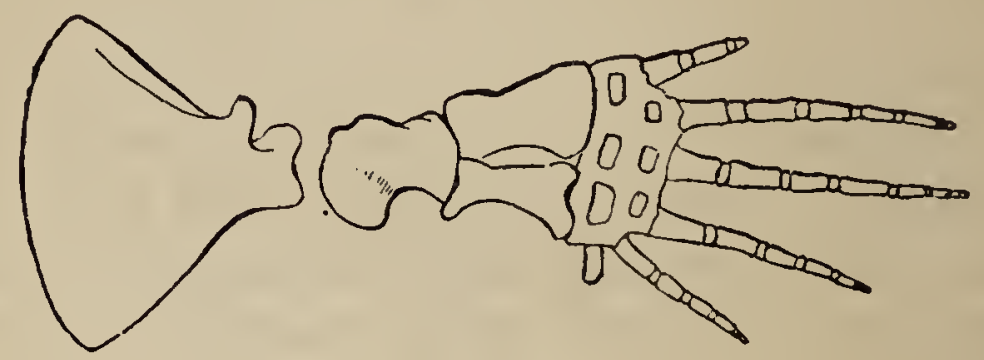

it is with the posterior or sacral. In the whole Cetacea they become wholly rudimental, and leave scarcely a trace behind. The progress of the change, as seen externally, which we exhibit through three successive links of the animal series, is beautiful and interesting; sketch $f$ shows them in the amphibiæ-the seal; sketch $g$, in the herbivorous Cetacea-the Dugong of the East Indies; and 
sketch $h$, in the ordinary Cetacea, as in the common porpoise.

As already remarked, the tail of the Cetacea is peculiar; not vertical, as in fishes, but horizontal ; by which great facility is given for their ascent to the surface, to which they must regularly resort for the discharge of the essential act of respiration. The agility of the lesser species, which they owe mainly to the tail, is universally known, and so powerful is it even in the most gigantic varieties, that by its means they frequently force themselves entirely out of the water. This instrunent of prodigious power is formed by a concentration of the muscles and tendons on all sides of the vertebral column. Mr. Hunter remarks, that the mode in which the tail is constructed is, perhaps, as beautiful as to mechanism as any part of the animal; being principally composed of three layers of tendinous fibres. It comprises, in the larger species, in a single surface, from eighty to one hundred square feet: its length is only five or six, but its width is from eighteen to twenty-six. In its form it is flat and semilunar; its motions are rapid and universal; its strength immense. It is nearly the sole instrument of defence as well as of motion. The greatest velocity is produced by powerful strokes against the water impressed alternately upwards and downwards, but a slower motion is produced by cutting the water laterally and obliquely downwards, in a similar manner as a boat is forced along by a single oar in the operation of skulling. So rapid 
is the progress of the order generally, that they not inappropriately have been denominated the birds of the sea. The fins again are generally stretched out in a horizontal position; and their chief application seems to be the balancing the animal ; as the moment life is extinct it falls over upon its back. They appear also to be used in bearing off their young, and in turning and giving a direction to the velocity produced by the tail.

But not only must the Cetacea regularly resort to the surface; it is a fact that they also descend into the unfathomable depths of the ocean, and then become exposed to a pressure which it is not easy to conceive, but which forces water through the pores of the hardest wood, so as to make it ever afterwards sink like lead in the abyss. Whales, therefore, must be prepared to resist this pressure; and the integuments, though soft and flexible like the finest velvet, are so curiously constructed as to enable them effectually to do so. These, as in most other animals, are composed of three parts; lst, Of the epidermis or scarf-skin, which in addition to its great smoothness, is remarkable for being covered with a mucous oily fluid, which exudes from the whole surface, though in a manner different from what we observe in fishes, which renders it remarkably slippery, and opposes every thing like maceration in water; $2 \mathrm{dly}$, Of the rete mucosum, as it is called, which confers colour on the negroe and in all races of man, and also distinctly in the whale tribe. Then succeeds. 3dly, ac- 
cording to the common account, first the true skin, and then the lard or blubber; the former is represented as thick and strong, and the latter is held to correspond with the subcutaneous fat in other animals. This is the view that naturalists generally, influenced probably by analogy, have taken; it is the view taken by Ray, Tyson, Pennant, Hunter, Scorseby, Cuvier, \&c. But we believe, that according to this account, the great peculiarity of the structure is disregarded, and the essential character, so much desiderated, is overlooked. According to Professor Jacob of Dublin, there is no distinction between the true skin and the blubber, and the whole is nothing more than modified skin. But he shall speak for himself, "That structure in which the oil is deposited, denominated blubber, is the true skin of the animal, modified certainly for the purpose of holding this fluid oil, but still being the true skin. Upon close examination it is found to consist of an interlacement of fibres crossing each other in every direction as in common skin, but more open in texture, to leave room for the oil. Taking the hog as an example of an animal covered with an external layer of fat, we find that we can raise the true skin without any difficulty, leaving a thick layer of cellular membrane, loaded with fat, of the same nature as that in the other parts of the body; on the contrary, in the whale it is altogether impossible to raise any layer of skin distinct from the rest of the blubber, however thick it may be; and in flensing a whale, the operator removes this blubber or skin from the 
muscular parts beneath, merely dividing with his spade the connecting cellular membrane." (Dublin Phil. Journ. vol. i. 356.) Without prosecuting this point farther, we can only in a word say, that we doubt not that this is the more correct view, which, by the by, had previously been maintained hoth by Pallas and by Professor Giesecki; and it is interesting to see how, in the productions of nature, often apparently the smallest possible alteration effects the most wonderful change. This is very conspicuous here. A soft wrapper of fat, though double in thickness to that usually found in the Cetacea, could not have resisted the superincumbent pressure; whereas, by its being a modification of the skin, always firm and elastic, and, in this case, being never less than several inches, and sometimes between one and two feet thick, it operates like so much caoutchic, possessing a density and resistance which the more it is pressed it resists the more.

Other uses of this peculiarity of the skin will readily suggest themselves to the reader's mind. The order is warm blooded, and yet is exposed to the keenest cold in the deepest recesses of the frozen seas. Hence this wrapper, or blanket, as it has been appropriately called, being a bad con ductor of caloric, will at once resist the surrounding cold and retain the animal heat. On this account alone, such an integument seems essential; its bulk and quantity is enormous, sometimes weighing thirty tons, which might appear sufficient to over- 
whelm the animal, and yet from being specifically lighter than the waters of the ocean, instead of oppressing, it buoys it up, and makes it relatively lighter, and so more active.

The flesh or muscles of the Cetacea is not so much like that of fish as like that of beasts, more especially the stronger, such as the bull or horse; it is firm and, with some exceptions, coarse. The same remark may be made respecting their osseous structure; in colour and solidity the bones resemble those of quadrupeds, though somewhat less compact; and they have no medullary cavity. The mammoe in the herbivorous Cetacea are pectoral; in the ordinary, abdominal. Their milk is stated to be very rich, and according to Messrs. Jenner and Ludlow, is like cow's milk to which cream has been added. (J.Hunter, in Phil. Trans. vol. Ixxvii.446.)

The internal structure is very much on the same model as that of the other mammalia, and this therefore is a sufficient reason for our not dilating upon it. Some differences, however, arise from the peculiarity of their circumstances, and on these we shall slightly touch.

No circumstance connected with the economy of whales is more extraordinary than the long period during which they can suspend the rital function of respiration. In most of the mammalia the inhalations succeed each other with great rapidity, and cannot be suspended for more than a few instants. In man, for example, even when at rest, they occur every three secouds; whilst this interval in the Ce- 
tacea is augmented many hundred and even thousand-fold ; for it is a fact, that the larger genera will remain an hour, and sometimes nearer two, under water. There must then be some essential peculiarity in their organization, to account for this extraordinary phenomenon; and yet we know not that any regular attempt at explanation has hitherto been made. It is with considerable hesitation, therefore, that we offer the following brief hints upon the point.

Respiration is in a great degree subservient to the circulation of the blood: the stimulus to inspiration is the accumulation of this fluid in the lungs, which when purified proceeds to the heart, whence it is propelled through the frame for the purposes of secretion, \&c.; after which it is again received into the veins, where it assumes its venous aspect, and is deprived of its arterial character. The circle thus described in man and the mammalia generally, is, so to speak, continuous and simple. In the Cetacea, however, it is not so; for in them the arterial portion, instead of being a simple and direct course to the venous, is complicated by the addition of a structure which we believe is peculiar to this order, and which is nothing less than a grand reservoir for the reception of a great quantity of arterial blood, which, as occasion requires, is emptied into the general circulation, and thus, for a time at least, supercedes the necessity of respiration.

This structure was first noticed by John Hunter, and with his usual minute accuracy; Dr. Barclay 
then described it as existing within the spinal canal of the white whale; more lately, Dr. Knox has observed it within the cranial cavity itself; whilst Messrs. Desmoulins and Breschet have noticed it in France. In a few words, we may describe it as a great irregular reservoir of arterial blood, contained within a plexus of arteries, deriving its blood from the vessels near the heart, which lines a large portion of the interior of the chest, insinuating itself between the ribs, forming a great cushion external to them near the spine, and also within the spinal canal and the cranium itself. Now it is this structure which we believe has been, and which we would venture again to adduce, as offering a satisfactory explanation of the extraordinary fact under review. None of the authors named above hare associated this remarkable structure with the no less remarkable phenomenon*; nor have they assigned any other use to it. It would appear that these great vessels, or cylinders, as Mr. Hunter calls them, do not communicate directly with veins; nor are they formed of ramifications which commu-

* Since writing the above, we have met with M. Dumeril's Report (Ann. des Sc. Nat., 1834) of M. Breschet's Paper on the Vascular System of the Cetacea, which bears the title of a Discovery in the Circulation, affecting the respiration of this order. We have in vain attempted to procure the Memoir itself. It was on the testimony of the Cyclopedia of Anatomy and Physiology for May, 1836, p. 577, that we stated that M. B.'s memoir contained "no facts or physiological inferences additional to Mr. Hunter's paper." The discovery as to the structure is certainly and clearly no discovery at all; but it appcars to us that M. Breschet has the merit of firct assigning to it its true and very important use. 
nicate freely with each other, but each may be followed to a great extent, and unravelled, as if twisted upon itself; and, upon the whole, we are free to allow that the suggestion of its use above afforded, presents itself to our view, as alike plau sible, simple, and satisfactory.

Mr. Hunter moreover remarked that the quan tity of blood belonging to the whale tribe is pro portionably very large, a circumstance which this reservoir at once explains; and $M$. Desmoulins states, that in the Cetacea the blood is at a higher temperature than in the terrestrial mammalia, rising as high as $104^{\circ}$. (Dict. Class. d'Hist. Nat.) Respecting the Lungs, J. Hunter has also observed that they are more than usually elastic; the pulmonary cells, too, are unusually small, and communicate with each other in a way that is not generally seen, for by blowing into one branch of the trachea, not only the lobe to which the air directly goes, but the whole lungs, are inflated. (Ib.418.)

When we reflect, that in the Cetacea, respiration is carried on through the lungs, and that they inhabit the ocean, we shall at once perceive that a peculiar apparatus must be provided for the performance of this function. They have no nostrils, accurately so called, and their mouths are seldom opened in free air, and therefore the process is carried on by tubes which open on the summit of their head, and which are called the blow-holes or spiracles. In man and the other mammalia, the mouth and nostrils, as every one knows, termi- 
nate posteriorly in a common pouch or bag, called the pharynx, from which both the windpipe and gullet take their origin; the former, and anterior, through an aperture called the glottis, which is covered by the epiglottis as a valve, which usually stands erect, but upon the passing of a morsel, shuts down like a lid, and so leaves a free passage for the food. In the Cetacea the spiracles admit free ingress and egress of air into and from the lungs; but as the mouth is at the same time usually filled with water, some mechanism must be provided to prevent it from rushing into these organs. The peculiarity then commences at this point. The epiglottis, instead of being a simple and usually unshut lid, forms in some of the Cetacea the anterior rim of the rima or slit, and in others encloses these parts at their base, and assists them in forming a projecting tube or canal. In this particular there is great variety in the individual species; and, as a sample merely, we refer to sketches $i$ and $k$, which exhibit the larynx in the common dolphin as sketched in the Encyclop. Methodique, and in the sea unicorn, as represented by Dr. Fleming; in both of which it will be seen that the rima glottidis is on the summit of a projecting cone or pyramid. This is received into the lower end of the blowing-tule, which is a circular aperture, surrounded with a strong sphincter muscle which includes the glottis in its grasp, thus uniting the windpipe and the blow-tube, which cross the fauces or swallow, and divide it into two passages. In some of the species 
there is an enlargement at the projecting end of the glottis, which would seem intended to prevent its retractation; but this peculiarity does not exist in others: The union of the glottis with the lower aperture of the tube makes a kind of joint to admit of motion, and of dilatation and contraction in the floating palate, in swallowing, owing to the glottis moving more into or out of the tube. Immediately above the lower aperture, the tube becomes considerably larger, and proceeds upwards and forwards, through the bones and soft parts, till it reaches the summit of the head. The tube is usually divided by a septum into two canals, which in the first subdivision of the ordinary Cetacea open by two blowholes, whilst in the second the septum ceases, and the tube terminates as it begins, by a single aperture. The whole of this singular mechanism is peculiar to the Cetacea. The other mammalia, when feeding, reside in a medium which, by means of their respiratory organs becomes the palulum vitoe, whilst the Cete in procuring sustenance are habitually under water, which were it to find entrance into their lungs, would prove as noxious as in man; und yet by a slight alteration in a few cartilages at the top of the windpipe, and in the direction of the air tubes, their feeding in the deep ocean is made as safe for them as that of the others in the balmy breeze.

Regarding the voice of this order, it would appear that we have not yet arrived at any definite conclusion. Mr. Scorseby states of the Greenland 
whale that "whales have no voice " and this is generally applied to all the other species. There is, however, a difficulty in adopting this conclusion, from the amount of testimony which affirms that they bellow loudly, under certain circumstances. In proof of this we do not go back to such statements as Anderson's concerning the rorqual, or to the Abbe Lecoz's regarding the sperm whale, or to the older voyagers, who often state that they heard them utter terrible cries, but we shall come to more recent occurrences. In January 1812, some fishers of Paimpol observing a number of small whales of the porpoise genus at some distance from shore, supplied themselves with arms and gave chase, endeavouring to drive them towards the shore. They succeeded in frightening them, and hunted one of the smallest of them from the deep. When stranded in shallow water it began to utter cries, which speedily brought others, among the first of which its mother was supposed to be one. She, however, was accompanied with many; the cries were augmented according as the number of those in peril was increased, and finally they all, to the number of seventy, violently precipitated themselves among the shallows and were taken. Cuvier, who received the details of this occurrence and published them (Ann. du Museum, tom. xix. 1.), subjoins the following remark : "As to their power of uttering cries and bellowings, more or less acute, we cannot, after the assertions which have been. made by those who heard them, any longer entertain a doubt." Is it 
not from this power of uttering cries, that the Melas of Dr. Trail has received the popular name of ca'ing, that is calling whale? The statements of the fishermen regarding it entirely agree with what has just been stated respecting the Griseus, viz. that no sooner is one of their numerous flocks in langer of being stranded, than it utters vehement cries, which being heard by the rest, they come to its relief, and usually share its dangers. We shall add another and not less pertinent statement on the respectable authority of Orbigny, regarding some animals stranded on the coast of $\mathrm{La}$ Vendee in 1822. "In the month of June many of the inhabitants of Aiguillon were aroused at eleven P. M. by a dreadful noise which apparently proceeded from the sea-shore, and which they compared to the bellowing of a hundred bulls. Some of the most courageous among them went to discover what it was; but, terrified with the extraordinary noise, more appalling during the silence of night, and increased by heavy. blows on the land and sea, they returned to their homes. When day appeared they saw four great animals (it was thought there had been others) struggling with death, and uttering frightful cries."

Is it, we would enquire, that this noise is wholly connected with the blowing apparatus, or may not these Cetacea, in the circumstances stated, have produced it through the windpipe and mouth, answering to the voice in other mammalia? But, however this may be, a still more important point is brought by the circumstance under consideration. 
If in any way they can produce a loud noise in air, what is to hinder them from doing the same under water? And if they have this faculty at all, then, according to well known accoustic principles, would not the sound be heard better, and conveyed farther than in air ; and would not this satisfactorily explain the fact so often stated, that they have some mysterious mode of intercommunication under water, to the extent in the sperm whale, according to Beale. of four, five, and even seven miles, of which no explanation, so far as we know, has hitherto been attempted? We venture to throw out this idea for the consideration of those who have better opportunities of judging than ourselves. It would probably require a more minute knowledge of the windpipe and neighbouring parts, ere we can minutely explain the mode in which these cries are uttered, and this voice, so to call it, exerted.

We need scarcely remark, that it is the apparatus above alluded to that has procured for the order the popular name of blowers, which is applicable to all the ordinary Cete. Their spoutings or jets d'eau, as they have been called, are heard as well as seen at a great distance, as much as two and three miles, and rise sometimes as high as twenty or thirty feet. It was for long supposed that this appearance was chiefly owing to the water which they take in with their food, and which, if swallowed, would only oppress them. But in opposition to this, it has more recently been maintained, that the proper egress of the water is the same as its ingress, and that by 
contracting the surrounding muscles, the throat and mouth can easily be cleared of the fluid. The spiracles, inoreover, have a secretion peculiar to themselves; and it is now the fashionable opinion among naturalists, that it is especially this secretion, together with the superfluous vapour of the lungs, which, along with the expired breath, forms the proper substance of the projected column. This is the opinion maintained, among others, by Scorseby and Blainville, certainly weighty names. Notwithstanding this, we venture to express doubts whether the point is either definitely or satisfactorily established. It would appear there is an allowed difficulty, arising from the great quantity of the fluid frequently expelled; which is met by the statement, that sometimes the ejected air comes in contact with some supernatant water, and raises quantities along with it. With a perfect cognizance of these opinions, however, we find that M. Lesson, from much personal observation, dissents from this opinion, and, as late as 1828 , maintains the old and now often scouted explanation. He states that, from having often seen the phenomenon, and frequently within the distance of a few yards, he feels constrained to oppose the prevailing view. $\mathrm{He}$ observes of the sperm whale, that when only breathing, and not feeding, it has no jets at all ; and that, when feeding and taking in water, it then expels some through its spiracles, though to no great height; whilst in other whales, the projected colunn long retains the appearance of a united stream, mounting high before it 
falls down again in a shower. (Cétaces, 308.) Amidst these conflicting statements we are the less surprised to find another opinion which embraces, if it does not quite reconcile, the other two. Thus Quoy and Gaimard, though they agree with Scorseby, that possibly no water may sometimes be expelled during expiration, yet having often observed that during stormy weather the jets took place both more frequently and more abundantly, account for the fact on the supposition, that as it is then that the Cetacea feed most freely, the projecting of the water takes place chiefly when they are engaged in this important process. These naturalists go further; "the habits of the smaller Cete," they maintain, "supply a convincing proof against the opinion of Mr. Scorseby ; for beyond doubt, if the jet was composed only of air and condensed mucus, the porpoises on our coasts would emit this vapour in a similar way, according to their size; and yet this is not the case. Those who inhabit the sea-coasts and great rivers, when sufficiently near, hear these animals make a great noise,- to grunt like a porpoise, is a proverb among sailors, but they never see any apparent jet from the blow-hole." (Zoologie de l'Uranie, p. 80.) Desmoulins expresses his opinion in these words, - "It is not water, but mucosity, which is expelled by the blow-holes during expiration; the animal spouts water only after deglutition, or in the moments of rage." (Dict. Classique.) This two-fold view of the matter has been adopted by an eminent British naturalist, as late as the year 1831. 
He states, the apparatus is used for getting rid of the superfluous water from the mouth, and that this takes place as well under water as on the surface. "As often as the whale opens its enormous jaws, its mouth of course immediately fills with water; but it is only the fish, fuci, or small marine animals, ' unsafe within the wave of such commotion,' that are actually swallowed. The water itself is partly regurgitated and partly made to pass upwards, and by a peculiar and very admirable mechanism is thrown out by the blow-holes. When the animal breathes on the surface, a moist vapour, mixed with mucus, is exhaled; but no water is thrown up, unless the expiration is made heneath the waves, or the creature itself is either in a sportive mood, or under the influence of rage or terror." (Illustrations of Zoology by James Wilson, vol. ii.)

Are we then to understand, that occasionally the mucosity only is discharged, and that sometimes again this is mixed with water? Among other arguments that are used against this latter alternative, Blainville states (Nouv. Dict. Hist. Natur. tom. xix.) that the construction of the parts does not admit of the ingress of water. This is a point to be ascertained. Is it true that such a peculiarity of con struction exists in all the genera; and that they have no power to use it for both purposes as occasion may require? Our own observations, grounded upon the examination of several genera, would lead us to answer that they had this power. In the meanwhile we remark, that as the mechanism is different in 
almost every genus, so the blowing is different in most of them; and to such an extent, that we believe an experienced observer could, even at a distance, determine the variety at any particular time in sight; and the utility of this to the whalers need not be insisted upon. When describing the genera, wa shall, as far as our materials enable us, point out these minute peculiarities.

One general remark, however, may here be premised, viz. that the blowing is most conspicuous in the largest genera, very marked also in those of intermediate dimensions, while in the smaller it is seldom or ever visible at all. Thus Lesson remarks, "we liave examined for hours many different species of dolphins sporting around the vessel, without witnessing the slightest column of water, or of vapour, being projected from the blow-holes." (Zool. de la Loquille, p. 177.) And so Quoy and Gaimard, " the dolphins very rarely spout; we were going to say never, because we have never seen it, but that Spallanzani states that he witnessed it whilst passing from Lipari to Stromboli, and Humboldt mentions he saw it in porpoises, in the fresh water, three hundred leagues from the mouth of the Orinocco." (Zoologie de l'Uranie, p. 79.) And this would appear to arise not only from their inferior size and energy, but also from a difference in the construction of the apparatus, which we do not think has been pointed out. In the smaller varieties the parts seem to be much less muscular; and hence, though quite efficient for all the purposes 
of life, they rarely produce visible spoutings, but carry on respiration in a manner more nearly resembling animals, not inhabitants of the water.

After " their spoutings are out," to avail ourselves of the expressive phraseology of the whalers, most of the Cete, as we have already stated, descend into the depths of the ocean, where they are sometimes exposed to the pressure of one hundred and fifty-four atmospheres, equal to about a ton upon each square inch. We have seen how this pressure is met, by a peculiarity of the integuments ovethe whole surface of the body; it now remains to state how the delicate apparatus we have just described is defended from danger from the same cause. The external opening of the blow-holes is in some of the larger species an opening or slit of a foot in length, the tube itself is of large dimensions, and the chest is a great chamber of air: by what means then is water prevented, under this immense pressure, from entering the lungs and so destroying the animals? We answer: It is mainly by a set of valves which act upon the same principle in all the genera, but which are varied in each, by a number of contrivances equally extraordinary, beautiful, and efficient. We shall illustrate this remark by epitomizing a short portion of Pallas' excellent account of the apparatus in the Beluga or white whale. The blow-hole opens in the most elevated part of the head, and this opening is circumscribed by a double arch. The skin is drawn towards this orifice, and forms over it in front a soft papillary 
ralve, which may be compared to an epiglottis, and which prevents the entrance of foreign bodies. The skin over the valve is scarcely two lines thick, but internally it envelopes a projecting body, which is about two inches thick, and which is composed of a network of tendinous fibres hard as wood, and which can scarcely be cut with a knife. A similar network of tendinous fibres, arranged in circles, forms, in this situation, the external wall of the blowing canal; and two strong muscles rising from the frontal bone, and peculiar to the canal, acting on these bodies, most effectually shuts them down, and thus secures the canal. It is an apparatus to which there is nothing similar in any of the other mammalia. We shall, on this interesting point, likewise avail ourselves of the interesting descriptions and sketches of Scorseby. In the true whale, he remarks, the first impression of each blow-hole on the upper part of the skull is marked by an oblong cavity (see 1, sketch $l$. Plate I. representing the upper surface of the anterior part of the whale's skull, the skin and fat being removed), which is the seat of a muscular substance attached by its anterior extremity to the surface of the skull, and also attached by its posterior and inferior extremity to the interior of the skull, at some depth in the blowing canal 1, l, sketch $m$. The part of this muscle which penetrates the bony canal is of a conical form, the apex downwards, or within, represented at 2 , in figure $m$, which is a vertical section of the skull; so that when this interior portion contracts, the muscular 
cone is drawn tight into the orifice, and completely closes the breathing canal 1, 1; while on the other hand, the action of the external part of the muscle draws the conical plug forward and upwards, and affords a free passage for the air in respiration. This beautiful structure it is which enables the animal, under the immense pressure to which it is sometimes exposed, to exclude the sea-water from its lungs: so far from the water being forced down the canals, the enormous load serves only more effectually to press down and close the valves that defend the passages to the lungs. (Journal of a Voyage, \&c. 152.)

To this we may add, that in those genera in which the external aperture to the ear is not covered by the common integuments, there is a valve placed in the passage to guard against the pressure of water upon the drum of the ear, whereby it would be broken and the organ of hearing destroyed. Mr. Scorseby's words, in relation to the Mysticetus, are,-there is an elegant appearance found near the external opening, in the shape of a little plug, like the end of the finger, which is inserted in a corresponding cavity in the interior of the canal, by a slight motion of which the opening can either be effectually shut, for the exclusion of water, or unclosed for the admission of sound : and M. Orbigny remarks, upon four of the $P$. Griseus which he had an opportunity of examining, "the external orifice of the ear was shut by a very fine valve which appeared to have the power of opening and shutting at the animal's will." (F. Cuvier's Hist., \&c. 185 ? 
The only other part of the animal to which we shall at present advert is the nervous system, which, from its vast importance on the habits and character of the living being, must ever be regarded with interest. It would appear that the observations made on this point are still by much too few to enable us to come to any thing like general results; and in systematic writers, we meet with the utmost contrariety of statement. Thus Cuvier, in his Lectures (Comp. Anat. ii. 265), judging from the limited opportunities which at that time had come within his reach, speaks of the brain of the Cetacea generally, as distinguished for its great breadth and height; whilst Lesson, on the other hand, states that it is always very small in relation to the size of the animals (Cétacés, 23). The truth appears to lie between these two opinions, and to have been expressed by Hunter when he says, "the size of the brain differs much in different genera of the tribe, and likewise in the proportion it bears to the bulk of the animal." (Loc. cit., p. 423.) It will probably require a distinct examination of each species before certainty is attained. From the present state of our knowledge, it would appear that the larger varieties have very small brains in proportion to the size of their bodies, whilst the smaller kinds again have very large and well developed brains. In regard to the mysticetus, Mr. Scorseby states, from actual examination of at least one specimen, that the brain lies in a small cavity in the upper and back part of the skull; its general appearance is 
not unlike that of other mammalia, but its smallness is remarkable. In a young specimen, 19 feet long; which weighed 11,200 pounds, the brain weighed only 3 pounds 12 ounces, which is only one three thousandth part of the whole animal; whilst in man it is calculated to weigh one thirty-fifth part. In a young rostrata, which measured 17 feet, $M r$. Hunter found that the brain weighed 4 pounds 8 ounces; and M. Delalande reports that in a rorqual, nearly 80 feet long, the brain filled only a cavity which measured 13 inches by 9 . On the other hand, Cuvier states, from five examinations of the porpoise and dolphin, that on the average the brain weighed one sixty-third part of the whole. This statement, regarding these smaller groups, is corroborated by Tyson, who in his Anatomy of the Porpoise remarks that the brain is large, its figure somewhat short, but what it wants in length it has in breadth; Ray observes that the largeness of the brain, and its correspondence to man's, argues this creature to be of more than ordinary wit and capacity; and Tiedemann, the highest living authority in this department, remarks, "that the brain of the dolphin is distinguished from that of monkies by its great size and developement; and, next to the brain of the orang-outang, approaches nearest, in this respect, to the human brain." We here introduce a sketch of Tiedemann's plate of the base of the brain in the dolphin, in illustration of his remark; and add, that considering the marked effect which the relative size of this important organ generally has on the 
OF THE CETACEA.

character of the animal, it seems desirable that every opportunity should be embraced to accumulate accurate information on the point.

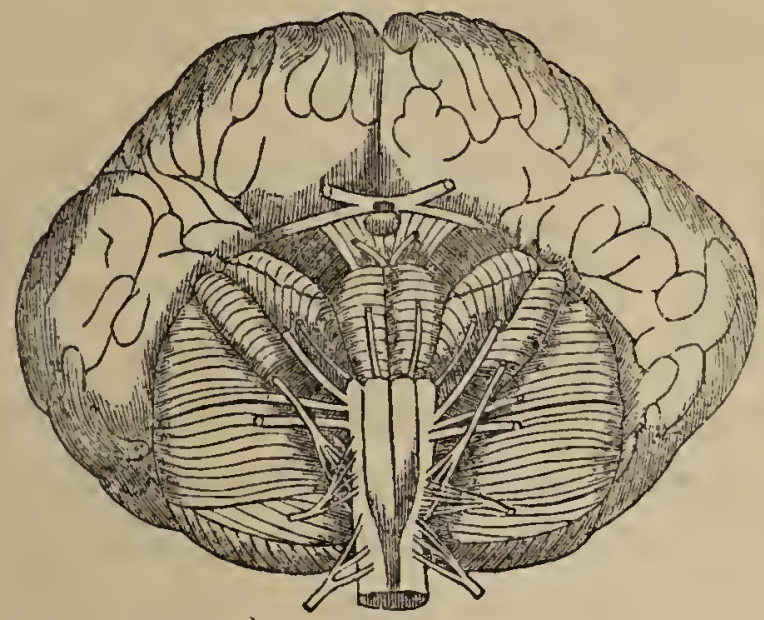

There is nearly an equal paucity of facts conceming the senses of this order. First, in relation to that of smell. Among the early fishermen and systematic writers this faculty was conceded, in the highest possible perfection, to the whole tribe. Thus Anderson, in his excellent account of Iceland and Greenland, narrates that the inhabitants of the Ferroe isles, when they perceived that their boats were pursued by the sperm whale, which, according to him, is a very dangerous species, used to throw some castor overboard, which made him sink to the bottom like a stone. Ginger was celebrated for similar virtues, and the blood of animals still more so. Chalk and sulphur had still greater powers, for no fish would come near a ressel freighted with these articles; and such opinions are very prevalent with sailors up to the present time. The comparative 
anatomists seem to have been the first to throw out difficulties in the way of this belief, by discovering that in the majority of the species the olfactory nerve does not exist, and that there is no opening in the skull by which that nerve can pass. Cuvier's words, in 1823, are,-in the Cetacea there is an absence of the olfactory nerve and the usual organs of smell. (Os. Foss. v. 235; see too, Comp. Anat. vol. ii. 683). Ray and Rondelitius were aware of this fact as it respects the dolphin, yet the latter of these authors still maintains that it has a very acute sense of smell, " as Aristotle testifies and experience manifests ;" a conclusion in which few, now-a-days, will be inclined to follow him. The same deficiency has been ascertained respecting the porpoise genus; and Cuvier's words are,_- " probably the other Cetacea likewise want them, as they have no æthmoidal holes." (Comp. Anat. ii. 199.) This, however, only shows the danger of reasoning from analogy in this order of animals, whose differences appear to be endless. "I believe," says Mr. Hunter, "the olfactory nerve is peculiar to the mysticetus and rorqual,-the large and small whalebone whales" (Loc. Cit. 429); and such an observation was more than sufficient to set the ingenuity of this extraordinary man to work. How do animals smell? have aromata any other vehicle than air? how can water be smelt? and according to him, water, in the Cetacea, never comes into contact with the sinuses in which their olfactory nerves are distributed; and their perceiving smells, through the 
medium of air, could be of no service when feeding in the depths of the ocean. These are some of the interesting questions that occurred to the mind of J. Hunter, and on which he dwells; though we cannot say that even his ingenuity has settled them. Lesson states that the olfactory nerve is wholly absent in the sperm whale (17); and Mr. Knox, in his account of the great rorqual, states, that this nerve is large. The prevailing opinion, therefore, now is, that the sense of smell is possessed by the true whales and the rorquals, and is wanting in all the rest. (See Dict. Class. d'Hist. Nat. Art. Baleine.) .We much doubt, however, if this should be regarded in any other light than an approximation to the truth.

The organ of vision in the Cetacea appears usually to be very small, in relation to the size of the animal ; Cuvier has made this remark with regard to all large animals, and especially the Cetacea. Notwithstanding the enormous bulk of the larger whales, their eye is stated not to exceed in size that of an ox. (See Arct.Reg. i. 456). In the beluga examined by Dr. Barclay, which measured between thirteen and fourteen feet, the eye is stated to be not so large as in man (Wern. Trans. iii. 393); and as it regards the porpoise, Tyson states, that it is not so large as the sheep's (199). In some species again, it appears to be proportionably larger. Thus Quoy and Gaimard state, that in the rorqual which they examined in the Falkland islands, about fifty-five feet long, the eye was five inches in the long diameter and four 
in the short. In Dr. Knox's great rorqual the organ is placed very far back in the head, obliquely above and behind the angle of the mouth, and near to that part of the animal which corresponds with its greatest breadth, so that by the simple motion of the eye it commands a wide range of vision. Cuvier has remarked that its axis of vision is directed obliquely downwards, so that it may at all times the more readily perceive its food as it floats below it; and, according to Scorseby, the sense of seeing is acute, since whales are observed to discover one another in clear water, when under the surface, at an amazing distance. $\mathrm{He}$ at the same time states, that when on the surface, the mysticetus does not see far. On the other hand, it has been remarked, that the sperm whale, when above the surface, appears to view objects very readily which are placed in a direct line with the eye; its common mode of looking at a boat or ship being to turn over on its side, so as to cause the rays from the object to strike directly upon the retina. When alarmed, and anxious to take as rapid a glance as possible on all sides, it assumes a perpendicular position in the water, with its head protruding above the surface and the eye directed to the object (Beale's Obs. on the Sperm Whale). This practice, as will subsequently appear, is not confined to the sperm whale.

The organ of hearing in the Cete is in many respects peculiar. It resembles considerably the mechanism in fishes, though in various particulars it approaches more or less to that of land animals. 
Being aquatic in their habit, the organ must especially have a reference to the laws of sound as connected with their native element; and yet several of the species seem so formed as to receive impressions conveyed through air. None of them have the external auricular appendages which are common in the other mammalia; neither have they any osseous meatus opening; their external meatus is nothing more then a very slender cartilaginous canal, which commences sometimes at, and much more frequently beneath, the surface of the skin, and takes a serpentine direction as it passes through the subjacent parts to reach the drum of the ear. In the sperm whale the external opening would admit a small writing quill. After the examination of the young mysticetus, Mr. Scorseby remarks, the opening of the passage is so small as not to be easily discovered; in the sucking whale it was only one-sixth of an inch in diameter (Journal, \&c. 154); and yet at a previous period he had stated that no orifice for the admission of sound can be discovered in the Greenland whale until the skin is removed. (Avct. Reg. i. 456). There is here a discrepancy in the statements of this generally accurate and ac complished author; and on the authority of the latter passage, it is usually stated that the mysticetus has no external aperture. In the beluga which was examined by Dr. Barclay, no external opening could be discovered, nor was any found in the toothless whale of Havre, fifteen feet long, examined by Blainville; nor in any of the seventy gloliceps, 
which were stranded in Brittany in 1812; nor in a rorqual, fifty-eight feet long, examined near Rocherort by M. Souty; and the same is true of a narmhal and dolphin, we have had an opportunity of examining. The internal ear is quite as peculiar, in that it is scooped out of a particular bone forming no portion of the usual cranial bones, and is attached to them only by ligaments. In several of the order, the eustachian tube opens high up in the blowing canal, answering, as we have seen, to the nose; and through this it evidently must be that the animal hears any sound that is communicated through the air: it is with this tube also that these cavities communicate, in which it is alleged that the nerves of smelling are situated; so that it is with some show of truth that it has been stated of the genera so organized, that they hear by the nose and smell by the ear. Tiedemann remarks, regarding the dolphin, "perhaps the most remarkable nerve for its great relative size is the acoustic, which testifies to the delicate sense of hearing in it."

The two remaining senses, taste and touch, seem to be possessed by the Cetacea in a very inferior degree, and concerning these we shall not now stop to make any observations.

The mental faculties of the Cete, so far as observations have been made on this very obscure point, appear to vary greatly in the different genera; for which reason we shall reserve all remarks on this subject till we come to treat of the different 
genera in detail. We shall do the same with regard to the dispositions manifested by the various species, which must be learnt in comnexion with their individual history. We may here, however, notice one point in which they seem all to agree, viz. the reciprocal regard they manifest for each other. This is common more or less to them all, whether as it regards the mother and her young, or the cub and its parents, or the several members of the same family or shoal. This amiable trait in the character of the whole order, is quaintly but beautifully illustrated in the following lines of the old poet, Waller, which bear intrinsic marks of being a delineation from nature. In his Battle of the Summer Islands, we are informed that two whales, an old and young one, were embayed in the shallows; and the following scenes were enacted.

The bigger whale like some high carack lay, Which wanteth sea-room with her foes to play:

This sees the eub, and does himself oppose

Betwixt his cumber'd mother and her foes:

With desperate courage he receives her wounds, And men and boats his active tail confounds; Their forces joined, the seas with billows fill, And make a tempest, though the winds be still.

Now would the men with half their hoped-for prey

Be well content; and wish this cub away :

Their wish they have; he (to direct his dam Unto the gap through which they thither came) Before her swims, and quits the hostile lake, A prisoner there, but for his mother's sake: She, by the rocks compell'd to stay behind Is by the vastness of her bulk confined,- 
They shout for joy! And now on her alone Their fury falls, and all their darts are thrown; Their fixed jav'lins in her sides she wears, And on her back a grove of pikcs appears. Roaring, she tears the air with sueh a noise As well resembled the eonspiring voice Of routed armies when the field is won, To reach the ears of her escaping son.

He, though a league removed from the foe, Hastes to her aid :-

The men amaz'd, blush'd to observe the seed Of monsters human piety cxceed !

Their courage droops, and hopeless now they wish For composition with th' unconquer'd fish ; Not daring to approach their wounded foe, Whom her courageous son protected so.The rising tide, ere long, their efforts aid, And to the deep a passage for them made; And thus they parted with excliange of harms, Much blood the monsters lost, and they-their arms.

WE now proceed to the survey of the several genera in their order; and in doing so, we beg to remind our readers that the whole order is divided into two great tribes, the Ordinary and Herbivorous Cetacea. The former is distinguished chiefly by being more pisciform in its appearance, and entirely so in its habits; ranging throughout the depths of the ocean, and feeding upon the usual prey of fishes; whilst the latter, though wholly aquatic, approximates to the amphibia, and resides at the estuaries of rivers, there feeding on the vegetables which grow on the shores and shallows. The former, 
too, is by much the most numerous and varied, being in fact one of the largest tribes which exists in nature.

Some further division, therefore, becomes indispensable. The first and most important group has, by Cuvier and others, been distinguished by a very striking peculiarity, viz. the enormous size of the head, which, according to common apprehension, appears disproportionate, extending to a fourth, and even a third, of the dimensions of the whole frame. Under this first subdivision we class the Common or Greenland Whale, the Rorquals, and the Spermaceti Whales. The two former of these have no teeth whatever, but whalebone or baleen only; and the Sperm Whale has no baleen, and has teeth in the lower jaw only. 
THE GREENLAND WHALE.

PLATE II.

Balæna Mysticetus, Linn._-Common Whale, Bonnaterre; La. cepede.-Greenland or right Whale of Scorseby and the Northern Fishers.-Balæna Borealis, Lesson.

As we owe our knowledge of this valuable animal principally to the investigations of Scorseby, it will only be doing justice to this eminent navigator, as well as conferring a favour upon our readers, to embody in our account an abstract of his excellent description (Arctic Reg. vol. i. 449-478).

It is this interesting animal which is the object of the important commerce to the Polar Seas ; it is productive of more oil than any other of the Cetacea, and being less active, slower in its motions, and more timid than any other of the order of similar magnitude, it is more easily captured.

In former times there was much exaggeration as to the size of this whale, eighty and one hundred feet being assigned as a frequent size, and one hundred and fifty and two hundred feet as not uncommon. Some of the ancient naturalists stated that it attained even a much greater length. From the researches, however, of Scorseby, it seems irre- 

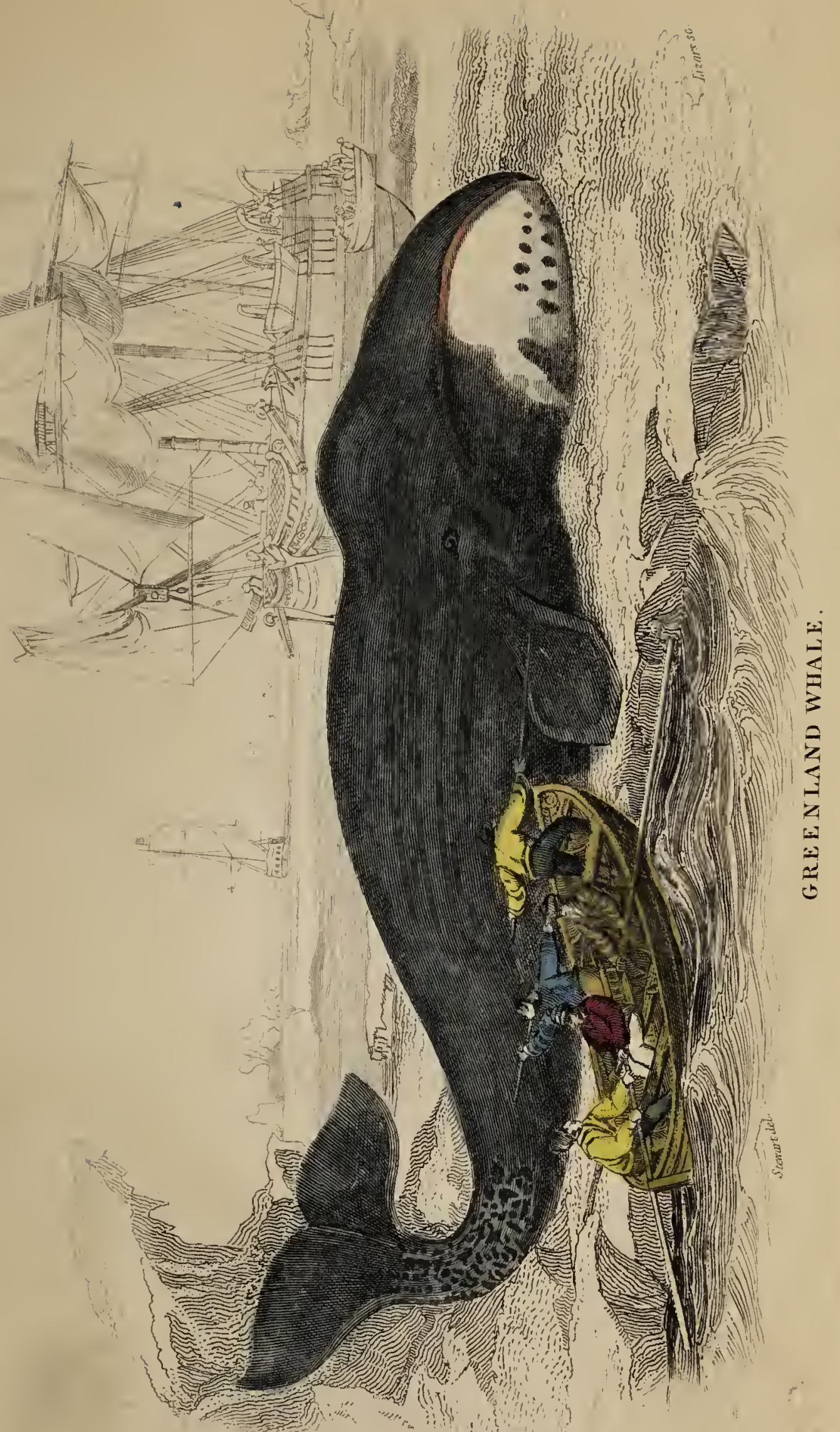

fragably established that the mysticetus at no time ever exceeds sixty-five or seventy feet.* He himself was personally concerned in the capture of three hundred and twenty-two, not one of which exceeded sirty feet. $\mathrm{He}$ adds, that an uncommon whale which was caught near Spitzbergen, the whalebone of which measured almost fifteen feet, was not so much as seventy feet in length; and the largest actual measurement he has met with is that given by the late Sir Charles Giesecki, who states that in 1813 a whale was killed at Godhaven of the length of sixty-seven feet. Its greatest circumference is from thirty to forty feet.

When fully grown, therefore, the length may be stated as varying from fifty to sixty-five, or very rarely seventy feet. It is thickest a little behind the fins (see Pl. Ir.), near the middle of its whole length, whence it gradually tapers in a conical form towards the tail, and slightly towards the head. The head is remarkably large, as is the case with the two succeeding genera, forming nearly one-third of the whole bulk. The under part, the outline of which is given by the jaw-bone, is flat, and measures from sixteen to twenty feet in length, and from ten to twelve in breadth. The lips, of corresponding dimensions, go to enclose the cavity of the mouth in a very striking way. The upper jaw, including the crown-bone, is bent down at its edges, like a boat upside down, so as to shut in the front and upper parts of the cavity of the mouth. When the mouth * See Edin. Phil. Journ. vol. i. 
is open, it presents a cavity as large as a room, and capable of containing a ship's jolly-boat full of men, being fifteen or sixteen feet long, ten or twelve high, and six or eight wide.

The mysticetus has no dorsal fin. The two pectorals are placed about two feet behind the angle of the mouth, and are about nine feet long and five broad. They cannot be raised above the horizontal position; and hence the account given by some naturalists that by them the whale supports its young on its back, must be erroneous. The tail is horizontal; its form is flat and semilunar, indented in the middle ; the two lobes are somewhat pointed, and turned a little backwards.

The eyes, which, according to Sir Charles Giesecki and Mr. Scorseby, are not much larger than those of an $o x$, and with a white iris, are situated in the sides of the head, about a foot obliquely above and behind the angle of the mouth. The sense of seeing is acute in the water, when clear ; not so, however, in air. On the most elevated part of the head, about sixteen feet from the anterior extremity of the jaw, are situated the blow-holes, consisting of two longitudinal apertures, very similar to the holes in the body of a violin, from eight to twelve inches in length.

The mouth, in place of teeth, contains two extensive rows of baleen, commonly called whalebone, suspended from the upper jaw and sides of the crown-bone. The plates of baleen are generally curved longitudinally, and give an arched form to 
the roof of the mouth. They enclose the tongue between their lower extremities, and are themselves covered by the lower lip. There are upwards of three hundred of these plates on each side of the jaw, resembling a frame of saws in a saw-mill; they are longest in the middle, whence they gradually diminish away to nothing both in front and behind: ten or twelve feet is their usual length. In the youngest whales, called suckers, the baleen is only a few inches long; when the length reaches six feet or upwards, the whale is said to be size: a large whale sometimes yields a ton of baleen.

As the formation of the baleen is curious, and forms the most striking peculiarity in this and the next genus, we shall supply some details concerning its formation, principally taken from the account of Mr. J. Hunter. This singular production does not proceed directly from the gum itself, but from a thin vascular substance resting upon it. This substance, which may be called the nidus of the baleen, sends out a thin broad process, answering to each plate, on which the plate is formed; so that each plate is necessarily hollow at its growing end, the first part of the growth taking place in the inside of this hollow. Besides this, the plate receives additional layers on the outside, which are formed in the same vascular nidus as it extends along the jaw. This part forms a semi-horny substance between each plate, which is very white, rises with the whalebone, and becomes even with the outer edge of the jaw. This intermediate substance fills up the spaces 
between the plates as high as the jaw, and acts as abutments to the whalebones, keeping them firm in their places. But this will be best explained by a reference to the accompanying sketches from Mr. Hunter. (See Plate I. $p, q, r$.)

(p.) - 1. Is the part analogous to the gum.

2. A fleshy substance covering the jaw, on which the inner lamina of the plate is formed.

3. A white substance which surrounds the whalebone, pass ing between the plates to form their cxtcrnal laminæ.

4. The part which projects beyond the gum.

5. The termination of the plate in a kind of hair.

Sketch $q$ exhibits a perpendicular section of several plates of whalchone in thcir natural situation; their inner edges or shortest terminations are removed, and the cut edges of the plates seen from the inside of the mouth. The upper part shows the base from which they spring, and the white substance in which they grow; the middle part shows the distance of the plates from cach other; the lower part, the rough surface formed by the hairy termination of each plate.

$(r)-$.1 . Is the basis on which the plates are formed, which adheres to the jaw-bonc.

2. 2. The intermediate white substance, laminæ of which are continued along the middlc layer, and form the substance of the plate of the whalebone.

3. The outline of another plate.

4. Onc of the outer layers growing from the intermediate substance.

5. The middle laycr of the plate, formed on the pulp passing up the centre of the plate. The termination of this layer forms the hair.

Mr. Hunter further remarks, " that in the growth of the whalebone three parts appear to be formed; one from the rising cone, which is the 
centre; a second on the outside; and a third being the intermediate substance. These appear to have three stages of duration; for that which forms on the cone, I believe, makes the hair, and that on the outside makes principally the plate of whalebone; this, when a certain length, breaks off, leaving the hair projecting, becoming at the termination very brittle ; and the third or intermediate substance, by the time it rises as high as the edge of the jaw, decays and softens away like the old cuticle of the sole of the foot."

The torngue is incapable of protrusion, being fixed. from the root to the tip; a slight beard, consisting of a few short scattered hairs, surmount the anterior extremity of both jaws. The throat is remarkably strait; Sir Charles Giesecki states it does not exceed an inch and a half in width.

The colour of the mysticetus is velvet-black, grey, and white, with a tinge of yellow. The back, most of the upper jaw, and part of the lower, together with the fins and tail, are black. The lips, the fore part of the lower jaw, sometimes a little of the upper, and a portion of the abdomen are white; and the eyelids, the junction of the tail with the body, a portion of the axilla of the fins, \&c. are grey. The older the animals the more they contain of white and grey, and some are all over pie-bald.

The surface of the body is somewhat furrowed; the scarf-skin is not thicker than parchment; the rete-mucosum in adults is about three-fourths of an inch in thickness, over most parts of the body: in 
suckers nearly two inches : it is generally of the same colour throughout its thickness. The oleaginous substance called blubber, and constituting the most valuable part of the animal, forms a complete wrapper round the whole body from eight to twenty inches thick. In some old animals it resembles the substance of salmon, whilst in the younger it is yellowish white. The lower jaw, excepting the two bones, consists almost wholly of blubber, and the crown bone is covered with it. The oil appears to be retained in the blubber in minute cells; it is expelled when heated, four tons of blubber generally affording three tons of oil ; and it in a great measure discharges itself out of the fenks, - the square pieces into which it is cut, whenever putrefaction in the fibrous tissue takes place. The blubber in its fresh state is without any unpleasant smell, and hence a Greenland ship is not unpleasant in ligh latitudes.

The flesh of a young whale is of a red colour, and when cleared of fat, broiled, and seasoned with pepper and salt, does not eat unlike coarse beef. That of the old whale becomes blackish, and is exceedingly coarse. The tail is very fibrous and sinewy, and is extensively used, particularly in Holland, in the manufacture of glue.

The bones are very porous, and contain large quantities of fine oil ; the jaw-bones, which measure from twenty to twenty-five feet, are often taken care of, principally on account of the oil which drains out of them. The external surface of the most porous is compact and hard; the ribs are 
nearly solid; the number, according to the late Sir Charles Giesecki, is thirteen pair.

The sense of hearing in the mysticetus is probably very different in air and water. A noise in the air, such as that produced by a person shouting, is not noticed by it, though at a distance only of a ship's length; but a very slight splashing in the water, in calm weather, excites its attention and alarms it.

Being somewhat lighter than the medium in which it swims, the mysticetus can remain at the surface with its spiracles and a considerable portion of its back above water, without any effort or motion. To descend, however, requires an exertion. The proportion which appears above water, when alive, is probably not a twentieth part of the animal ; but, within a day after death, when the process of putrefaction commences, it swells to an enormous size, till at last a third of the carcase appears above water, and sometimes the body is burst by the force of the air generated within.

Bulky as the whale is, and clumsy as it appears to be, it might be imagined that all its motions must be sluggish, and its greatest exertions productive of no great celerity. The fact, however, is the reverse. A whale extended motionless at the surface of the sea, can sink, in the space of five or six seconds, beyond the reach of its human enemies. Its velocity along the surface, and in other directions, is the same. I have observed, savs Scorseby, a whale descending, after I had harpooned it, to the 
depth of about one-fourth of a mile, with the average velocity of seven or eight miles an hour. The usual rate, however, at which these whales swim, when on their passage from one situation to another, seldom exceeds four miles an hour. They are capable, however, for the space of a few minutes, of darting through the water with the velocity of the fastest ship under sail ; and of ascending with such rapidity, as to leap entirely out of the water. This feat they sometimes perform apparently as an amusement, to the high admiration of the distant spectator; but to the no small terror of the inexperienced fisher. Sometimes the whales throw themselves into a perpendicular position, with their heads downwards, and moving their tremendous tails on high in the air, beat the water with awful violence, which, cracking like a whip, resounds to the distance of two or three miles; the sea is thrown into foam, and the air filled with vapours. This performance is denominated " lob-tailing."

When the animal retires from the surface, it first lifts its head, then plunging it under water, elevates its back like a segment of a sphere, deliberately rounds it away towards the extremity, throws its tail out of the water, and so disappears.

The mysticetus usunlly remains at the surface to breath about two minutes, seldom longer; during this time it "blows" eight or nine times, and then descends for an interval usually of five or ten minutes; but sometimes, when feeding, fifteen or tweuty minutes. According to Scorseby, the right 
whales have no voice, but in blowing they make a loud noise. The vapour they discharge is ejected to the height of some yards, and appears at a distance like a puff of smoke; they blow strongest, densest, and loudest when in a state of alarm, or when they first appear on the surface after being a long time down. The depth to which they commonly descend is not accurately known; but, when struck, the quantity of line they sometimes take out of the boats, in perpendicular descent, affords a good measure of the depth. By this rule they have been known, according to Scorseby, to descend about a mile, and with such velocity, that instances have vccurred in which whales have been drawn up by the attached line from a depth greater than the bighest mountains in Scotland, and have been found to have broken their jaws, and sometimes their crown-bone, by the blow struck against the bottom. Whales are seldom found sleeping; yet instances of it have occured among ice in calm weather.

The food of these animals, so vast and strong, is too remarkable not to claim a moment's attention. They have no teeth, and hence we at once perceive they cannot prey on the smaller of their own kind, or on the larger fishes; and their throat is so small, that they could not dispose of a morsel which is swallowed by an ox. The well provided pasture grounds, however, as they may be called, exhibit, to the contemplation of the curious, one of the most wonderful manifestations of Beneficence and Power. A very considerable portion of those spaces in which 
this whale is found is occupied by what is called green-water. Something analogous, though of a yellowish or reddish tint, occurs in southern latitudes, as will be afterwards noticed. Captain Scorseby, in 1816, first investigated the peculiarities of the green-water. This accomplished naturalist states, that it forms perhaps one-fourth part of the Greenland sea, between the parallels of $74^{\circ}$ and $80^{\circ}$, equal to about twenty thousand square miles: Though it is liable to alteration of position from the action of currents, still it is always found, year after year, near certain situations. It often constitutes long bands or streams, of varying length and breadth, extending $2^{\circ}$ or $3^{\circ}$ of latitude in length, and from a few miles to thirty or forty in breadth. It is usually an olive-green, and of striking opacity; sometimes it is nearly grass-green, or with a shade of black.

Mr. Scorseby examined the qualities of this water, and, to his astonishment, found that it obtained its colour from the presence of immense numbers of animalcules, most of them invisible without the aid of the microscope. The greatest number consisted of an animal of the medusa kind, belonging to an order with which most of our readers will be familiar, under the vulgar name of sea-blubber, a soft gelatinous substance, often found lying on the sea shore, and exhibiting no signs of life, except shrinking when touched. He found the prevailing specimens to be globular, transparent, and from one-twentieth to one-thirtieth of an inch 
PIATE III .

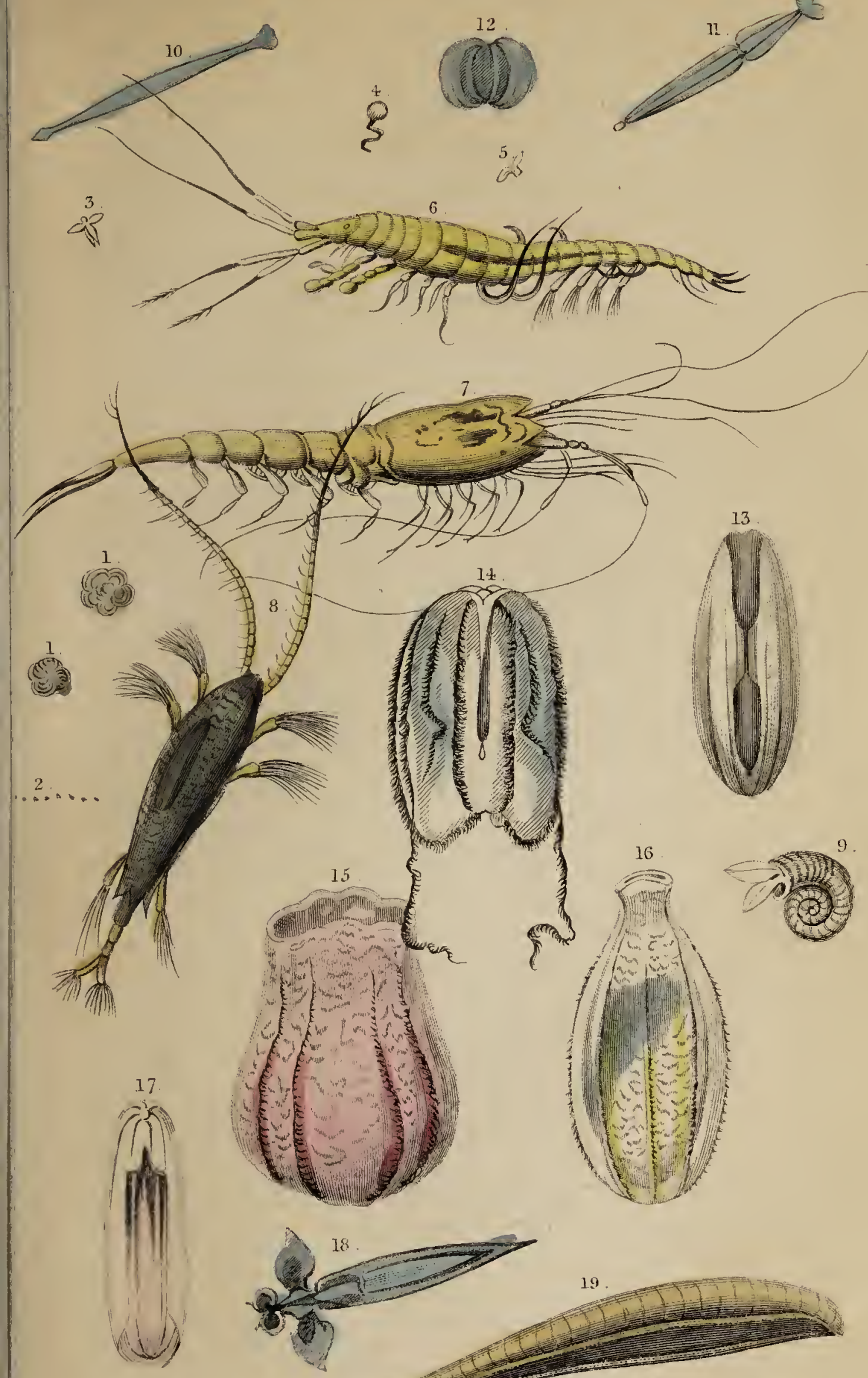



in diameter. (See Plate III.) Figure 1 is a specimen of this, of course greatly magnified ; figure $\mathbf{2}$ represents another of these minute animals, resembling small portions of fine hitir, somewhat dark in colour, and verging in length from a point to onetenth of an inch. There appeared to be about thirty bead-like articulations in the largest, being thus beautifully monoliform; their diameter appeared to be about one three-hundredth part of an inch. Figs. 3, 4, 5, exhibit other minute animals which were wholly invisible to the naked eye. The number of medusa was found to be immense. Mr. S. estimates that two square miles contained $23,888,000,000,000,000$; and as this number is above the range of human thought, he illustrates it by observing, that 80,000 persons must have started at the creation of the world to complete the enumeration at the present time. These animalculæ are not to be considered as the immediate food of the whale; they form, however, the food of the various shrimps and minute crabs, lobsters, and seasnails (figs. $6,7,8,9)$, and medusa, \&c. $(10,11$, $12,13,14,15,16,17,18$ and 19,) upon which the monster of the deep is supported. In this plate is seen at one glance the common food of this enormous whale; and its dependence on these minute insects, as well as that of the greater number of animals which inhabit those prodigious and dreary seas, is almost too clear to require demonstration. As before stated, the invisible animalculæ supply nourishment to the innumerable small 
shrimps, crabs, \&c.; they in their turn are the food of the smaller fishes, which again supply nourishment to the larger, which are devoured by seals, dolphins, and other Cetacea; the bear again feeds upon the seal, and thus there is a wonderful dependent chain of existence formed, every link of which seems essential to the integrity of the whole.

When this whale feeds, it swims with considerable velocity below the surface, with its jaws widely extended. A stream of water consequently enters its mouth, and along with it large quantities of water-insects; the water escapes again at the sides ; but the food is entangled and sifted in the baleen, which, from its compact arrangement, and the thick internal covering of hair, does not allow a particle the size of the smallest grain to escape.

It is presumed the period of gestation is nine or ten months, and the whale has but one at a lirth, instances of two accompanying the female being very rare. The young one, at the time of birth, i, ten or fourteen feet long. According to Sir Charles Giesecki, it turns on the one side on the surface of the water when it gives suck to its young, and then the cub attaches itself to the teat. It goes under the protection of its mother, probably for somewhat more than a year, till by the growth of the baleen it is enabled to procure its own food. It appears to attain its full growth at the age of twenty or twenty-five. The marks of age are an increase of the quantity of grey colour on the skin, and a change to a yellowish tint of the white parts; a 
decrease in the quantity of oil, and an increase in the hardness of the blubber. It is supposed to attain a great age.

The natural affection of this species is interesting. The cub being insensible to danger is easily harpooned, when the attachment of the mother is so manifested, as to bring it almost certainly within the reach of the whalers. Hence, though the cub is of little value, yet it is often struck as a snare for the mother. In this case she joins it at the surface whenever it has occasion to rise for respiration, encourages it to swim off, and seldom deserts it while life remains. She is then dangerous to approach, but affords frequent opportunities of attack. She loses all regard for her own safety in anxiety for the preservation of her young, dashes through the midst of her enemies, despises the danger that threatens her, and even voluntarily remains with her offspring after various attacks on herself. In 1811, says Mr. Scorseby, one of $\mathrm{my}$ harpooners struck a sucker, with the hope of leading to the capture of the mother. Presently she arose close by the "fast boat," and seizing the young one, dragged about six-hundred feet of line out of the boat with remarkable force and velocity. Again she rose to the surface, darted furiously to and fro, frequently stopt short or suddenly changed her direction, and gave every possible intimation of extremc agony. For a length of time she continued thus to act, though closely pursued by the boats; and inspired with courage and resolution by her 
concern for her young, seemed regardless of the danger which surrounded her. At length one of the boats approached so near that a harpoon was hove at her; it hit, but did not attach itself. A second harpoon was struck, but this also failed to penetrate; but a third was more effectual and held. Still she did not attempt to escape, but allowed other boats to approach; so that in a few minutes three more harpoons were fastened, and in the course of an hour afterwards she was killed. There is something, continues this interesting writer, extremely painful in the destruction of a whale, when thus evincing a degree of affectionate regard for its offspring, which would do honour to the superior intelligence of human beings; yet the object of the adventure, the value of the prize, the joy of the capture, cannot be sacrificed to feelings of compassion.

The mysticetus, though often found in great numbers together, can scarcely be said to be gregarious ; for they are found most generally solitary; or in pairs, excepting when they are drawn to the same spot by the attraction of an abundance of palatable food, or of a choice situation among the icebergs.

The habitat of this valuable species (as we shall presently see of others) is a point of the highest economic importance, and more especially now, when it has been chased from its older haunts into nearly the impenetrable and certainly the most hazardous recesses of the Polar Seas. In the Athenæum of 
the current year, January 1836, it is stated, "that the whole of the whales which frequent the Polar Seas pass annually to the southward, and may be equally well encountered in the Atlantic Ocean, in well known positions and seasons ; that they pass in bodies in the months of March and April, about midway between the coasts of Iceland and Newfoundland; and that a much nearer and less dan: gerous fishery might be established at that season than by the present voyage to the Arctic Seas." The great importance of the point at issue has induced us to give this statement from our much respected cotemporary; though we fear it is inaccurate, and might be adduced as an illustration of the prevailing ignorance concerning the whale tribes. If "the whole of the whales" go southward in March and April, how does it happen that, for hundreds of years, so many have been captured in the Polar Seas during the summer and autumnal months? Another scarcely less serious objection is the decided statement of Mr. Scorseby, the very highest authority on this subject, and which we believe has never been contradicted, that the true mysticetus has never been seen beyond the limits of the Arctic Regions. Besides, the green-water or feeding grounds of the whale, as well as the mollusca and other small animals on which they feed, are rare, or not at all seen, in lower latitudes. Mariners, it is true, often make such statements as the above; they have in this way reported, that great shoals of the largest whales frequent the northern shores of Lap- 
land; and this is so far true; but, on examination, it is found not to be the mysticetus, but the rorqual, which comes next under our review, and we are disposed to think, that " the bodies of whales" will be found to belong to this species, which, we shall presently see, is usually avoided as unworthy of capture.

A description of the more valuable products of the whale will follow in the succeeding sketch of the fishery; but we shall now say a few words of those portions of it which are used in the domestic economy of uncivilized nations.

Although, to the palate of the refined European, the flesh of this whale would be viewed with abhorrence as an article of food; yet by some of the inhabitants of the borders of the frozen seas, it is regarded as a choice article of subsistence. The Esquimaux eat the flesh and fat, and drink the oil with great greediness. Indeed, some tribes which are not familiar with spiritous liquor, carry along with them in their canoes, bladders filled with oil, which they use in the same way and with a similar relish as a toper does his dram. They also eat the skin of the whale raw, both adults and children ; even the infants suck it with apparent delight. Blubber, when pickled and boiled, is said to be very palatable ; the tail, when parboiled and then fried, is said to be not unsavoury, but even agreeable eating ; and the flesh of young whales is by no means indifferent food.

Besides forming a choice eatable, the inferior products of the whale are applied to other purposes by 
the inhabitants of the Arctic Regions. Some membranes of the abdomen are used for the upper articles of clothing, and the peritoneum, in particular, being thin and transparent, is used instead of glass in the windows of their huts; the bones are converted into harpoons and spears, for striking the seal or darting at sea-birds, and are also employed in the erection of their tents, and, with some tribes, in the formation of their boats; the sinews are divided into filaments, and used as thread with which they sew, with great nicety, the different articles of their dress.

\section{NORTHERN WHALE FISIERY.}

WE should feel the more regret, that our limited space will not permit us to present a detailed account of the commerce and adventures of the northern fishery, or that of mysticetus, if we could not refer our readers, with the utmost confidence on these heads, to the very elaborate work of $\mathrm{Mr}$. Scorseby, and also to a short but masterly account, brought down to the present day, in the last edition of the first volume of the much esteemed work of our contemporary, the Edinburgh Cabinet Library. Both of these, and especially the former, are mines of the most interesting and important information ; and we lament we cannot more freely bring their eontents under the notice of our readers. We find 
we must entirely omit even the short abridgement we had prepared, concerning the early and past history of the trade, as prosecuted by the Basques, the British, Dutch, and other nations, first on the coast of France and northern Europe; then with amazing energy and success at Spitzbergen; then in the Greenland seas ; and finally, in Davies' Straits and the northern shores of America. All we can now attempt is a few very brief statements regarding the present condition of the trade.

The following summary is given by Mr. Scorsehy as the average quantity of shipping fitted out in different ports for nine years, ending 1818; and the comparison of it with the number sent out in 1830 , taken from the Edinburgh Cabinet Library, will show the state of the trade at that date. The table likewise shows the share of the trade which is taken by England and Scotland; that it has very much been diminishing in the former country and soinewhat increasing in the latter.

\begin{tabular}{|c|c|c|c|}
\hline & & $\begin{array}{l}\text { Average of } \\
1810-18 .\end{array}$ & In 1830. \\
\hline England, Berwick & . & $17-9$ ths & .1 \\
\hline Grimsby & . & $14-9$ ths & 0 \\
\hline Hull & . & $534-9$ ths & 33 \\
\hline Liverpool & . & 1 8-9ths & 0 \\
\hline London . & . & $178-9$ ths & 2 \\
\hline Lynn & . & $14-9$ ths & 0 \\
\hline Newcastle & . & 47 -9ths & 8 \\
\hline Whitby . & . & 8 8-9ths & 2 \\
\hline & & 9] 5-9ths & 41 \\
\hline
\end{tabular}




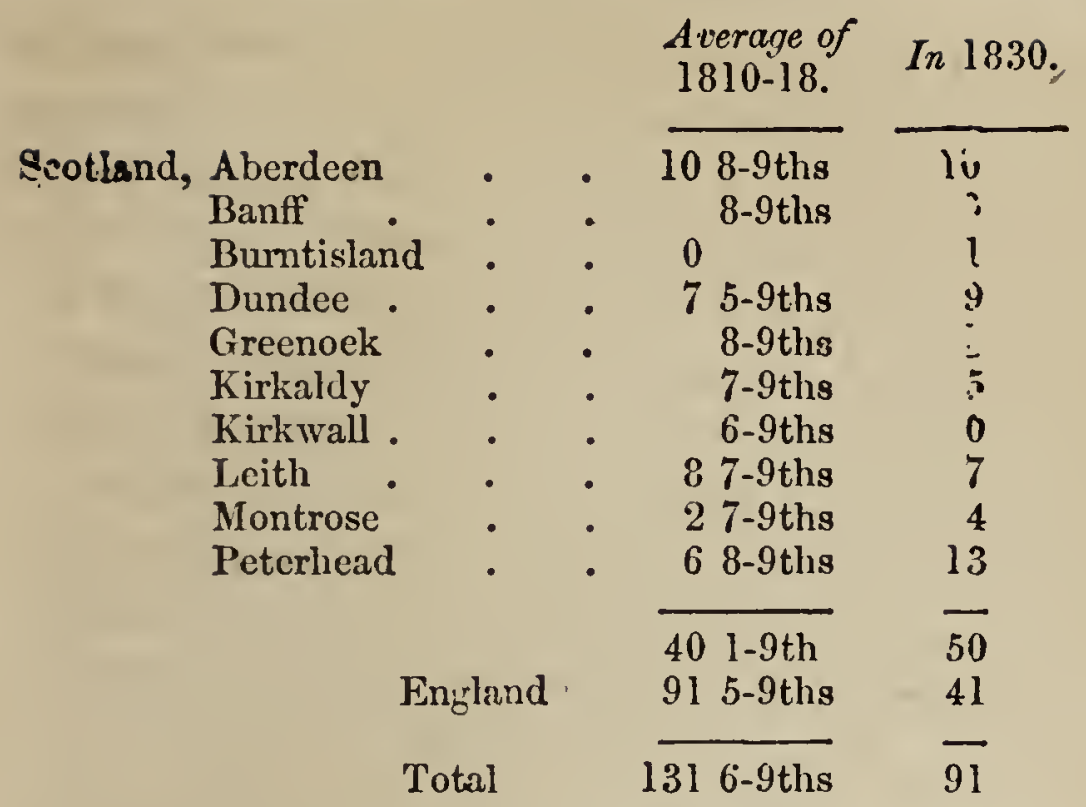

The decrease so marked in the above table, in comparing the year 1830 with the former average, has been steadily going on up to the present time. In 1831 there were eighty-eight ships engaged; in 1832, eighty-one ; in 1833, seventy-seven; and in 1834, seventy-six.

For many years the fishery in Davis Straits was considered less hazardous than that of Greenland, in as much as the sea was clearer of ice, and the climate, on account of the lower latitude, somewhat more mild. The alterations, however, which have occurred in this fishery are precisely similar to those which occurred at Spitzbergen. The fish have gradually retired more and more to the northward, and deserted those localities in which they used to be captured in abundance. Twenty years ago, they were caught in great numbers in the opening of Hudson's Straits, and at the borders of the western 
ire, near the coast of Labrador. In 1817, some of tne Davis Straits whalers proceeded through the straits into Baffin's Bay, to a much greater length than they were in the habit of adventuring, where, in the months of July and August, they found the sea clear of ice, and, in some parts, abounding with whales. In this state of the trade, the vessels destined for this quarter usually sailed in March or April. They proceeded first to the northern parts of Labrador, or to the mouth of Cumberland Straits, carrying on what was called the south-west fishery. After remaining there till about the beginning of May, they crossed to the east shore of the straits, and fished northwards along the coast. About the month of July they usually crossed Baffin's Bay to Lancaster Sound, which they sometimes entered, and occasionally even ascended Barrow's Straits In returning, they fished down the western coast. If the ships were not previously filled, they remained there till the end of September, and, in some instances, persevered till late in October.

But this south-west fishery, and that on the eastern shore, to a high latitude, have shared the fate of the others we have alluded to; and, in the language of the whalers, have been "fished out." Captains Ross and Parry, on returning from their :elebrated voyages, reported that, on the northwestern shores of Baffin's Bay, whales had been seen in vast numbers, and this information immediately kindled the spirit of enterpise, and, for a time, signal success was the result. Since that period, the ori 
ginal grounds in Labrador and Davis Straits have been regarded only as secondary objects; and every nerve has been strained to reach those interior shores in high latitudes, where whales are still found in abundance. If, however, the prize is here found, so also is a corresponding risk; and dangers far exceeding those previously met with, have been encountered, and disasters which had never been previously equalled, even in this hazardous trade.

The British capital embarked in this branch of commerce is calculated to be at the present time upwards of $\mathfrak{L}^{2} 1,000,000$ Sterling. The average return for the five years, ending with 1818, was $£ .567,000$ per annum; that of 1814 , a year peculiarly favourable, was above $\mathscr{\ell} .700,000$; that of .829 was upwards of $£ .376,000$; and that of 1830 , including the South Sea Fishing, was $£ .428,59$ i. When a ship returns clean, the loss is estimated about $\mathfrak{L} .2000$; and the total expenses of a voyage, which yields two hundred tons of oil, is about $£ .3500$.

The average price of oil for the last twenty years has been about $\mathfrak{E} .30$ per ton; and of whalebone \&.163. The greatest cargo ever known by Mr. Scorseby, to have been brought from the northern seas, was that by Captain Souter of the Resolution of Peterhead, in 1814. It consisted of forty-four whales, yielding two hundred and ninety-nine tons of oil, which sold at $£ .9568$; and adding the bounty and whalebone, the entire returns amounted $£ .11,000$. In 181\% both $\mathrm{Mr}$ Seorseby and his 
father, who spent a long and honourable life in the trade, secured cargoes which, though less in quantity, yet, from the price being higher, yielded a larger return. This latter gentleman, in the course of twenty-eight voyages, killed four hundred and ninety-eight whales, whence were extracted four thousand two hundred and forty-six tons of oil, the value of which, with the bone, exceeded $£ .150,000$ !

So keenly has the fishery keen prosecuted, and so great has been the number of whales taken, that it has been feared that, unless some restriction be imposed, the race will be extinguished, and the trade destroyed. Mr. Scorseby states, that, during the four years ending with the summer 1817, the number of whales killed by the British Greenland ships was three thousand five hundred and eight; and by those of the Davis Straits fishery, one thousand five hundred and twenty-two, in all five thousand and thirty. Upon the whole, it seems evident, that all those localities which were once crowded with the mysticetus, after the whalers have visited them for some time, become nearly deserted, and thus our fishers are time after time compelled to seek for new grounds for their exertions. And if the trade continue to be prosecuted with the same eagerness, there seems reason to fear that the mighty giant of the deep will finally share the fate of the most gigantic species of land animals, which would appear to have become extinct within the records of history, and that chiefly through the increasing slaughter and pursuit of man. 
PROCEEDINGS IN CAPTURING THE WHALE.

Bur it is now time to give a short sketch of the method practised in capturing the whale. The first object is to fit out a ship adapted for the trade; and constructed, therefore, in such a manner as to possess a peculiar degree of strength. Its exposed parts, accordingly, are secured with double or treble timbers; whilst it is fortified internally with ice beams and cross bars, and externally with iron plates, \&c. so disposed as to make the pressure on any one part to be supported by the whole fabric. A ship of about three hundred and fifty tons is deemed the most eligible, with a crew of about fifty men; six or seven very light and swift boats are required for the immediate pursuit; and one of the essential requisites is the crow's nest, or hurricane-house, invented by the elder Scorseby, a species of watch-tower, made of hoops and canvass, placed on the main-top mast for the use of the master or officer on watch, to shelter him from the blast, where he may be called to sit for hours at the temperature of zero, and whence he can discover all the movements of the surrounding ice or fish, and give directions accordingly.

The whaling vessels, in going north, usually touch at the Shetland Islands, to complete their water, provisions, \&c. and leaving the land generally about the beginning of April, they arrive within the Polar Seas before the end of that month. As soon as they 
reach the haunts of the whale, the crew must be every moment on the alert, keeping watch day and night. The boats, hanging over the ship's side, are ready to be launched in an instant; and when the state of the sea admits, one of them is usually manned and afloat. The officer in the crow's nest surveys the waters to a great distance, and the instant he perceives a whale he gives notice to the watch on deck, some of whom start instantly with the first boat, which is immediately followed by a second. Each of the boats has a harpooner and other subordinate officers; and is provided with an immense quantity of rope, carefully coiled and stowed in different parts of the boat, the different parts being spliced together, so as to form a continued line usually exceeding 4000 feet in length. To the end is attached the harpoon. The boat is

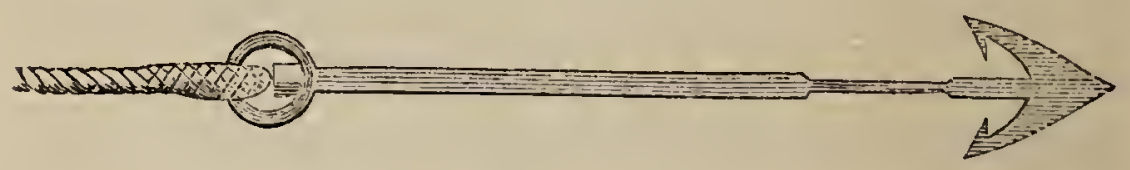

now rowed towards the whale with the greatest possible speed, in the deepest silence, cautiously avoiding giving alarm : sometimes a circuitous route is adopted in order to approach it from behind. Having reached within a few yards, the harpooner darts his instrument into the giant, who in the surprise and agony of the moment makes a convulsive effort to escape. This is the moment of danger, for the boat is exposed to the most violent blows of the whale's head or fins, and still more of its tail, which sometimes sweeps the air with such tre- 
mendous fury, that both boat and men are exposed to a common destruction.

The moment that the wounded whale disappears, a jack or flag is displayed in the boat; on the sight of which, those on watch in the ship give the alarm by stamping on the deck, accompanied by the continued shout of "a fall, a fall." At this signal the sleeping crew are aroused, jump from their beds, rush upon deck, with their clothes tied in a string in their hands, and crowd into the boats. With a temperature at zero, should a fall occur, the crew would appear on deck, covered only with their under garments, in the anticipation of dressing themselves, in part at least, as the boats are lowered down, though sometimes they are disappointed, and cannot get the process accomplished for a length of time afterwards.

The first and usual effort of the fast-fish is to escape from the boat by sinking under water, plunging with rapid flight under some neighbouring mountain of ice, or into the deep abyss. When fleeing from his pursuers, and then darting at the rate of eight or ten miles an hour, the greatest care must be used, that the line to which the harpoon is at tached may run off readily along with him. Should it be entangled for a moment, the whale would draw the boat beneath the waves. Sometimes, however, to retard its motion, it is usual for the harpooner to cast one or more turns of the line round a kind of post, called the bollard, which is fixed near the stern of the boat for the purpose; and such is the 
fiiction of the line, when running round the bollard, that it frequently envelopes the harpooner in smoke; and if the wood were not repeatedly wetted, it would set fire to the boat. Notwithstanding this manœuvre, the line is often run out in eight or ten minutes; its end is then attached to the lines of the next boat, and even those of a third are sometimes put into requisition. When the crew of a boat see there is a prospect of their own store being exhausted, they hold up one, two, three, or more oars, according to the urgency of the required aid; for if none arrives, there is only one resource left, which is to cut the line, and thus lose it, fish and all.

The period during which a wounded whale remains under water is various, but, at an average, may be stated at half an hour. It is sometimes an hour, and more rarely longer still; and it has been asserted, on good authority, that a case has occurred of a wounded whale being dragged up alive after having been an hour and a half continually under water; a singular fact, certainly, in the history of warm-blooded animals. When it remains long under water, it becomes asphyxiated or nearly drowned, and in all instances is greatly exhausted for want of fresh air, and by means of the enormous pressure, equal according to Mr. Scorseby to upwards of 200,000 tons, which exceeds the weight of sixty of the largest ships of the British Navy, when manned, provisioned, and fitted for a six months cruise.

When the fast fish is under water, the assisting boats take up those positions near to which they cal- 
culate he is most likely to rise, in order that one of them at least may be within a start, as it is called; that is, within two hundred yards of his place of re-appearing, at which distance they can easily reach him before he is prepared to descend again. On its rising, they hasten towards the spot, and as they reach it, each harpooner plunges his weapon into its back, to the amount of three, four, or more, according to the size of the whale, and the nature of the situation. Most frequently, however, the animal descends a few minutes after receiving the second harpoon, and obliges the other boats to await its return to the surface, before any further attack can be made. After this it is actively plied with long and sharp lances, which are thrust into its body, and aimed deep at its vitals. At length, when exhausted with numerous wounds and the loss of blood, which flows in copious streams, it indicates the approach of dissolution by discharging blood from the spiracles, along with the air and mucus, and finally, jets of blood alone appear. The sea to a great extent is dyed with the blood,--and the ice, boats, and $m \in n$, are sometimes drenched with it Its track is likewise marked by a broad pellicle of oil, which exudes from its wounds, and appears on the surface of the sea. The final capture is sometimes preceded by a convulsive and awful struggle : and in dying, it turns over on its side or back; which joyful circumstance is announced by three loud huzzas, and the striking of the flags. No time is lost, ere the tail is pierced and fastened with ropes 
to the boats, which drag the carcase to the ship amidst shouts of triumph.

What is the time requisite for capturing a whale? In answer to this question, Mr. Scorseby states, that he has seen a whale despatched in fifteen minutes, and others alive, after severe treatment, at the end of fifty hours. Much depenils on the conduct of the animal itself,-much on the activity of the whaler,-and much, also, on the nature of the situation and weather. $\mathrm{He}$ states, that the average time does not exceed an hour.

As bearing on this point, and exhibiting the surprising vigour of the mysticetus, we shall here introduce an anecdote related by Mr Scorseby. In 1817 the Royal Bounty of Leith fell in with whales at a distance from land and ice, there being at the same time a brisk breeze and clear weather. The boats were manned and sent in pursuit. After a chase of five hours, one of the boats struck the whale about four A. M. The captain followed in the ship, and though for a time he lost sight of them, yet he again descried a boat at eight A. M., with a signal displayed of being fast. Some time after, he observed another boat approach the fish, a second harpoon struck, and a new signal displayed. As, however, the fish drew the two boats away with considerable speed, it was mid-day before any assistance could reach them. Two more harpoons were then struck; but such was the vigour of the whale, that, though it constantly dragged through the water from four to six boats, together with a length of nearly a thousand 
feet of line to each, yet it pursued its course nearly as fast as a boat could row ; and such was the terror. it manifested on the approach of its enemies, that whenever a boat passed beyond its tail, it invariably dived. All endeavours, therefore, to lance it were in vain. The crews of the loose boats, being unable to keep pace with the fish, moored themselves to the fast boats, and for some hours afterwards all hands were constrained to sit idle, waiting for some relaxation in the speed of the whale. Its general course had been to windward, but its changing enabled the ship, which had previously been at a great distance, to join the boats at eight, P. M. The vessel took one of the fast lines on board, with the view of retarding its progress. The sails were lowered and furled, but after supporting the ship for a few minutes, head to wind, the harpoon lost its hold. The whale immediately set off to wind ward with increased speed, and, for three hours, the ship could not again approach it. Another line was then taken on board, but immediately broke. A fifth harpoon had previously been struck, but its line was speedily cut. Various schemes for arresting the speed of the fish were then resorted to, which occupied close attention for nearly twelve hours; but its velocity was still such, that the master, who had himself proceeded to the attack, was unable to approach sufficiently near to strike a harpoon. After a long chase, however, he succeeded in getting hold of one of the fast lines, and attached another line to it. The fish then fortunately turned 
towards the ship. $\Lambda$ t four P. M., thirty-six hours after ii was struck, the ship again joined the boats, when, by a successful manœurre, they secured two of the fast lines on board. The wind was blowing a moderately brisk breeze, and the sails were lowered; but notwithstanding the resistance a ship thus situated must necessarily have offered, she was towed by the fish directly to windward, with a velocity of two knots, during an hour and a half; and then, though the whale must have been greatly exhausted, it beat the waters with its fins and tail in so tremendous a way, that the sea around was in a continual foam, and the most hardy of the sailors scarcely dared to approach it. At length, about eight P. M., after forty hours of almost incessant exertion, this formidable enemy was slain.

After a whale has been caught and secured at the sides of the ship, the next operation is that of flonsing or securing the blubber and whalebone. This disagreeble process can, with the whole strength of the crew, be effected in about four hours. Each seaman receives a dram, and some of the more important personages receive two. The huge carcass is somewhat extended by strong tackles placed at the snout and tail : a band of blubber two or three feet in width, encircling the fish's body at what is the neck in other animals, is called the kent, because by means of it the fish is turned over or kented. To this band is fixed the lower extremity of a combination of powerful blocks, called the kent-purchase, by means of which, the whole circumference of the 
animal is, section by section, brought to the surface. The harpooners then, having spikes on their feet to prevent their falling from the carcass, begin with a kind of spade, and with huge knives, to make

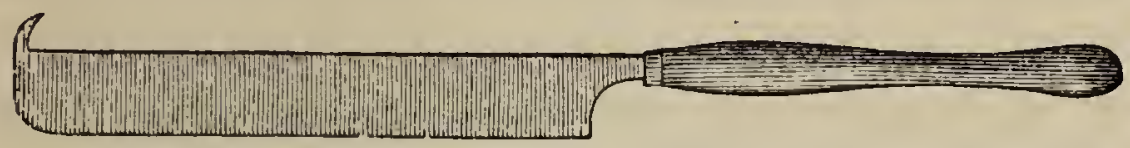

long parallel cuts from end to end, which are divided by cross-cuts into pieces of about half a ton. These are conveyed on deck, and, being reduced into smaller portions, are stowed in the hold. Finally. being by other operations still further divided, it is put into casks, which is called making-off, and packed down completely by a suitable instrument.

When this flensing is proceeding, and when it reaches the lips, which contain much oil, the baleen is exposed. This is detached by means of bone handspikes, bone knives, and bone spades. The whole whalebone is hoisted on deck in one mass, where it is split by bone-wedges into junks, containing five or ten blades each, and stowed away. When the whole whalebone and blubber are thus procured, the two jaw-bones, from the quantity of oil which they contain, are usually hoisted on deck, and then only the kreng remains, - the huge carcass of flesh and bone, which is abandoned either to sink, or to be devoured by the birds and sharks, and bears, which duly attend on such occasions for their share of the prey.

It will be readily believed that none of the pro- 
ceedings which we have now been considering are free from numerous perils. In a high sea the flensing itself is often difficult or impossible; and those upon the body of the fish are exposed to considerable risk. Sometimes they fall into the whale's mouth, at the imminent hazard of being drowned. In the case of a heavy swell, they are drenched, and often washed over by the surge. Occasionally they have their ropes broken, and are wounded by each others' knives. Mr. Scorseby mentions an instance of a man, who, after the flensing was completed, happened to have his foot attached by a hook to the carcass, when it was inadvertently let go. $\mathrm{He}$ caught hold of the gunwale of the boat; but the whole immense mass was now suspended by his body, occasioning the most excruciating torture, and even exposing him to the risk of being torn asunder ; when his companions contrived afresh to hook the carcass with a grapnel, and brought it back to the surface.

In the account which we have presented of the capture, all circumstances are supposed to be favourable; but often it is the very reverse. A storm may arise, and a fog often envelopes the whole operations; immense islands or floes, i.e. masses of field-ice, may be impelled upon them by the tempest, and with such velocity as to overwhelm them in a moment, or a frost may make them fast in its hard and icy grasp. It is such incidents as these which make this employment one of the most trying and hazardous that can be pursued: while they 
occasionally lead to the most extraordinary adventures; as examples of which, we subjoin a very few narratives of facts.

The whale itself, though for the most part undesignedly, is the cause of the greatest number of accidents which occur. Injuries are often sustained by entanglement with the lines. A sailor belonging to the John of Greenock, in 1818, happening to slip into a coil of running rope, had his foot entirely cut off, and was obliged to have the lower part of the leg amputated. A harpooner belonging to the Hamilton, when engaged in lancing a whale, incautiously cast a little line under his foot: The pain of the lance induced the whale to dart suddenly downwards; his line began to run out from under his feet, and, in an instant, caught him by a turn round the body: He had just time to call out, "Clear away the line-Oh dear!" when he was almost cut asunder, dragged overboard, and never seen afterwards. The following graphic and tragical scene is taken from Mr. Scorseby's Journal. Two boats belonging to the Baffin of Liverpool having been many hours absent from the ship, and occasioned much anxiety, were at last descried pulling towards the ship. On their approach, we r were a little surprised by some unusual appearances, particularly their want of their proper complement of oars, and the solemn countenances of the rowers. As soon as they came within hail, I inquired what had happened. "A bad misfortune, indeed," was the answer, "we have lost 


\section{0}

Carr!" - the principal officer of the boat. The particulars were as follow: The two boats which had been so long absent had in the outset separated from their companions, and allured by the chase of a whale, they proceeded till they were far out of sight of the ship. The whale led them amidst a great shoal; one rose so near the boat of which Carr was harpooner, that he ventured to pull towards it, though it was meeting him, and offered but an indifferent prospect of success : he, however, succeeded in harpooning it. The boat and fish passing each other with great rapidity after the stroke, the line was jerked out of its place, and, instead of " running" over the stern, was thrown over the gunwale; its pressure in this unfarourable position so careened the boat, that the side sank under water and began to fill. In this emergency the harpooner, who was a very fine active fellow, seized the line, and attempted to relieve the boat, by restoring it to its place; but a turn of the line flew over his arm, in an instant dragged him overboard, and plunged aim under water to rise no more! So sudden was the accident, that only one man, who had his eye upon him at the moment, was aware of what had happened; so that when the boat righted, which it immediately did, though half full of water, they all at once, on looking round at an exclamation from the man who had seen him launched overboard, inquired "What had got Carr?" It is scarcely possible to imagine a death more awfully sudden ir unexpected. The accident was, indeed, so in- 
stantaneous, that he had no time for the least exclamation; and the person who witnessed his extraordinary removal observed, that it was so exceedingly quick, that although his eye was upon him at the instant, he could scarcely distinguish the object as it disappeared.

A large whale became the subject of a general chase, says Scorseby, on the 23d of June. Being myself in the first boat which approached the fish, I struck my harpoon at arm's-length, by which we fortunately evaded a blow which appeared to be aimed at the boat. Another boat then advanced, and another harpoon was struck, but not with the same result; for the stroke was immediately returned by a tremendous blow from the fish's tail. The boat was sunk by the shock, and at the same time whirled round with such velocity, that the boat-steerer was precipitated into the water on the side next to the fish, and carried down to a considerable depth by its tail. After a minute or so, he arose to the surface, and was taken up along with his companions into another boat.

Some boats of the Aimwell, on the 26th May, being in pursuit of whales, harpooned one. When struck, this individual only dived for a moment, and then rose again beneath the boat, struck it in the most vicious manner with its tail and fins, stove, upset it, and then disappeared. The crew, seven in number, got on the bottom of the boat; but the unequal action of the lines, which remained entangled with the boat, rolled it over occasionally, and thus 
plunged the crew repeatedly into the water. Four of them, after each immersion, recovered themselves and cling to the boat; but the other three were drowned before assistance could arrive. The four men being rescued, the attack on the whale was continued, and two more harpoons were struck. But the whale, irritated instead of being enervated by its wounds, recommenced its furious attack. The sea was in foams; its tail and fins were in awful play; and, in a short time, harpoon after harpoon drew out, and the fish escaped.

We produce the following account, not because we believe it refers to the Greenland Whale (we think it did not), but because the adventure elicited the statement, that the same feat is often exhibited by it; as is true, we believe, of all the larger genera. Dr. Foster, indeed, in Cook's Voyages, very clearly tells us he saw it in the southem rorqual, as will be found in our account of that animal. The following anecdote is extracted from the interesting fragments of Captain B. Hall, and occurred when that gentleman was midshipman on board his majesty's ship Leander, which was lying at the time in the roads of Bermuda, the locality already signalized on page 73. As on the former occasion, a great whale, between fifty and sixty feet in length, which was embayed within the coral rocks, and swimming about the vessel, soon attracted the attention of the crew. All hands crowded into the rigging to see it floundering about, till at length some one proposed to pay him a visit in one of the ship's boats, "and 


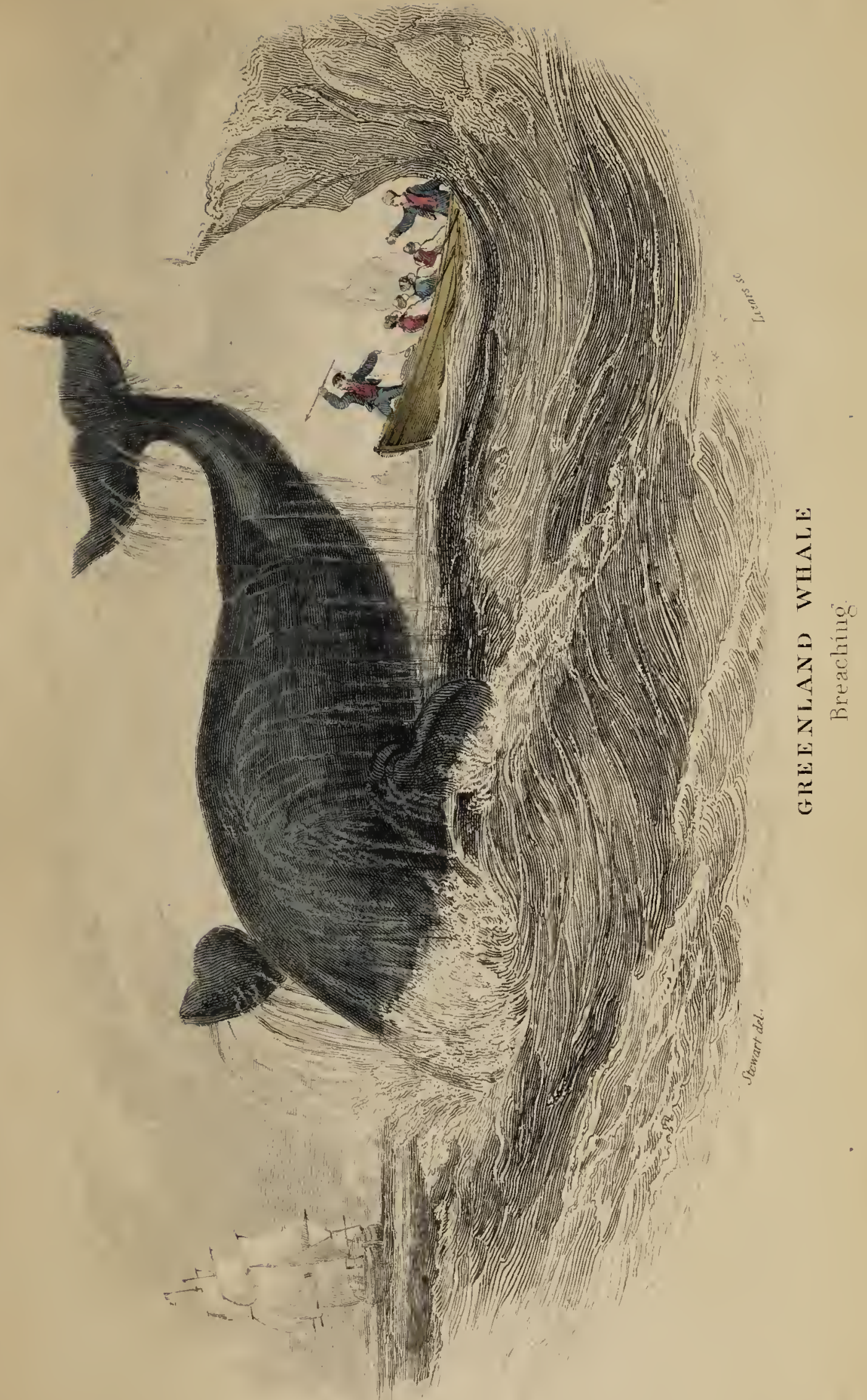



array we (viz. some of the midshipmen) went," says the Captain, "in our wild-goose whale-chase. All eyes were now upon us, and, after a pause, it was agreed unanimously that we should run right on board of him and take our chance. So we rowed forward, but the whale slipped down, clean out of sight, leaving only a monstrous pool, in the vortex of which we continued whirling about for some time. As we were lying on our oars, and somewhat puzzled what to do next, we beheld one of the most extraordinary sights in the world; at least, I do not remember to have seen many things which have surprised me so much, or made a deeper impression on my memory. Our friend the whale, probably finding the water disagreeably shallow, or perhaps provoked at not being able to disentangle himself from the sharp coral reefs, or from some other reason of pleasure or pain, suddenly made a leap out of the water. So complete was this enormous leap, that for an instant we saw him fairly up in the air, in a horizontal position, at a distance of at least twenty perpendicular feet over our heads! While in his progress upwards, there was in his spring some touch of the vivacity with which a trout or a salmon shoots out of the water ; but he fell back again on the sea, like a huge log thrown on its broadside, and with such a thundering crash, as made all hands stare in astonishment, and the boldest held his breath for a time. Total demolition, indeed, must have been the inevitable fate of our party, had the whale taken his leap one minute sooner, for he would. 
then have fallen plump on the boat. The waves caused by the explosion spread over half the anchorage; nor, if the Leander herself had blown up, could the effects have extended much farther."

After preparing the foregoing narrative for the press, Captain Hall, in order to fortify himself by the lighest authority in these matters, wrote to Mr. Scorseby, detailing the fact, and inquiring if he had ever witnessed any thing of the sort. This elicited the following reply, "I have much pleasure in being able to speak to the point in attestation of the not infrequency of the exhibition of the high leaps which you witnessed, however ignorance might charge it as ' very like a whale.' Whilst engaged in the northern whale fishery, I witnessed many similar exploits of whales of forty or fifty feet in length, forgetting their usual gravity, and making these odd exhibitions of their whole form from head to tail. Certainly, I have several times seen whales leap so high out of water, as to be completely in air, which, reckoning from the surface of the back, could scarcely be less than twenty feet, and passibly might be more. I have at different times pursued these frolicksome fish, but they have always escaped."

"In one of my earliest voyages," remarks Mr. Scorseby, on another occasion, "I observed a circumstance which excited my highest astonishment. One of the harpooners struck a whale, it dived, and all the assisting boats had collected round the fast boat before it arose to the surface. The first boat that 


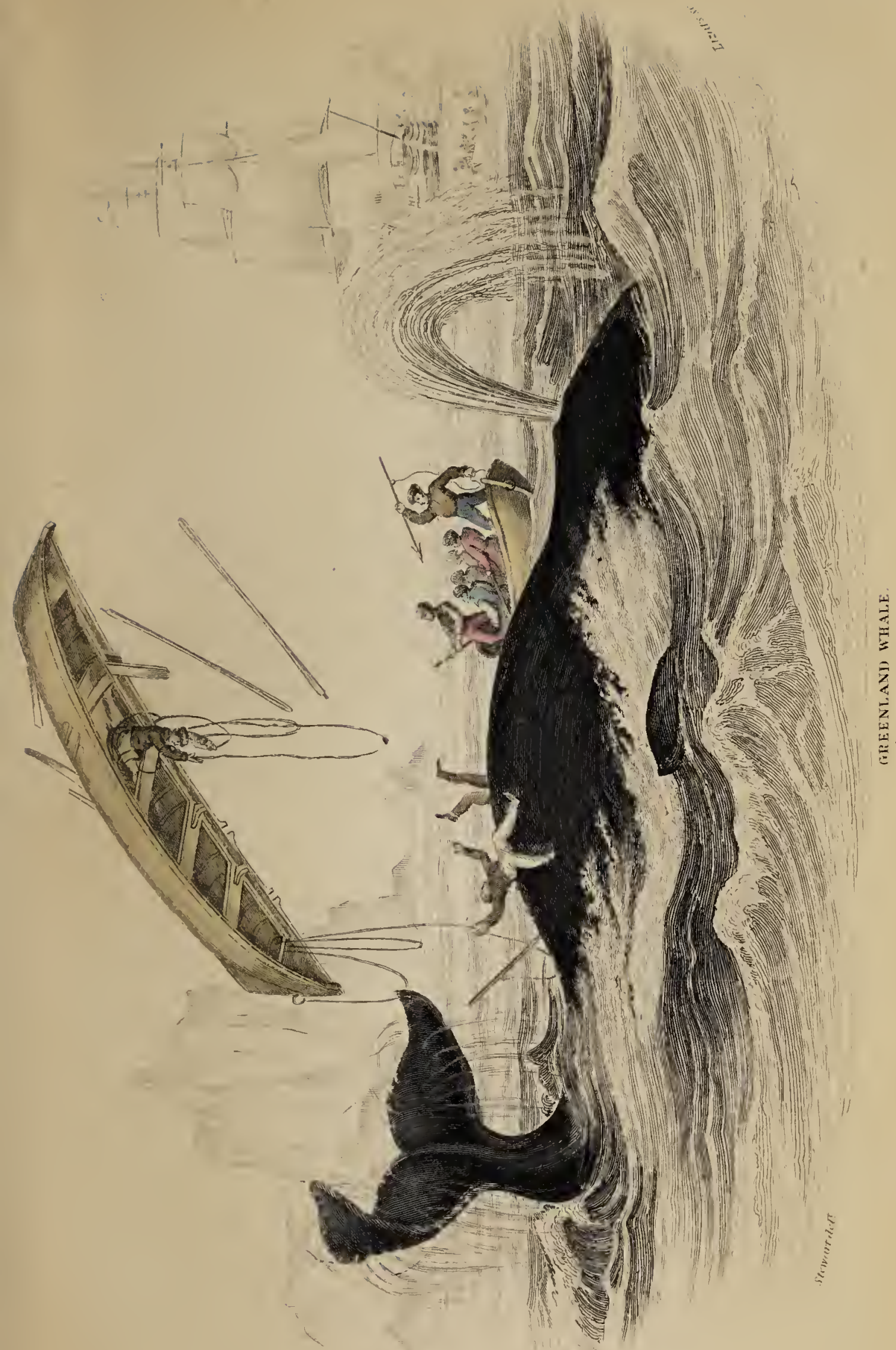



approached it advanced incautiously. It rose with unexpected violence beneath the boat, and projected it and all the crew to the height of some yards into the air. It fell on its side, and cast all the men into the water; one was somewhat injured, but the rest escaped."

Captain Lyons of the Raith of Leith, in 1802, despatched four boats after a large whale on the coast of Labrador, and two of them succeeded in approaching so closely together, that two harpoons were struck at the same moment. The fish descended a few fathoms in the direction of another of the boats, which was on the advance,- - rose beneath it, struck it with its head, and threw the boat, men, and apparatus about fifteen feet into the air. It was inverted by the stroke, and fell into the water with its keel upwards. All the people were picked up alive by the fourth boat, except one man, who, having got entangled in the boat, fell beneath it and was drowned.

The following anecdote illustrates the dangers arising from the ice. On the commencement of a heavy gale of wind, May 11, 1813, fourteen men put off in a boat from the Volunteer of Whitby, with the view of fixing an anchor on a large piece of ice, to which it was intended to moor the ship. The ship approached on a signal being made, and a rope was fixed to the anchor; but the ice shivering with the violence of the strain when the ship fell astern, the anchor flew out, and the ship went adrift: She attempted again to approach the ice, 
but in vain, owing to the violence of the gale, and scudded to leeward; thus leaving fourteen of her crew to a fate the most dreadful, the fulfilment of which appeared almost inevitable. The temperature was at $15^{\circ}$ Fahrenheit, when these poor fellows were left upon a detached piece of ice of no considerable magnitude, without food, without shelter from the inclement storm, and depirved of every means of refuge, except a single boat, which, on account of the number of men and the violence of the storm, was incapable of conveying them to their ship. Death stared them in the face whichever way they turned, and a division of opinion ensued. Some were wishful to remain by the ice; but it could afford them no shelter and would probably be soon broken to pieces by the increasing swell; others were anxious to attempt to join their ship whilst she was yet in sight; but the force of the wind, the violence of the sea, and the smallness of the boat, were objections which would have appeared insurmountable to any but men in a state of despair. Judging that, by remaining on the ice, death was but retarded for a few hours, as the extreme cold must eventually benumb their faculties, they determined to make the attempt of rowing to the ship. Poor souls! What must have been their sensations at this moment? They made the daring experiment, when a few minutes trial convinced them that the attempt was impracticable. They then, with longing eyes, turned their efforts towards recovering the ice which they had left; but 
their utmost exertions proved unavailing. Every one of them now considered his doom as sealed: how great then must have been their delight, and how overpowering their sensations, when, at this critical juncture, a ship appeared in sight. She was advancing directly towards them; their voices were extended, and their flag displayed; though not heard, they were seen; and their mutual courses being so directed as to form the speediest union, a few minutes saw them in safety on the deck of the Lively.

But we must draw these interesting anecdotes to a close, and we shall do so by epitomizing a narrative from the Journal of Mr. Gibson, surgeon of the Trafalgar, which especially illustrates the great and numerous dangers which arise from icebergs, or more properly ice-islands. "August 12, 1822, four, P. M. Blowing a fresh gale with rain; the floe to which the ship was made fast set down under the lee-ice, so as to render our situation perilous. Towards midnight we became unexpectedly entangled among heary pieces of ice and floes, where the ship received some severe blows on her beams. Finding it impossible to get out, we lay to, and in half an hour the ship was close beset. Though I retired to bed when the ship was enclosed, I expected every minute to be called to quit the ship. About three A. M., a large piece of ice pressing on the ship opposite my bed-cabin, broke two or three of the timbers with a dismal noise. Thinking all was over, I sprang out of bed. On going 
upon deck, I found to my great consternation that the ship was under an enormous pressure from numerous huge masses of ice surrounding her on all sides, without an opening of water sufficient for a hoat within two miles: and no other ship was in sight, though the weather was clear. Most of the crew were providing for shipwreck, and many of the people were supplicating Divine Mercy for deliverance. At nine A. M. most gave up all hopes of saving the ship, and mine were very faint of saving ourselves. Four days' allowance were cooked with all speed; other provisions were taken upon deck, and every thing of importance placed in readiness to be thrown on the ice. At eleven A. M., however, our drooping spirits were greatly revived by observing a slight relaxation of pressure; but in half an hour we were again thrown into despair by the return of the pressure. At noon, a man on the mast-head saw a ship (the Baffin), on which we instantly made signals of distress. At this time a dead silence prevailed throughout the ship; the crew looking on one another in awful suspense: At one time the pressure was so strong that the pannels of the captain's state-room were forced out of their framing. About half an hour after this the ship was suddenly thrown upon her larboard side, on which all hands sprang upon deck. I shall never forget the confusion of the poor men, nor their wild looks when they gained the deck; for half of them were below at the time of the shock, and from the smallness of the hatch, only one could get up at 
a time. Some leaped upon the ship's side and were going upon the ice, when the captain cried out to them to behave like men and stick to the ship as long as she remained above water! We all stood on that part of the ship nearest the ice, with our bags of clothing on our shoulders. For fifteen minutes we had patiently waited our doom; when, by the interposition of Divine Providence, the wind changed, - the ice began to set off from the ship, and in fifteen minutes more she recovered her upright position. The water now rapidly spread among the surrounding ice, and, finally, the vessel was warped out and floated uninjured on the waves."

We add one other more recent and still more awful occurrence. It is pretty generally known that the year 1830 proved peculiarly disastrous to the whale fishery, in as much as nineteen British vessels were totally wrecked during the season, and twelve more materially damaged, at a computed loss of upwards of $\mathfrak{L} .142,000$. Most of this injury was received in Baffin's Bay, in the high latitude of Melville $B a y$, and was principally caused by the ice being drifted in immense quantities among the vessels, and so agitated during a succession of storms as finally to overwhelm them. We have room only for a short extract, taken from the highly interesting account given in the Edinburgh Cabinet Library (i. 448). "A small squadron, consisting of six very fine vessels, in attempting a passage to the west side, encountered a fresh gale, which drove in upon them masses of ice, by which they were soon 
beset. They ranged themselves under the shelter of a large floe, having water barely sufficient to float them. Here they formed a line, one behind another, standing close, stern to stern, and being at the same time so pressed against the ice, that in some places a boat-hook could with difficulty be inserted in the interval. In the evening of the 24th the sky darkened, - the gale increased-the floes began to overlap each other, and closed upon the ships in an alarming manner. The sailors then attempted to saw out a sort of dock, where they hoped to be relieved from this severe pressure ; but soon a huge floe was driven upon them, with a violence completely irresistible. The Eliza Swan of Montrose received the first shock, and was saved only by the ice raising her up. It next struck the St. Andrew of Aberdeen midship, breaking about twenty of her timbers, and staving a number of casks ; but it then fortunately moved along her side, and went off by the stern. Now, however, pursuing its career, it reached successively the Baffin of Leith; the Achilles of Dundee; the Ville de Dieppe, a French ship ; and the Rattler of Leith, and dashed against them with such tremendous fury, that these four noble vessels, which had braved for years the tempests of the Polar deep, were, in a quarter of an hour, shattered into fragments. The scene was awful,--the grinding noise of the ice tearing upon their sides,- - the masts breaking off and falling in every direction-were added to the cries of two hundred sailors leaping upon the frozen surface, with only such portions of their 
clothes as they could snatch in a single instant. The Rattler is said to have become the most complete wreck almost ever known. She was literally turned inside-out; and her stem and stern carried to the distance of a gunshot from each other;-and the Achilles had her sides nearly pressed together, her stern thrust out, her decks and beams broken into innumerable pieces. It has been well observed, under such circumstances as these, that a ship, even the strongest which human art can construct, becomes like an egg-shell, when opposed to the full force of so terrific an agent."

The only other species of this genus, which we shall bring under review, is the Baloena Australis, or 
WHALE OF THE SOUTHERN SEAS.

Balæna Australis, Desmoulins._B. Antarctica, Lesson.

Thrs species, nearly up to the present period, has been confounded with the former, and probably we might still have been ignorant of the difference, had not $M$. de Lalande, during his residence at the Cape of Good Hope, succeeded by his energy and zeal in preparing one of these animals and transmitting its skeleton to France, where, on its arrival at the Jardin des Plantes, Cuvier soon detected its specific differences.

The whale of the southern seas is decidedly smaller than that of the north, measuring usually thirty-five or forty-five feet, but frequently extending to fifty feet. Its baleen, owing to the great curve of the upper jaw, appears to be relatively longer ; usually reaching to about nine feet in a fish of forty feet. The head is very frequently covered with barnacles, having layer above layer, so that its aspect is very different from the northern Mysticetus, being often of a white colour. The pectoral fins appear to be longer and more pointed, whilst the lobes of the tail are less marked than in the former species. When cleared of its covering of shells, it is of a uniform black colour.

There seems to be good ground for supposing 
that this is the whale which has been so extensively fished in the southern seas as the Mysticetus; and that it was on its account that so many establishments were set agoing in many parts of the Brazils, which, after being carried on for a time with great success, are now nearly abandoned; D'Orbigny states, that in 1834 the whales had nearly disappeared from this coast. They seem, however, to frequent many other places in abundance: they are found in the Bays off Terra del Fuego, and on the western coast of South America, and they are also found around New Holland as well as the coast of Africa. It is in the month of June they visit the Cape of Good Hope, principally the females, and for the purpose of bringing forth their young.

The method of fishing this animal is very different from that we have been considering at such length, and is, upon the whole, a much more easy operation. According to Lesson, from whom we principally derive our account, this species is usually found at no great distance off the coast, and where the water is beginning to get shallow. When struck, it often dives to the bottom, the depth being seldom more than two hundred fathoms; it then returns to the surface after an interval of a few minutes; and occasionally dives a second, third, or even a fourth time. Sometimes it takes a horizontal course, and " runs" along shore twenty or thirty miles in a direct line. When observed by others of the species, they usually take the alarm, and running off, are followed by the fast whale as long as it is able. 
The harpconer generally endeavours to strike two harpoons at the first attack, both of which are attached to the same line, by which he has a double hold of the fish. The harpoons are usually thrown at the whale when at the distance of six or eight yards, and the lances, which are kept in fine order, are sometimes used in the same way. Two boats are considered sufficient to kill an individual of this species, so that, when it can be accomplished, two are struck at the same time. Whenever the animal re-appears on the surface, the fast boat is hoisted up towards it by means of the line ; thus affording an opportunity to the harpooner to lance it, and enahling him often to capture his prize without the assistance of any other boat.

When it is flensed, which is done in the same manner as in the sperm whale, to be afterwards described, the upper jaw, with all the baleen attached, is usually hoisted on board. The whalebone is then divided into junks, and these, at the first leisure, are subdivided into single blades and stowed away after the gum is removed. If a storm happen to arise before the fish is flensed, a hawser is fastened to it, and the ship rides by it; at the conclusion of the gale it is brought along side and "cut in." If, however, an interval of more than two or three days occur before the flensing is commenced, the whale swells, the blubber becomes impregnated with blood, and must be abandoned as useless. 



\section{Second Genus.-RORQUALUS.*}

Characters. No teeth; baleen short; has a dorsal fin; and folds under chin and throat.

RORQUALIS BOREALIS, CUv.; LRSs.

\section{PLATE V.}

Great Northern Rorqual._Razor-back and Finner, of whalers.

Oun readers will please to observe that we have, after the example of Cuvier, adopted the name Rorqualus as a generic term, and include in this genus some species, or at least supposed species, with which some of them may be familiar. After the Mysticetus there followed, according to the prevailing arrangements, first a genus whose principal distinction was its being supplied with a dorsal fin; and then another, which, in addition to this third fin, had certain folds extending from the under lip along the chest and abdomen. Under the former of these was included the Gibbar of Lacépède, which was the same as the Physalis of Linnæus, and the Razor-back of whalers; and under the latter, among others, there was the Jubartes of Lacépède, the Boops of Linnæus, and also the Musculus of Linfoldx.

* Rorqualus, in the Norwegian tongue, means whale with 
næus, the Broad-nosed whale of Scorseby, and thr Rorqual of Bonnaterre and Lacépède.

But it admits not of a doubt, that, up to the present time, there exists not the vestige of evidener in the records of Cetology, of the existence ot the gibbar or physalis. True it is that systematic writers give very circumstantial accounts of it, but few, if any, from their own observations; and Mr. Scorseby, in his interesting notices respecting it, says it is "supplied with distinct rugae or sulci;" whence it clearly follows it is a true Rorqual. With regard to the specific differences assigned to the others, we shall only state, in a word, that as great difficulties and objections stand in the way of their being admitted as established varieties. We do not expressly deny that some of them may be real species, and may differ from each other; but we assert, after the example of Cuvier, that these still remain to be pointed out and demonstrated; and in the meanwhile it will be understood, that the remarks which follow respecting this genus, apply to the facts really ascertained concerning all the forenamed alleged species.

The northern Rorqual is the largest of the whale tribe, the mightiest giant of them all, and probably the most powerful and bulky of created beings. Its head is to the entire length, as one to four. It differs from the Mysticetus, in its body being longer and more slender ; in its form being less cylindrical; in having a dorsal fin; in its skin or blubber being much thinner, usually not exceeding six inches; in its speed being greater, its action quicker and 
more restless, and its conduct bolder ; in its blowing being more violent, and its baleen being much shorter and less valuable.

The cause of this last important difference is very plain; and may be best illustrated by a glance at the accompanying sketches, in which there is a side view, fig. $n$, Plate I. of the head of the Mysticetus, and fig. $o$ of the Rorqual. It will at once be seen that the upper jaw of the former is relatively larger and much more curved; the intervening space in both is filled with baleen, which accordingly must be long in the Mysticetus and short in the Rorqual; the longest laminæ seldom measuring four feet.

In Mr. F. Knox's account of the great Rorqual, which will subsequently be more particularly alluded to, we read that three hundred and fourteen plates were counted on each side; and on further examination it was found that these extended mesially (towards the middle line) only about fifteen inches, and were then succeeded by a vast number of smaller plates, which gradually became less and less, till finally they were converted into bristles ; so that, correctly speaking, there were probably not fewer than four or five thousand distinct plates of whalebone. The baleen, when recent, was highly elastic and soft, the fringed edge being as pliable as the hair of the human head, and thus forming a sieve of the most perfect kind. From the same source we also learn, that the posterior arch of the palate was so large that it could admit a man, 
being thus a great vestibule to the windpipe and gullet; which last was quite closed when first seen, and appeared as if it would admit with difficulty a man's closed fist.

Upon the whole, however, the baleen is coarser than in the Mysticetus, and the swallow is comparatively larger ; and in both points this is a positive advantage to the Rorqual, and only in keeping with its requirements, because the proper food of this genus is not only the small medusa, shrimps, \&c. which have been depicted on Plate III. as the food of the Mysticetus, but consists of medusa of a larger size, and of fish, such as herring, haddock, cod, salmon, \&c. ; and there seems no ground to question the opinion, that these whales often follow in the tract of these fish, and devour them in quantities which it would not be easy accurately to conceive. Thus M. Desmoulins states, that six hundred great cod and immense quantities of pilchards have been found in the stomach of a single whale of this genus.-Dict. Class.

The plicæ or folds, whence the genus derives its name, constitute a singular structure, the precise use of which has not hitherto been very clearly ascertained. John Hunter described it with his usual accuracy in one of the whales which he examined, and observed that it must increase the dilatability and elasticity of the integuments of the part, but confessed he could not perceive wherefore this should be, or how it was made useful. Lacépède also particularly describes it, and it has since been 
generally mentioned by subsequent authors. It consists of a number of longitudinal folds, nearly parallel, which commence under the lower lip, occupying the space between the two branches of the lower jaw, passes down the throat, covering the whole extent of the chest, from one pectoral fin to the other, and somewhat further, and terminates far down the abdomen. It often happens that two of these folds are distinct at their extremities, but form one only in the middle portion. They are of different width according to the size of the individual, varying from half an inch to two or three inches. The external portion of these folds is of the colour of the neighbouring skin, whilst the parts which are usually folded in are of a more delicate appearance, generally of a pale white, and in some species of a beautiful red colour, corresponding to that of the lip. M. Lacépède congratulates himself on having made a great discovery respecting the use of this structure, which suggested itself whilst examining certain drawings which were transmitted to him by Sir Joseph Banks. He supposes it to be a great bladder placed between the branches of the lower jaw, extending far underneath the body ; and conceives the whale can fill this pouch with atmospheric air from the spiracles, so as to give it a circumference of ten or twelve feet. In short, he considers it as a kind of swimming bladder, by which the animal raises itself at will towards the surface; and by it he accounts for the extraordinary agility and nower it displays, in the pursuit and eapture of its 
prey. One of his plates, his eighth, is supplied for the express purpose of illustrating its appearance and size. This account seems generally to have been received, and is propagated in our latest English and foreign treatises; and yet we are persuaded that it is wholly erroneous. No description has been given of the canal which conveys the air into the sack; anatomical observation contradicts the assertion, and the bladder exhibited in the plates appears to be nothing more than gas generated by decomposition, and collected in the loose cellular membrane of the lower jaw, as it rapidly does in other parts of the body. We may add, that the process of its formation has been actually witnessed by Messrs. Quoy and Gaimard. A whale of this species was killed by the crew of the ressel in which they sailed. When alive, and during the next day, the mouth was shut. The day after, this reputed swimming bladder began to appear, and speedily it presented an insuperable obstacle to the shutting of the jaws (Voyage, p. 83). The simplest seems the most plausible, as it is probably the correct account of the matter. The Rorqual has not, in the upper jaw, that large segment of a circle in which the Mysticetus collects its food; but to compensate for this, has it in the lower: when it opens its prodigious mouth, the water, rushing in, opens these folds, and so forms, as it were, a great well in which its prey is collected; on shutting its mouth and contracting the folds, it expels the water, whilst the strainer formed by the baleen retains the fish, \&c. which 
forms its food, and which now become a suitable morsel, as they are an easy prey*.

This animal attains the vast length of from one hundred to one hundred and ten feet,-Sir A. Capel Brooke says, one hundred and twenty (Lapland, 141); with a circumference of thirty or forty, which is the same as that of the Mysticetus. Mr. Scorseby remarks, it is seen apparently of the length of a ship, that is, from ninety to an hundred and ten feet (Thomson's Ann. of Phil. vi. 314); and, as will presently appear, it has more than once been actually measured at one hundred and five feet. The body is not cylindrical, but compressed at the sides, and angular on the back. The head is small when compared with the former genus, and the tail is relatively somewhat less broad. The dorsal fin is small, and placed opposite the vent; the pectorals are considerably distant from the angles of the lips and are slender, straight, and pointed at the extremities. The blubber is usually about six or eight inches thick, and does not yield above eight or ten tons of oil, sometimes none at all ; its colour is a pale bluish black, or dark bluish grey, somewhat resembling a sucking Mysticetus.

Its blowing is very violent, and may be heard in calm weather at a great distance. Though this species is sometimes mistaken for the Mysticetus, yet its appearance and action are so different that it may generally be distinguished. It seldom lies quietly on the water when blowing, but usually has

* See, too, p. 143. 
a velocity of four or five miles an hour; and when it descends, it very rarely throws its tail in the air, which is the general practice of the other.

The Rorqual occurs in great numbers in the Arctic Seas, especially along the edge of the ice between Cherie Island and Nova Zembla, and also near Jan Mayen. Persons trading to Archangel have often mistaken it for the common whale. It is seldom seen amidst much ice, and seems to be avoided by the Mysticetus; and the whalers therefore view its appearance with concern. It inhabits most generally in the Spitzbergen quarter, the parallel of from $70^{\circ}$ to $76^{\circ}$; but in summer, when the sea is open, it advances to the northward as high as the $80^{\circ}$ of latitude.

The Rorqual swims with a velocity at the greatest of about twelve miles an hour. It is by no means a timid animal, and usually does not appear to be revengeful or mischievous. When closely pursued by boats it manifests little fear, and does not attempt to outstrip them in the race, but merely endeavours to avoid them, by diving and changing its direction. If harpooned, or otherwise wounded, it then exerts all its energies, and escapes with its utmost velocity. Thus, we can readily credit the story related by Martin, of the sailors of a small vessel having fixed their harpoon in one of these Cetæ, when it darted off with extreme velocity, so much to the astonishment and surprise of all on board, that, panic struck, they lost all self-possession, omitted to cut the fatal cord which connected them to the animal, and 
were drawn under a vast bank of heavy ice, where they all perished. This great speed and activity renders this species a dangerous object of attack, whilst the small quantity of oil it affords makes it unworthy of the general attention of fishers. When struck, it frequently drags the fast boat almost immediately beyond the reach of assistance, and speedily out of sight both of boats and ship. Hence the striker is under the necessity of cutting the line, and sacrificing his employer's property, for securing the safety of himself and companions. "I have made," says Mr. Scorseby, " different attempts to capture one of these formidable creatures. In the year 1818 , I ordered a general chase, providing against the danger of having my crew separated from the ship, by appointing a rendezvous on shore, not far distant, and preparing against the loss of much line by dividing it at two hundred fathoms from the harpoon, and affixing a buoy at the end of it. Thus arranged, one of these whales was harpooned by a shot from the harpoon-gun, and another was struck in the common method. The former dived with such impetuosity, that the line was broken by the resistance of the buoy as soon as it was thrown into the water; and the other was liberated within a minute by the division of the line, occasioned, it was supposed, by the friction against the dorsal fin. Both escaped. Another was struck by one of my inexperienced harpooners, who mistook it for a Mysticetus. It diver obliquely with such velocity, that 2880 feet of line were withdrawn from the boat in about a minute of 
time. This whale was also lost by the breaking of the line."

Sometimes, though rarely it would appear, this species manifests a tendency to retaliate against its pursuers, and especially when those endeared to it are attacked. We speak not merely of the affection of the mother for its young; the following narrative occurs in Lacépède, and seems to exhibit no common share of conjugal regard."The male and female of this species (the jubarte)," he remarks, "seem united by the strongest bands of affection. Duhamel reports that two were taken in 1723, which were swimming along together, and were probably male and female. The one which remained free exhibited much uneasiness on its companion being wounded; it then swam to the boat, and with one stroke of its tail killed three men and precipitated them into the sea. The two remained to the last in close company with each other; and when the one was killed, the other uttered lamentable and terrible cries."

But though the regular whalers usually decline all encounter with this species, yet it is not so with the natives of the polar regions, whose wants compel them to make every exertion which promises the least success, and whose circumstances are frequently peculiarly favourable. In Lapland they sometimes yield fifteen tons of oil, and are worth about $\mathfrak{£ . 1 5 0 .}$ -(Brooke's Lapland, 141.) We have met with two accounts of their mode of attacking it. Thus the late Sir Charles Giesecki states that the following 
is the method which the native Greenlanders take of securing some of the smaller animals of this species (the Balæna Boops), which frequent their coasts in the summer months. Both men and women engage in the adventure, the former in their kayacks, the latter in their bomiaks. The men in their light skiffs follow the whale as close as possible, and continue to throw as many harpoons and lances into him as possible, until he dies of loss of blood; they then join their canoes together, fasten their spoil to them, and carry their booty home, where it is faithfully divided (Art. Greenland, Edin. Encycloped.); in the words of one of the most powerful and interesting poets of the present day:

Trained with inimitable art to float,

Each balanced in his bubble of a boat,

With dexterous paddle steering through the spray,

With poised harpoon to strike his plunging prey;

As if the skiff, the seamen, oar, and dart,

Were one compacted body, by one heart

With instinct, motion, pulse empow'red to ride

A human nautilus upon the tide.

Montgomery's Groenland.

Sir Arthur de Capell Brooke gives a somewhat different account of its mode of capture by the Laplanders on the Finmark coast. They pursue the animal with all the strength the party can muster, and wounding it as severely and rapidly as possible, they leave it. For the time, it escapes them; but, in the course of a few days, it is generally found dead on some part of the neigh- 
bouring coast. The person who finds it immediately gives notice, and those who were engaged in the bunt come and identify their property by their name or mark on the instruments employed. The finder is then rewarded with a third of the booty, to which he is by law entitled, whilst the remainder is shared among the rest. (Travels in Nornay, 300).

As herring and other fish are the occasional if not habitual food of the Rorqual, and as these often resort to the estuaries of our rivers and the enclosed and shallow bays of our coasts, where they are keenly pursued by the whales, it not unfrequently happens that even these immense monsters are taken by surprise, left by the retiring tide, and stranded on the shore. A curious fact is on record with regard to one individual, seventy-eight feet long, who had been for long a keen hunter, and was at last surprised and cast away. The circumstance, as narrated by Sir Robert Sibbald in his Phalainologia, took place at Abercorn in the Frith of Forth in September 1692. This individual had been for twenty years known to the fishermen from its pursuit and capture of herring, and had been termed by them "the hollie pike," because there was a hole in its dorsal fin, which had been produced by a musket ball, and therefore supplied a very distinguishing mark. Its death was considered by them as a subject of great joy. It has also been frequently observed, that on an exposed coast, after a great 
storm, some of these Cetæ were cast ashore, injured by the tremendous sea, or dead from some accidental cause. When an event of this sort takes place in a populous district, it never fails to prove at least a nine days' wonder, and crowds from far and near are attracted to behold what no description can ever adequately represent. These occurrences have sometimes proved eras in the science, and we shall therefore give a list of the principal of those we have met with in the records of Cetology.

As already hinted, two have been observed which measured one hundred and five feet. One of these was found dead, as mentioned by Scorseby, in Davis Straits (Arct. Reg. i. 481); and Captain Clarke measured the skeleton of one near the Columbia River, which extended to one hundred and five feet. Allowing five or six feet for the tail, this appears to be the largest animal of which we have an accurate measurement ('Travels to the Missouri by Captains Lenis and Clarke, p. 422).

2,105 feet, as above.

I, 101 feet, stranded on the banks of the Humber in 1750 .

1,95 feet, earried into Ostend in 1827.

1, 84 feet, stranded at Boyne in Banffshire at close of seventeenth eentury, as mentioned by Sir R. Sibbald.

1, 83 feet, eonveyed to North Berwick in 1831. Messrs. Knox's.

1, 82 feet, embayed and killed in Balta Bay, Shetland, in 1817.

1, 78 feet, at Abercorn, as above alluded to, in 1692 .

2, 70 feet; one on the coast of Cornwall in 1797, the other on west coast of Ireland in 1825. Jac. Dub. Phil. Jour. i. 
1, 63 feet, conveyed into Brighton in 1830. Loudon's Mar gazine, iv. 163.

1, 57 feet, at Rochefort, in 1827 ; Souty, in Lesson, 345.

1, 52 feet, at Eyemouth, Berwickshire, 1752.

2, 46 feet; one at Bumtisland, 1690, Sibbald ; ditto, 1761 , Dr. Walker, recorded by Dr. Neil.

1, 43 feet, near Alloa, Frith of Forth, 1808. Dr. Neil. Besides various others whose dimensions are not given, or smaller than the above, on the coast of Ireland, in the Western Isles, the Orkneys, in the Thames, the coast of Holland, \&c.

Many of the occurrences above alluded to were of great moment, in as much as they afforded an opportunity which men of zeal and science improved, in the more particular examination of the structure of the order, and thereby improved our acquaintance with them: they thus became landmarks in the acquisition of knowledge, at which those who laboured acquired for themselves a well merited and substantial praise.

In no instance has this zeal been more conspicuous, than as it was excited by No. 5 in the above list, found in the neighbourhood of North Berwick in 1831. It was immediately purchased by the present proprietors, Dr. Knox and his brother, Mr. Frederick Knox, the latter of whom superintended the process of flensing, and for more than three years with praisewrorthy assiduity, carried on the preparation of the skeleton, and of some of the soft parts, which were exhibited in 1835, in Edinburgh and Glasgow, to the admiration of thousands. To the former of these gentlemen, especially, men of science will look for some interesting addi- 

tions to the present stock of information on this subject; and to both of them we are indebted for the liberty they have given us of supplying the accompanying accurate representation of the skeleton (Plate vi.), which cannot but interest our readers, and for which we thus beg them to accept our best thanks.

According to the short account published by Mr. F. Knox, the following are a few of the measurements of the specimen:

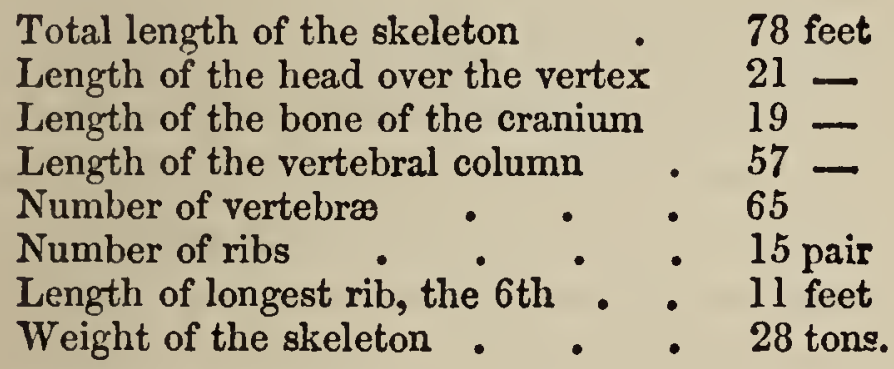

The larger vertebræ were fourteen inches in the diameter of their bodies, and from six to seven feet from tip to tip of their transverse processes; they gradually lessened towards the tail, till they did not exceed a hen's egg in bulk. A vertical section of the skull exhibited a part of its walls more than three feet in thickness.

It is a specimen of the same species, No. 4 of the above list, which forms our Plate v., the skeleton of which was exhibited in London in 1833, and is now we believe being exhibited throughout the United States of America. We apprehend we may safely state this to be the skeleton of the largest animal that has ever been preserved, and, like the 
former, could not be beheld without exciting the iveliest astonishment. It was a female.

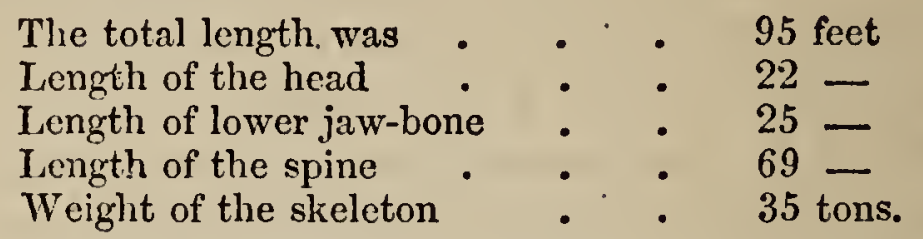

And as animals of these gigantic dimensions are sometimes cast ashore in our day, so were they many centuries ago in other countries, and probably of other genera. A curious notice is made on this point, at a very early date in the records of history. Nearchus, general to Alexander the Great, undertook, as is well known, a voyage from the mouth of the Indus to the Persian Gulf in the year 327 before the common era. In this perilous voyage Nearchus coasted along the country of the Ichthyophagi, considered by Ptolemy as a part of Karmania. In his narrative we are informed that these people live generaily in small cabins, the better sort nnly having houses, which are constructed of the bones of whales thrown upon the coast. When the flesh Is rotted off they make planks and doors of such as are flat, and beams and rafters of the ribs and jarvbones; and many of the monsters, it is said, are found a hundred and fifty feet in length. Strabo confirms this statement of Arrian. (Vincent's Nearchus.-Kerr's Voyages, xviii. 71.)

We cannot dismiss this short notice respecting the stranding of the Cetæ, and be it remarked they are not always of the size indicated in the table, without stating that the circumstance may always be 
turned to an important economical purpose in connexion with agriculture. It is well known that the richest manure is formed from decayed animal matter, and hence the great value of bone manure as an article of commerce and of increased productiveness. Now, no animal matter can exceed in richness that which ss supplied by the fatty matter so abundantly contained throughout the whole frame, bones and all, of the Cetacea. Hence the late Sir John Sinclair, with that enthusiasm for his country's good which ever characterized him, called the attention of the agriculturist to this subject; and, more lately Mr. William Bell has supplied an interesting notice to the Quarterly Journal of Agriculture, vol. i., concerning the use of $d r e g$, or coarse whale oil, in converting peat moss, \&c. into rich manure, and finally into fine mould. His experiments on this point were highly successful, and the result of his promised additional observations will be esteemed by the practical farmer. 
THE LESSER RORQUAL.

\section{PLATE VII.}

Rorqualus Minor, Knox.-Bal. Rostrata, Fab., Hunter.Balænoptera Acuto-Rostrata, Lacepede, Scorseby.

For the undisputed establishment of this species, the scientific world is indebted to the zeal and assiduity of Dr. Knox; to whom, and also to his brother, our readers, and still more we ourselves are especially indebted for the accompanying representation of a striking drawing in the possession 01 the latter gentleman. It is true that Fabricius described this species with his accustomed elegance and precision; Mr. Hunter likewise met with and delineated it, having probably examined it with care, as he makes frequent allusion to it in his published works; Mr. Scorseby's work also contains an exact representation, supplied through Dr. Trail. But notwithstanding all this, the details collected were so meagre and slight, that not only were much ignorance and error prevalent concerning it, but many naturalists, of whom Cuvier, in 1823, was one, were led to doubt even its existence: "Mais qui oserait soutenir que ces différences ne venoient pas de l'âge." (Oss. Foss. v. 366.)

Dr. Knox's specimen was taken in February, 


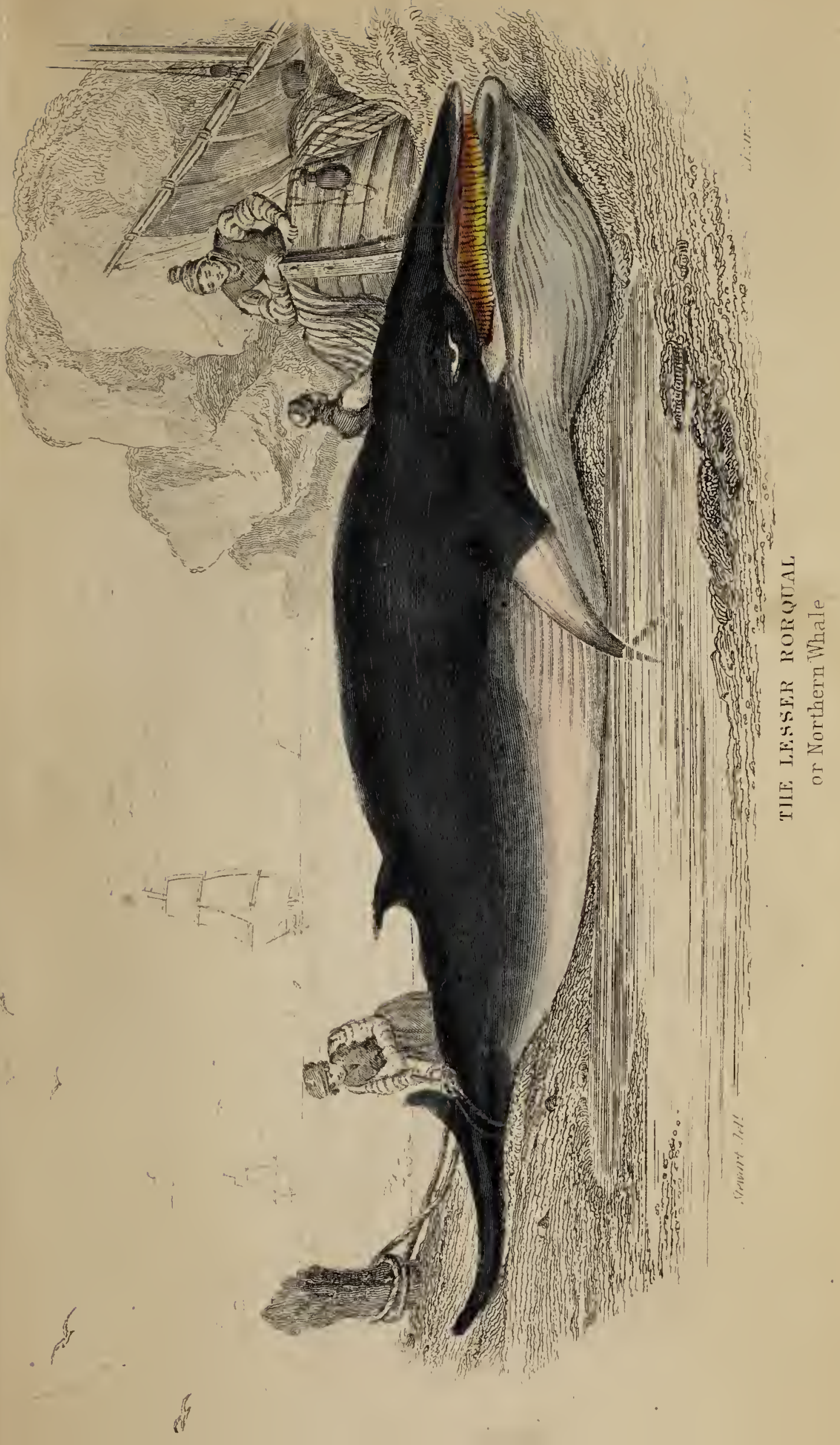



1834, near Queensferry, Frith of Forth. It was a young one, measuring only ten feet. On obtaining possession of it, Dr. K. thought of suspending it horizontally as in the posture of swimming. "By this means," he remarks, "the proper character of the head and mouth were given, and this so much altered the appearance of the animal, that the author thinks all previous views extremely incorrect, besides tending to mislead the naturalist as to the real capacity of the mouth of the genus, which is really very great. The lower part of the mouth is an enormous pouch or bag which, in the great northern Rorqual, must at times contain an incredible volume of water. The tongue was free towards the apex, almost as much as in man." (Notice of a Paper read to Royal Soc. of Edin.)

Passing by this observation on the tongue, which, so far as we know, is original, we cannot but felicitate our readers on the simple but ingenious thought which led this gentleman to place the individual as much as possible in its natural position, whereby, we agree with him, a new character was given to the appearance of its most striking feature, and every thing like doubt removed concerning the true use of that peculiar structure, which hitherto has perplexed all naturalists who have directed their attention to it. It was from this discovery that, when treating of the Great Rorqual (on p. 131), we did not hesitate to assign this use, viz. that of a pouch for augmenting the capacity of the mouth to the part; and no adequate judge, we apprehend 
can look at the Plate, without being irresistibly impressed with the conviction that this is its true and appropriate use. This examination has also, we apprehend, put an end to all the idle hypotheses concerning the alleged swimming bladder under the tongue, which were grounded on a mistake of Sir Joseph Banks, which was at once rejected by John Hunter, but which has misled the accurate Lesson, as well as more recent writers on the subject.

But we have yet to state how Dr. Knox established that the Lesser Rorqual must be considered as a distinct species. He has done so as a comparative anatonist, in a single instance, and for ever. We have already expressed our obligations to him as the proprietor of the skeleton of the Great Rorqual; he also possesses that of the one now under review, and the examination of their osteology gives the following result:

\begin{tabular}{l|c|c|c|c} 
& Vertebra, & Dorsal. & Remaining. & Total. \\
cervical. & 13 & 43 & 63 \\
Great Rorqual & 7 & 13 & 30 & 48
\end{tabular}

Other differences than those involved in this single statement might be mentioned, which quite agree with more popular observations; but these, at this time, must suffice.

Before laying Dr. K.'s short notice aside, we must introduce his remarks concerning the valves of the spiracles. "Two bolster-like substances filled the canals, which are withdrawn from them at the moment of breathing, by muscles provided for that 
purpose; the mechanism is admirable, and would sustain a pressure from above, though the animal were to descend thousands of fathoms:" also concerning that mass of vascular tissue, closely resembling the "erectile," which he discovered within the cranium; " it filled a very large proportion of the interior of the cranium, extending thence into the spinal canal, three-fourths of whose cavity it also occupied ;" and finally, his statement " that its olfactory nerves were at least as large as those of man." All these observations suggest many important considerations, on which our space forbids us to enter, but which we trust will speedily be offered to the public by this indefatigable observer.

We have already stated that the specimen now before us was a young one. Both Mr. Hunter's and that supplied by Dr. Trail measured seventeen feet; another taken at Cherbourg, mentioned by Lacépède, was fifteen feet: twenty-five is stated as the ordinary limit of its length, and it is therefore the smallest of the known Rorquals. We refer to our plate as a substitute for all remarks on its external characters. Its baleen is white and short; the rosy tint of the plicæ was mentioned by Fabricius, whose account is still the best we have seen. It frequents the rocky bays of Greenland, especially during summer, and also the coasts of Iceland and Norway; sometimes, though rarely, coming into lower latitudes. Its food is the arctic salmon and other fish. In its habits it is very active; so much so, that though much valued in norther mimates for the 
esteemed delicacy of its flesh, yet the natives never attempt to harpoon it. They wound it with their darts and spears, and, after a fortunate hunt, hope to discover it, dead and stranded. Its oil also is regarded as peculiarly delicate, and is esteemed by the Icelanders as an article of their Materia Medica.

RORQUAL OF THE SOUTHERN SEAS.

Rorqualus Australis, Cuvier._Balænoptera Australis, Lesson.

As after our account of the Greenland whale we added a few remarks concerning another mysticetus, which was an inhabitant of the southern seas, so the only other existing species of rorqual we shall here introduce to the notice of our readers, is one which within these few years has been discovered in the Southern Ocean, and ascertained to be a new and distinct species. These discoveries recall to mind an interesting remark of Buffon's, in which he states, that every part of the globe, according to its parallel of latitude, has animals peculiar to itself. It is true, this law has not very frequently been demonstrated in reference to the inhabitants of the ocean, although it has been remarked that the place of their habitation is to be reckoned, not by the sea which they frequent, but rather by the latitude; and hence it is alleged, that the intertro- 
pical zone includes the same species throughout its whole circumference, and that as we remove from it, both northward and southwards, each parallel has its peculiar varieties, whose limits are terminated by the different meridians of the globe. In the present state of our knowledge, it would be going too far to affirm that none of the Cetacea plough the wave indifferently in every clime, but, as we have seen, Mr. Scorseby decidedly states the mysticetus has never been seen in European seas; and since that time, it has been proved that there is both a distinct mysticetus and rorqual in the Southern Ocean. This then is sufficient to excite renewed attention to the subject, and the inquiry should henceforward be prosecuted with fresh zeal.

The Southern Rorqual was first examined at the Cape of Good Hope by M. Delalande. Its most evident peculiarity is a long dorsal fin, which, instead of being placed near the tail, is situated immediately over the pectorals. The body is black above and pure white beneath, except within the folds, which are of a well marked rosy hue. Cuvier has accurately detailed the differences in the osteology, and to his work we shall refer the scientific reader (Oss. Foss. v. 372); only remarking it has seven cervical vertebre, fourteen dorsal, and fourteen pair of ribs, and thirty-one lumbar and caudal, making a total of fifty-two vertebræ.

The Southern Rorqual but rarely approaches the coasts of the Cape, since it is stated that only two or three are observed there during the year; nor 
does any one think of pursuing it, since its great power and velocity make it difficult and dangerous of capture, and the product by no means repays the risk and labour.

It is manifestly this species which Dr. Foster states that he encountered near Terra del Fuego, when returning to England with the illustrious Cook. As illustrative of its habits we shall give an extract:- "When between Terra del Fuego and Statten Island, Lieutenant Pickersgill was sent into Success Bay, and on this occasion it was remarked that no less than thirty large whales played about them in the water. Whenever they were seen blowing to windward, the whole ship was infected with a most destestable rank and poisonous stench, which went off in the space of two or three minutes. Sometimes these huge animals lay on their backs, and with their long pectoral fins beat the surface of the sea, which always caused a great noise, equal to the explosion of a swivel. This kind of play has doubtless given rise to the mariners' story of a fight between the thresher and the whale; the former of which is said to leap out of the water in order to fall heavily upon the latter. Here we had an opportunity of observing the same exercise many times repeated, and discovered that all the belly and under side of the fins and tail are of a white colour, whereas the rest is black. As we happened to be only sixty yards from one of these animals, we perceived a number of longitudinal furrows on its belly. Besides flapping with their fins in the water 
these unwieldy animals, of forty feet in length, sometimes fairly leapt into the air, and dropt down again with a heavy fall. The prodigious quantity of power required to raise such a vast creature out of the water is astonishing, and their peculiar economy cannot but give room to much reflection." (Cook's in Kerr's Voyages, xv. 4.)

Though not without some hesitation, yet we are inclined to believe that this is the species which by the southern whalers is denominated the black fish or black whale, and which most frequently they are solicitous to avoid. It is this whale which Captain Colnett states that he saw, in innumerable shoals, on the shores of California. (Voy. to the S. Pacific.)

One other of the habits of this species we shall mention. The black fish, of all other whales, most frequently place themselves in a perpendicular position, with the head only above water, presenting in this position a most extraordinary appearance when seen from a distance, resembling large black rocks in the midst of the ocean; this posture they seem to assume for the purpose of surveying more perfectly, or more easily, the surrounding expanse. (Beale.)

The southern seas supply the appropriate food of these whales in the richest luxuriance. Thus, M. Lesson, who spent a considerable time in these latitudes, states, that the whale does not so much seek its food as its food seeks it. The sea is often very rough, and the height and violence of the waves is such, that the spray in breaking over the ressel brings along with it great quantities of medusa 
and flying fish. It is under these circumstances that these giants are most active, as if enjoying the storm, and then appear busiest in pursuing their prey.

\section{FOSSILE RORQUALS, ETC.}

WE have already hinted that most of the Cetacea have been found in a fossile state, and we scarcely know any thing which is more calculated to demonstrate the extraordinary revolutions which have taken place on the surface of the globe, than the fact that specimens of these great whales are now to be found in the bowels of the earth, in the centre of mighty continents, and elevated high in vast ranges of mountains. Thus there are distinct records of portions of skeletons of whales having been discovered on the continent of Europe, as well as in various parts of Britain, \&c.

One of these was discovered by $M$. Cortesi in 1806 on the east flank of Monte Pulgnasco, one of the Apennines, about six hundred feet under the summit, which is itself elevated twelve hundred feet above the neighbouring plain. In this part, the hill consists of regular beds of bluish clay, inclined towards the north, and filled with marine shells. The whale was found lying in the same direction with the strata which inclosed it, the head pointing northwards. This skeleton was nearly perfect, although some of the ribs were somewhat out of their proper position. The vertebræ were lying on the right side; a great many teeth of 
a small species of shark, and innumerable shells surrounded it, especially a small variety of oyster, many of which were attached to the left side of the vertebræ, lying uppermost. The regular attachment of these oysters is well worthy of consideration, as it goes to show that they must have been fixed to their position while alive, and consequently, that the skeleton had long lain at the bottom of the ocean.

The head is six feet long, and the vertebræ occupied a space of fifteen feet, giving twenty-one feet for the whole length of the skeleton. According to Cuvier, the form of the head presents, at one and the same time, all the characters of a new sub-genus and of a distinct species. The other bones agree with the indications supplied by the cranium. It had twelve pair of ribs, the largest of which, along its convexity, was three feet seren inches; the vertebræ were forty-one in number. In the Dict. Class. d'Hist. Nat. this species is denominated Baloena Cuvieri by M. Desmoulins.

M. Cortesi discovered another skeleton in 1816 , in the same kind of strata, and in a neighbouring valley. It was not in such good preservation, and could not so easily be disengaged from the surrounding rock. Its head was only four feet long, and the total length twelve feet, five inches. It was situated at a lower level than the other, at 1200 feet under the summit of Monte Pulgnasco, and 1400 feet under that of Monte Grogo, the two nearest hills. This has been designated, by the authority last quoted, B. Cortesii. 
A cetaceous animal of much larger dimensions was discovered in 1775 in Paris. A wine merchant in La Rue Dauphine, while cutting trenches in his cellar, discovered a fossile bone of considerable dimensions in a yellowish and sandy clay, which appears to be the natural soil of the locality. Solicitous to spare the labour necessary for its entire extraction, he broke it, and raised a portion weighing two hundred weight. This attracted the attention of the curious; a cast was taken by Lamanon, and a sketch and description were published in the Jour. de Physique for 1781. This cast, with additional sketches, fell into the hands of Cuvier, and he, with that success which attended all his labours in this department, detected it to be a portion of the right temporal bone of a whale. He compared it with corresponding portions $o$ others, and concluded that the length of its head was about sixteen feet, and that the total length of the animal to which it belonged could not be less than fifty-four feet, without including the tail or lips, which would raise its size to about sixty feet. Cuvier moreover remarks, that although this size agrees with that of the mysticetus, yet the details of the shape, and the comparison of the proportions, indicated decided differences. His conclusion is, that, according to all appearance, this fragment belongs to a cetaceous animal of a species which is unknown, even among fossiles.

Several remains of fossile whales of great dimensions have been discovered, deposited in marine 
diluvium in various parts of Scotland. Three instances of this sort have been particularly pointed out. One of these occurred at Airthrey, on the Forth, near Alloa. The bones belonging to an animal about seventy-two feet long, were imbedded in clay, twenty feet higher than the surface of the highest tide of the river Forth at the present day; and are now deposited in the Royal Edinburgh Museum. See "Mr Bald on the Skeleton of a Whale," Edin. Phil. Jour. i.393. Another consisted of one vertebra only, found twelve feet above the level of the sea at Strathpeffer, Ross-shire, as described by Sir George Mackenzie in vol. x. of the Edin. Phil. Trans. The third was found at Dunmore Park, Stirlingshire. The bones of this specimen belong to an individual seventy or seventy-five feet long; and are imbedded in clay twenty feet higher than the present level of the Forth.-Edin. Phil. Jour. xi. p. 220. 415. The exact species to which these remains belong has not yet been determined.

In Loudon's Magazine for 1831, p. 164, the following statement occurs :- "Mr. Mantell, about two years ago, discovered, on Brighton Cliffs, part of a jaw-bone, nine feet long, of a whale in a fossile state. It was lying included in the ancient diluvial shingle of the cliff, in which the teeth and bones of elephants are also found." This circumstance is mentioned by Mr. Mantell in his Geology of the South-east of England, 1883, p. 42. He moreover states that a narwhal and porpoise have been found in alluvial deposits of the district; but scarcely any particulars are given. 


\section{Third Genus.-CACHALOT.*}

The general characters which belong to this genus are the great head, but no baleen; teeth in the lower jaw only; spiracle single; supplying the spermaceti and ambergris of commerce.

THE SPERMACETI WHALE.

\section{PLATE VIII.}

Cachalot, Cuvier.-Physeter Catadon. Linn.-Grand Cachalot, Bonnat._Cachalot Macrocephalus, Lacepede, Desmaret, \&c.

Some of our readers may perhaps be surprised that under the generic term Cachalot we introduce to their notice only one species of this variety of whale. 'This we do, not because we deny the existence of others; far from it, but only because these others have not hitherto been accurately described or established. Desmaret but a few years ago admitted three sub-genera and seven species; and Lacépède has three genera and eight species, inclading his Cachalots, physalus, and physeters. Every one who, previous to our own days, had attempted to reconcile the many contradictory accounts which have been given of this extraordinary animal, seems in his turn

* Cachalot from Cuchou, a tooth, in the Basque language. 


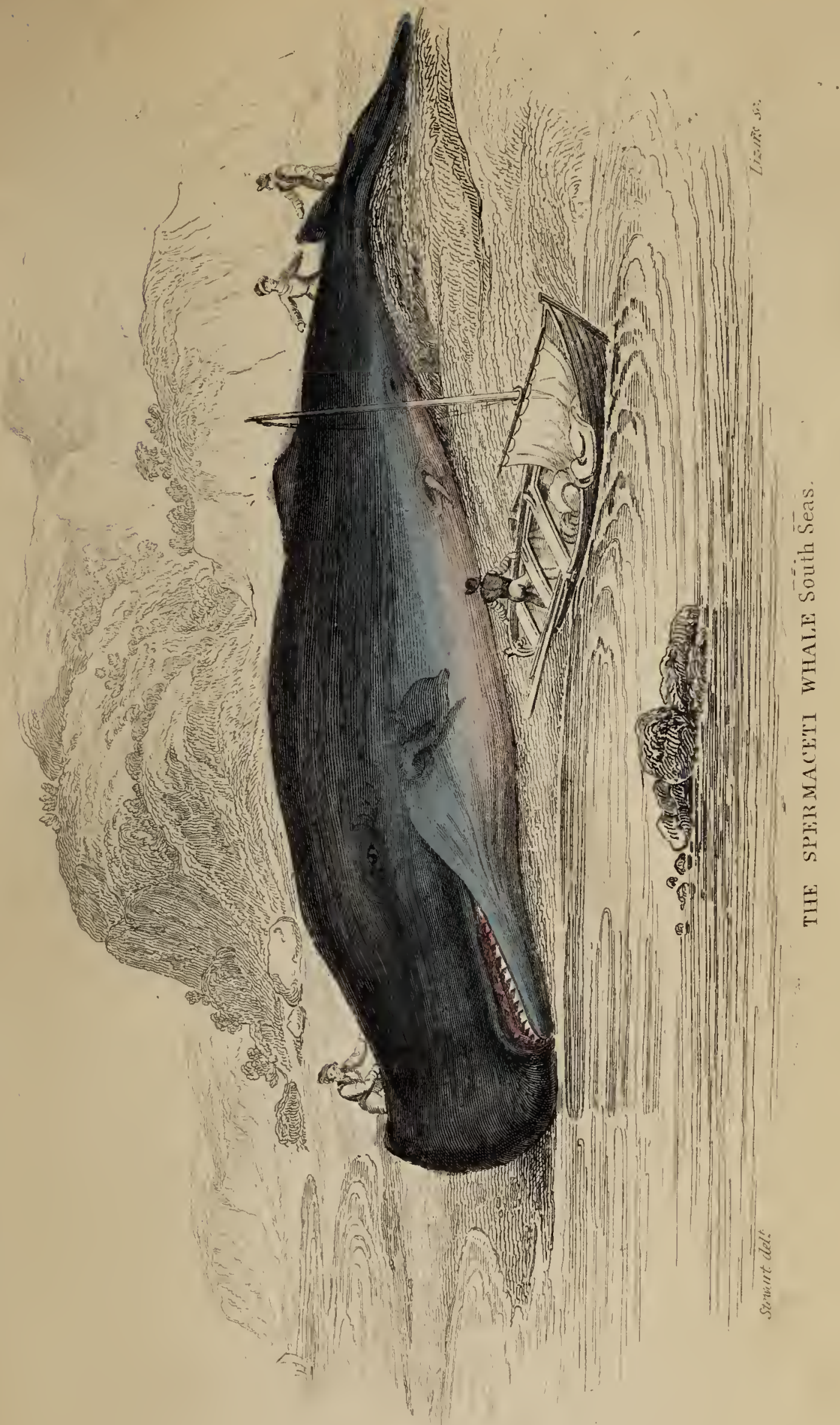



to have been foiled; and it was reserved for Cuvier to cut at all events, if not to unravel the knot. $\mathrm{He}$ remarks, "the history of this animal is so perplexed, so many beings have been confounded with it, and the species have been so wantonly multiplied, that, to obtain some precision on the subject, I have been necessitated to review, chronologically, every thing that naturalists have written on the point." After making this review, he concludes with these words: "Will it now then be regarded as great temerity in me, after having produced the ideas of so many learned men, to maintain that, up to the present time, there is no ground to suppose that there is more than a single species of Cachalot?"

And as, till the time of Cuvier, there was the greatest confusion regarding alleged species, so, till a much more recent date, there was an almost unaccountable paucity of information regarding its real habits and history; though, in a national and commercial point of view, it is second in interest only to the Mysticetus. From the difficulty of examining these animals, and the few opportunities presented to zoologists, there is really very little at all satisfactory about them in the annals of Cetology, and even the economical notices are but few and meagre. We rejoice to say, that this deficiency has to a considerable extent been supplied during the past year by a gentleman, who, for upwards of two years, was engaged in its capture, and who read a paper upon it to the Eclectic Society of London in 1835. When engaged in the fishery, Mr. Beale, who is a 
surgeon, and was, we presume, professionally employed, had no thought of publication, and therefore overlooked many circumstances which would otherwise have engaged his attention. But notwithstanding this, he has judged wisely, we conceive, in complying with the request of his friends to furnish such information as he had; and we cannot but proffer him our best thanks, and warmly recommend his little work to all who are curious in natural history. It will appear in the sequel that he supplies by far the most copious and satisfactory information on the subject.

We take our description very much from that afforded by Cuvier (Oss. Foss. v. 339). Externally, according to the most authentic accounts, it is one of the largest Cetacea, attaining the length of seventy and eighty feet; its head is very large in all dimensions, and its length does not appear to have been much exaggerated when stated to be about a third of the whole body; the snout is very obtuse, and apparently truncated; the lower jaw, very narrow, is received between the upper lips as in a furrow, the teeth entering, when the mouth is shut, into cavities on the edge of the palate. The blow-hole, twelve inches long, in form of an $f$, is on the anterior extremity of the head, in the centre of a round protuberance, which is formed of thick fibres, which act as a sphincter. The pectorals are small and obtuse; there is a small dorsal protuberance only, far down the back; and sometimes two or three smaller ones; the tail is very large The colour, above, is a blackish 
and somewhat greenish-grey; below it is whitish, as also round the eyes. The immense cavity at the upper part of the head, covered only by a tendinous but very resisting integument, is divided interiorly into compartments, also tendinous, which communicate with one another, and into cells filled with oil, which is fluid when the animal is alive, and which, when it is dead, takes the concrete form with which we are familiar, under the name of spermaceti; and which, very absurdly, was long regarded as the brain, which occupies a very small space in the interior of the cranium. The spermaceti is also distributed along the back, and in many other parts of the hody, in a way which is not yet clearly explained. The ambergris, again, is found in the intestinal canal, but it has not yet been ascertained in what precise part and under what exact circumstances. The skin is so dense and insensible in its nature, that usually large shells attach themselves to it as to a rock, and there fix their permanent abode: these shells, which are very numerous, are sometimes mistaken for white patches of the skin. The eyes are alleged to be remarkably small, unequal, and the left often useless. This want of symmetry about the eye and other parts of the face seems a curious circumstance, which, however, is not confined to this species. The blowing-tubes are likewise very unequal, that on the right side not being one-fourth so large as that on the left. This great size of the left nostril points out the direction of the blowing apparatus, and explains the circumstance first mentioned, we believe, 
by Schewediawer in the Phil. Trans. 1783, that the Cachalots often project the column towards the left side.

When we turn from the classical description of Cuvier to the more popular statement of Beale, we find that, though there is a general agreement, yet there are also several discrepancies ; as there is likewise between his pictorial representation (see Pl. Ix.) and those which had been previously published; of which we consider our Plate viri., taken from Mr. Robertson's in the Philosoph. Trans. as the most authentic and the best. Whether these discrepancies arise from differences of species, time alone can show. He perfectly agrees as to the size, making it eighty feet, and adds, that its largest circumference seldom exceeds thirty or thirty-five feet. The colour over the greater part of the surface is very dark; in parts quite black, on the sides it assumes a lighter tint, and on the breast is silvery grey. Sometimes it is piebald. "Old bulls," as the old grown whales are called by the fishers, have generally a portion of grey on their nose, and they are then said to be grey-headed. The blubber in a large whale, on the breast, is about fourteen inches thick, and on most other parts of the body it measures from eight to eleven inches. This covering the southern whalers call the blanket; it is of a light-yellow colour, and when melted down yields the sperm oil. Mr. Beale does not corroborate, or rather, by saying nothing about it, contradicts the statement regarding the want of symmetry in the eyes and the blow-holes. 


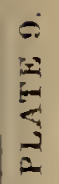



The opening to the ear, he states, is of sufficient size to admit a small quill. The throat is capacious enough to give passage to the body of a man, in this respect presenting a strong contrast to the contracted gullet of the Greenland whale. According to Mr. Beale, the peculiarity of the sperm whale, which strikes every beholder, is the unwieldy bulk of the head : but this, instead of being an impediment, is conducive to its lightness and agility, for the greatest part of it containing oil, which is lighter than water, gives the head a tendency to rise so far above the surface as to elevate the blow-hole for the purpose of respiration; and should the animal wish to increase its speed to the utmost, the narrow lower part of the head, which bears some resemblance to the cut-water of a ship, is the only part exposed to the pressure of the water in front, thus enabling it to pass with the greatest velocity and ease through the ocean.

One of the characteristics we have mentioned as generally stated, is, that the teeth are confined to the lower jaw ; and this as a popular character is a very good one. Literally speaking, however, it is not accurately true. Teeth in the upper jaw have been seen and described by Fabricius, and they are also mentioned by the Abbé Lecoz and by Anderson: they are, however, wholly rudimentary, are hidden under the jaws. and can scarcely therefore be used by the animal.

Mr. Beale's observations on the swimming of this whale are curious : he states that when undisturbed 
it passes tranquilly along just below the surface of the water, at the rate of ahout three or four miles an hour, its progress being effected by a gentle oblique motion of the tail from side to side: when proceeding at its usual rate, the body lies horizontally, the water by its progress being somewhat disturbed, is known by the whalers under the name of "white water ;" and, from its greater or less appearance, an experienced eye can, from the distance of several miles, judge of the rate at which the whale is advancing: in this mode of swimming it is able to obtain a velocity of about seven miles an hour. When it swims at a more rapid rate, the action of the tail is altered; the water is struck directly upwards and downwards, and each time the blow is made with the inferior surface, the head sinks down eight or ten feet, and when the blow is reversed, it rises out of the water, presenting to it only the sharp cutwater portion. The blow with the upper enrface appears to be by far the most poverful, and as, at the same time, the resistance of the broad part of the head is removed, this appears to be the principal means of rapid progression. This mode of swimming (see Plate Ix.) is what is called going heod out; and in this way the whale can attain a speed of ten or twelve miles an hour, which is probably its greatest velocity.

According to Beale, the food of the Sperm Whale, when in deep seas, which he regards its usual resort, is the sepia octapus, a molluscous animal, called "syeid" by the sailors; and when near shore, a fish 
of the size of a moderate salmon, which abounds in the bays and creeks. He remarks, it is difficult to conceive how so large an animal can ever catch a sufficient quantity of such animals if it has to pursue them individually, and the more so, as neither of those specified are known to exist in shoals or closely congregated. The theory of the sailors on the point is, that when one of these Cetæ is inclined to feed, it descends a certain depth, and there remains as quiet as possible, opening its enormous mouth, and allowing the lower jaw to hang down at a right angle with the body. The internal parts of the mouth, and the teeth, being of a white glistening colour, are supposed to attract its prey, and when a sufficiency is within the mouth, the jaw is closed and the morsel is seized. Mr. Beale adopts this opinion. and thinks it confirmed by two singular facts which he adduces ; first, that of a whale he met with, which must have been long blind, and was yet found in excellent condition when captured; and, secondly, the frequent occurrence of great deformity of the lower jaw, so as to make the capture of small bodies inpossible, and yet animals so circumstanced are as rich in oil as healthy ones. The latter deformities, we may remark in passing, arise from the severe contests which the animals maintain against each other, in which the jaws are closely locked, and the force mutually exerted is enormous.

We have entered into these details as they embody the opinion of observers, which we: would treat with respect; and also, because so far as the squid 
and fish are concerned, it is a fact that they have often been found in the stomach after death, and so constitute the occasional food of this whale. We would, however, venture to suggest to those who may have opportunities of observing, whether this whale may not also frequently resort to the medusa and minute fish, which, in so remarkable a manner, supply food to some of the smaller, as well as to the other genera of the gigantic whales. That there is an abundant supply of this provender, both in the Antarctic Ocean and the more smiling latitudes of the Southern Seas, can easily be proved by a reference to Lesson's statements as on p. 149 , and also by other observations. Captain Colnett on one occasion remarks, "The set of the currents on the coast of Chili may at all times be discovered, by noticing the direction of large beds of small blubber with which the coast abounds, and from which the water derives a colour like that of blood: I have often been engaged for a whole day in passing through various sets of them ;" and again, when approaching the southern point of America ; "during this forenoon we passed several fields of spawn, which eaused the water to bear the appearance of barley covering the surface of a bank." (Voyage, \&c. p. 170 and 10.) Orbigny also remarks, that there are immense tracts off the coust of Brazil filled with small creatures, so numerous as to impart a red colour to the sea; large portions are thus highly coloured, and receive from the whalers the name of Banc du Bresil. This bank extends 
along a great part of the coast of Brazil, keeping at nearly the same distance. $\mathrm{He}$ also states, that another similar bank occurs near Cape Horn in $57^{\circ}$ south latitude. Statements of this sort could easily be multiplied; and hence we cannot but suppose that this kind of food which is ascertained to afford such rich nourishment to the other great Cetacea, may very possibly be appropriated by the Sperm Whale to the same purpose.

The Sperm Whale is remarkably distinguished from its congeners by its blowing, so that it may be recognized at a great distance even by the most inexperienced whaler. When at the surface for the purpose of respiration, it usually remains still; but occasionally makes a gentle progress during the whole process. If the water be smooth, the first part observed is the hump, projecting two or three feet above the surface: at very regular intervals of time the snout emerges, at the distance of forty or fifty feet; from the extremity of the snout the jet is thrown up, and when seen from a distance, appears thick, low, and bushy, and of a white colour; it is formed, says Mr. Beale, by the air expired forcibly through the spiracle, acquiring its white colour from minute particles of water, previously lodged in the external fissure: it is projected at an angle of $45^{\circ}$ in a slow and continuous manner, for about three seconds, and may be discovered at the distance of four or five miles.

The regularity with which the actions connected with breathing are performed is very remarkable. 
The length of time this whale remains at the surface, the number of spoutings made on one occasion, the intervals between them, and the time it remains beneath, are all, when the animal remains undisturbed, as regular in succession and duration as it is possible to imagine. With different individuals the time varies, but in each the several acts are minutely regular ; and this is of considerable use to the fisher, for when the periods of any particular whale are once noticed, he knows to a moment when to expect it again at the surface, and how long it will remain there. Immediately after each spout, the nose sinks under water, scarcely a second intervening for the act of inspiring, which must consequently be done very quickly. There is no sound caused by the inspiration, and very little by the expiration.

In a " large bull," so an old male is called, the time from the termination of one spouting to that of another is ten seconds; during six of these the snout is under water, three are occupied by the expiration, and one by the inspiration ; and at each breathing time, the whale makes from sixty to seventy respirations, and therefore remains ten or eleven minutes at the surface. When this is ended, or, as the sailors say, it has had "its spoutings out." the head sinks slowly, the posterior part of the body appears above water, the tail is lifted high into the air, and the animal having thus assumed a straight position, descends perpendicularly to an unknown depth : this act is performed with great regularity 
and slowness. It continues hidden under water for an hour and ten minutes; some will remain only for an hour, and others for an hour and twenty minutes, but these are exceptions. The females remain on the surface for a shorter time, and as might be expected, ascend more frequently to respire: they come up about every twenty minutes. The times of the young whales seem regulated by their respective ages and sizes.

When disturbed or alarmed, this regularity in the breathing is no longer observed; for the instant a " bull" is disturbed, as by the approach of a boat, he inmediately plunges under the wave, though he may not have been on the surface half his time; he will then soon rise again, not far distant, and will complete his time. In this case, generally, also he sinks without previously assuming the perpendicular position, and with remarkable rapidity, leaving a sort of vortex in the place he lately occupied. When urging his rapid course through the ocean, in that mode which is called going "head out," he spouts every time the head is raised above the wave, and, under these circumstances of violent exertion, as might be expected, the respiration is much more hurried than usual.

This leviathan is, like the mysticetus, remarkably timid, and is readily alarmed by the approach of any unlooked for object. When frightened, the whale is said by sailors to be "gallied," probably galled; and in this state it performs many actions in a manner very different from the usual 
mode. One of these is what is called "sweeping," which consists in moving the tail slowly from side to side on the surface of the water, as if feeling for any object that may be near. This whale has also an extraordinary fashion of rolling over and over on the surface, and especially when harpooned; and in this case it will sometimes coil an amazing length of line around it. But one of its most surprising feats, as has been mentioned of the genera already described, is leaping completely out of the water, or "breaching," as it is called. The mode in which this appears to be done, is by its descending to a certain depth, and then making several powerful and rapid strokes with its tail, thus imparting great velocity to the body before it reaches the surface, when it darts completely out of the water. The body forms, when just emerged and at its greatest elevation, an angle of $45^{\circ}$, the tail being parallel with the surface; in falling, the body rolls over on the side: it seldom breaches more than twice or thrice at a time, and in quick succession. This performance may be seen in a clear day at a distance of six miles from the masthead. As has also been previously stated regarding the mysticetus, "lob tailing" is another frequent and favourite amusement with this genus.

The Sperm Whale is a gregarious animal, and the herds are of two kinds, the one consisting of females, and the other of young and not fully grown males; the latter are again generally subdivided into groups according to their ages. These herds are called 
"schools," and occasionally consist of two, four, or even six hundred. With each herd of females several large bulls are always to be found, the lords of the herd, or, as they are called, the "schoolmasters." These males are extremely jealous of intruders, and fight fiercely to maintain their rights.

The full grown male whales, or "large whales," almost always go alone in search of food; and when they are seen in company, they are supposed to be making passages from one feeding ground to another. The "large whale" is generally very incautious, and, if alone, is attacked without difficulty, and generally easily killed; as he frequently, after receiving the first plunge of the harpoon, appears hardly to feel it, but continues lying like a log of wood before he makes any attempt to escape. Large whales are sometimes, however, remarkably cunning and full of courage, when they will commit dreadful havock with their tail and jaws.

According to Beale, the female breeds at all seasons, and the time of her gestation is " not very long." $\mathrm{He}$ also states, that she is much smaller than the male, in the proportion nearly of one to four or five. This appears a novel, and we presume to think, a somewhat doubtful assertion. They are not only, like other genera, greatly attached to their young, but are likewise remarkable for their strong feeling of sociability and attachment to one another ; and this is carried to such an extent, that if one female of the herd be wounded, her faithful companions will remain round her till the last 
moment, or till they are wounded themselves. This act is called by the whalers " heaving to;" and whole schools have been destroyed by dexterous management, when several ships have been in company. This attachment is remarkably strong in cubs, and hence they remain about the ship long after their parent is destroyed. Captain Colnett remarked, that if one of a herd be harpooned, more mischief was done by the loose fish, than by those to which the boats were fast.

The young males or " young bulls" generally alsn go in schools; but differ remarkably from the females in disposition, inasmuch as they make an immediate and rapid retreat when one of their numher is struck, and this unfortunate individual is left to take the best care of himself he can. They are also very cunning and cautious, keeping at all times a good look-out against danger. The whaler, accordingly, must be extremelycareful in approaching them, so as, if possible, not to be seen or heard; for they have a mode of communicating with one another through a whole school in an incredible, short space of time. This remark is true of all Sperm Whales, which thus hecome apprized of the approach of danger, though at the distance of four, five, or even seven miles. (See p. 57.) Young bulls are consequently much more troublesome to attack, and more difficult and dangerous to kill than when full grown. When three quarters or a half grown, they separate from each other, and go singly in search of their food.

According to Beale, this species is never or very 
rarely seen in soundings; it inhabits the unfathomable ocean : far away from land, it seeks its prey, produces its young, and follows all its natural inclinations. At times it may approach the shore, but only within a certain distance, and where the water is still unfathomable. This account is different from any we have before seen, and we will therefore supply, along with it, the statement of another professional gentleman, an eminent naturalist, who spent many a year in its pursuit, with his attention peculiarly directed to it. Lesson states that the individuals of this species are true cosmopolites, and throughout the year may be found in every quarter of the globe. Yet, according to him, there are certain and not very long seasons, when they congregate together in great herds towards the coasts, in the quiet bays; and a union once formed, the different pairs immediately separate from the band, and direct themselves at random throughout the boundless ocean. $\mathrm{He}$ adds, could the times and places at which these re-unions take place be ascertained, they would much diminish the labours of the whaler.

The method of conducting the southern fishery differs in several particulars from that followed in the north, and these differences we shall now endeavour to point out. Some of the ships are fitted out solely for fishing the Sperm Whale, whilst others keep a sharp look-out for the mysticetus 
also ; and others, it would appear, in lack of these, hesitate not to attack almost any kind of whale that comes within their reach.

When a whale appears in view, the signal is given, and the boats hanging at the ship's side, and completely ready for the attack, are instantly lowered. These boats are supplied with a mast and sail, and plenty fresh water, with headsman, steersman, and rowers; with harpoons, two of which are attached to the lines, with lances and a buoy to which. a signal is attached, \&c. The boats steer so as to approach the animal from behind, and if there be more than one in view, each boat fastens to a distinct fish, and each crew kill their own. Sometimes the first stroke of the harpoon is mortal, but generally it is otherwise, and the harpooner on the instant, rapid like lightning, darts his second harpoon. On this the animal, irritated by the pain, plunges into the deep; and this movement, which the fishers call "sounding," requires the greatest attention lest the line be entangled. When the line is exhausted, the buoy with its flag is attached to the extremity, and thrown into the sea. This buoy, carried along with the animal, is the compass which guides the boats till they again seize the end of the line when their victim is enfeebled, and its speed diminished by the loss of blood. So soon as its energy is relaxed, the line is carried round the bol lard, and all the resistance is offered that can safely be employed. When the animal requires again to come to the surface, the boat pulls upon the line, 


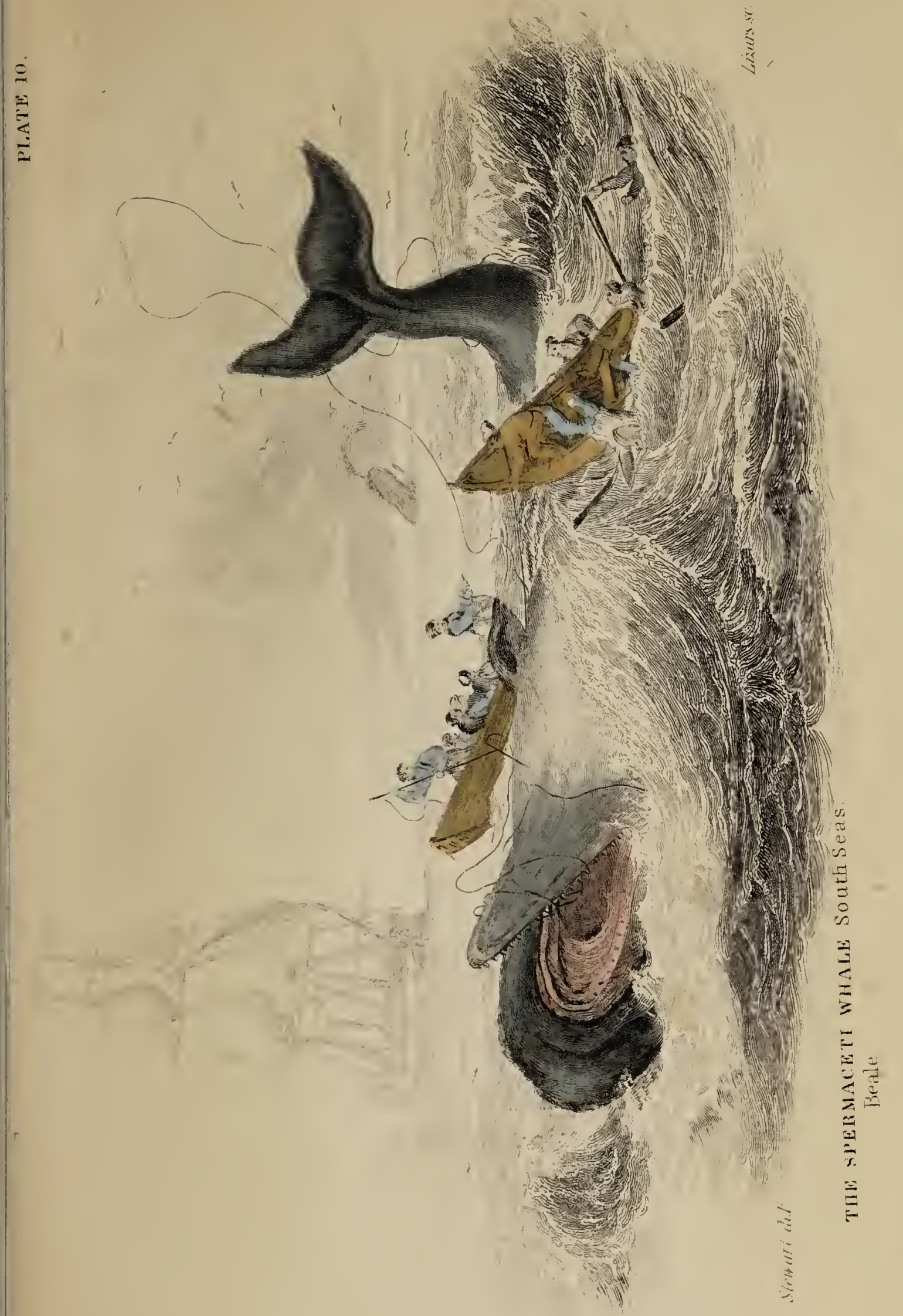


approaches the fast fish as rapidly as possible, and renews the contest. On thrusting or darting his lance, the headsman calls out "Stern-all," when the boat immediately recedes. Upon feeling the lance, the whale generally plunges, and throws itself in all directions, lashing the water with its tail, and threatening destruction with its formidable jaw. The dying struggles are sometimes tremendous, and the hoats at this time generally keep aloof, as otherwise they might be dashed to pieces. (See Plate x.)

The larger whales, such as yield eighty or more barrels of oil, not being nearly so active, are generally, by expert whalers, killed easily, and with less danger than the smaller ones. These enormous creatures, however, are sometimes known to turn upon their persecutors with unbounded fury, destroying every thing that meets them in their course. Mr. Beale was witness of an occurrence of this sort, off the coast of Japan, in July 1832. Captain William Swain of the Sarah and Elizabeth of London had, with two other boats, been engaged in chasing a large whale nearly the whole of the day. At four P. M. the captain was considerably a-head of the other boats, and had succeeded in harpooning it; and, being a dexterous whaler, he succeeded in lancing the animal twice before it recovered from the blow; these wounds having penetrated the chest, caused the abundant ejection of blood through the spiracle: it however suddenly descended to the depth of about forty fathoms, and as suddenly rose, striking the boat with 
excessive force, which threw it into the air in fragments, with the men and every thing it contained. The men, though much bruised, managed to support themselves with oars, \&c. for about three quarters of an hour, when they were relieved by the arrival of another of the boats. All this time the whale continued near them, and several sharks, attracted by the blood. The whale was finally secured.

Numberless stories are told of fighting nhales, one or two of which we shall mention. In the year 1804, the ship Adonis, being in company with several others, struck a large whale off the coast of New Zealand, which "stove" and destroyed nine boats hefore breakfast, and the chase was consequently given up. After destroying the boats belonging to many ships, this whale was at last captured, and many harpoons of various vessels were found in its body. This whale was extensively known under the designation of "New Zealand Tom," and many" traditions about it are carefully preserved.

But it is not boats only, for ships even are sometimes destroyed by these powerful creatures. It is a well authenticated fact, that the American ship, the Essex, was destroyed in the South Pacific Ocean by an enormous Sperm Whale. When the greater part of the crew were absent in the boats killing whales, the few people remaining on board saw an enormous whale come up close to the ship, and when very near, it appeared to sink down for the purpose of avoiding the vessel; and in doing so, struck its body against some part of the keel, which 
was broken off by the force of the blow and floated to the surface. The whale was then observed to rise a short distance from the ship, and to come with apparently great fury towards it, striking one of the bows with its head with amazing force, and so completely staved it in. The ship of course immediately filled, and fell over on her side; in which dreadful position the poor fellows in the boats saw their only home, and many hundred miles distant from the nearest land! On returning to the wreck, they found the few who had been left on board, hastily congregating in the remaining boat, in which they had scarcely taken refuge when the vessel capsized. With much difficulty they obtained a scanty supply of provisions from the wreck, their only support for the long and dreary passage before them to the coast of Peru, whither they endeavoured to make their way. Three only of the whole crew survived; the remainder having perished under unheard of sufferings and privations, over which we willingly draw a veil. These three were found in a state of stupefaction, allowing their boat to drift along where the winds and waves listed. One of the survivors was the master: by kind and careful attention they were eventually rescued from the jaws of death.

The flensing or "cutting in" process is somewhat peculiar. On being attached to the side of the ressel, a frame work is thrown over the fish, and a strap of blubber is cut in a spiral direction, which being raised by certain purchases, turns the fish round as 
on an axis till nearly the whole blubber is stript off. To show how this process is conducted, and as exhibiting a faithful outline, taken by measurement, of a young individual of this genus, we refer to the accompanying cut copied from a sketch of Colnett's.

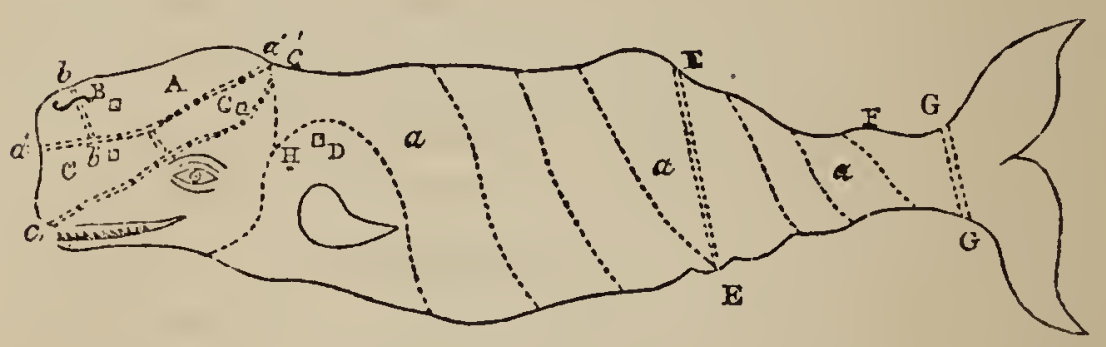

The tackles arc hooked at $\mathrm{D} ; a, a, \alpha$, are spiral stripes successively removed; when removed as far as $\mathrm{E}$, the carcase will no longer "cant" in the tackles, and it is therefore cut through at the line $\mathrm{E}, \mathrm{E}$, and also at $\mathrm{G}$, G, the tail being of no value. The compartment $A$ shews the part of the head which contains the liquid oil. Being suspended by the tackles, the front part is cut off at $b, b$, and the oil baled out witl buckets. When the whale is small, the hear is divided at the line $c^{\prime}, c^{\prime}$, previous to its bcing looisted on deck; the space bctween $a^{\prime}, \alpha^{\prime}$, and $c^{\prime}, c^{\prime}$, also contains much oil. $\mathrm{B}$ is the blow-hole; $\mathrm{H}$, the ear.

The head matter when congealed is put into casks in its crude state, and refined at the conclusion of the royage. The blubber, however, is reduced into oil immediately in "try-works," with which every ship is provided for the purpose. The coppers in the try-works are two in number, and are placed near the fore hatchway; they are surrounded with a casing of brick-work, which forms a cistern, the water in which is changed every two hours so as to defend the deck from injury. The fuel is the blubber fritters, which produce a fierce fire. A large 
fish produces about three tons of oil, a small one from one to two. A hundred whales sometimes go to form the cargo of a ship, the produce of which, in boiled sperm oil, may be from one hundred and fifty to two hundred tons, besides head matter.

The South Sea fishery was not regularly established as a branch of British trade till towards the close of the last century. The vessels are usually between three and four hundred tons burden; and the voyage occupies frequently three and even four years; but when all kinds of whales are attacked, it may be stated as lasting from twenty months to two years. In the course of the voyage they occasionally put into harbours to refit and refresh the crew. The officers and crew are stimulated to exertion by certain shares of the cargo obtained. The captain receives perhaps a twelfth; the harpooner a fortieth, \&c. Several years ago, the complete outfit amounted, besides the ressel, to about $\mathscr{L} .4000$, and a cargo of the highest value might yield $\mathfrak{E} .25,000$ or $\mathscr{E} .30,000$. The success was tolerably certain; and the trade has been found upon the whole lucrative. In 1791, seventy-five vessels were engaged; but the number has not since been so great. In 1830, only thirty-one ships were sent out, of the burden of eleven thousand tons, all from the port of London, carrying nine hundred and thirty-seven men. The relative values of the products of the different fisheries may be seen frost the 
market quotations of November 1835. Sperm oil, L.75 per ton. Greenland, $\mathfrak{L} .40$. South Sea oil, L.42. Pale seal, $\mathfrak{E} 43$. Whalebone from northern fishery, $£ .250$ per ton. Whalebone from southern fishery, £.145.

The Anrericans for a long time have prosecuted this trade with great vigour, and more success perhaps than any other people. They commenced it in 1690, and for about fifty years found an abundaut supply of fish on their own shores; but the whales having abandoned these resorts, the American navigators entered with extraordinary ardour into the fisheries carried on in the northern and southem sceans. Mr. Burke, in his famous speech on American affairs in 1774, adverted to this wonderful dis$\eta$ lay of daring enterprise as follows :- "While we are carrying on the whale fishery under the Arctic circle, we hear that they have pierced into the opposite region of Polar cold; that they are at the antipodes, and engaged under the frozen serpent of the south. Falkland island, which seems too remote and too romantic an object for the grasp of national ambition, is but a stage and resting-place for their victorious industry. Nor is the equatorial heat more discouraging to them than the accumulated winter of both poles. We learn, that when some of them draw the line or strike the harpoon on the coast of Africa, others run the longitude and pursue their gigantic game along the coast of Brazil. No sea but what is vexed with their fisheries. No climate that is not witness of their toil. Neither 
the perseverance of Holland, nor the dexterous and firm sagacity of English enterprise, ever carried this most perilous mode of hardy industry to the extent to which it has been pursued by this recent people; a people who are still in the gristle, and not hardened into manhood."

Within the last few years the colony of New South Wales has been busily employed in this branch of commerce, and with great benefit to those engaged in it. The colonists are situated so much nearer the fishing grounds, that neither the time mor this expense of outfit can be compared with that of the ships equipped from Britain. Of sperm oil there was exported in 1835, two thousand nine hundred and eighty-nine tons, valued at $£ .151,738$; and of hlack oil, fourteen hundred and seventy-seven wns, valued at $\mathfrak{L} .19,357$.

We annex, from Mr. Beale's work, a very condensed enumeration of the rarious stations in which this whale has been scen in greatest number:-New Guinea, New Iceland, New Britain, King's Mill Group, Byrou's Island, equinoctial line from longitude $169^{\circ}$ to $175^{\circ}$ east; Ellis Group ; off the east coast of New Holland; off New Zealand and the Navigators' Islands, coast of California, Chili, and Peru; the Gallapagrs; the Moliuccas; Straits of Timor; the Mozambique thannel; off Japan ard the China seas; Lonchar Islands, \&c. \&c.

These localities, $\mathbf{i}$ will ? observed, are all in the southern hemisphes:; but it must not thence be inferred that Sperr. Whales are confined to its seas. 
We have seen that at one time they frequented the shores of North America, and they are also found in the Northern Pacific. Though not observed in great troops, yet they are said to be sometimes taken in Orkney and Shetland (Statistical Account, v. 190), and they are occasionally stranded on the British coasts. Thus Mr. Pennant states that a large specimen was stranded on the coast of Norfolk, which is particularly commemorated by Sir Thomas Brown (Zoology, ii. 500); one came ashore, fiftytwo feet long, in 1689, at Limekilns in the Forth, and is described by Sibbald; two others, each measuring fifty-four feet, were in 1769 cast ashore near the village of Cramond in the same Frith (Statistical Account, i. 220); and one, sixty-three feet long, was in 1756 stranded on the west of Ross-shire: one, fifty-eight feet long, was stranded on the Yorkshire coast, as noticed by Mr. Anderson in the Trans. of the Cambridge Phil. Soc. for 1827; seventeen were cast ashore in the Elbe in 1723, half of which were males; and thirty-one, in 1784, were stranded at one time in the Bay of Audierne in Lower Brittany, nearly all of which were females. (Fr. Cuvier's Hist. p. 268. 271.) It would thus however appear they are, alive or dead, but rare in this part of the world.

On its introduction into commerce, spermaceti, to which, when refined, the French have applied the name of cétine, was chiefly employed in medicine, in which its use is still continued. It has also been freely used in the cosmetic art. Its largest and most 
valuable application, however, has long been in the manufacture of candles, in which it maintains a considerable rivalry with wax, as cheaper and not less elegant and agreeable.

Ambergris, according to its quantity, is a peculiarly valuable product of the Sperm Whale; often, however, we might say generally, it is not at all found in them. Sometimes it sells in London not much under $£ .1$ an ounce, but frequently two or three voyages are accomplished, and successfully too, without any ambergris being obtained. It is seldom or ever found in the young fish ; but only in those of full size, or rather of great age. It is generally considered the result of some diseased process in the intestinal canal, to which the individual has been subjected. The quantity obtained, therefore, is very various. The mate of the Ocean reported to Messrs. Quoy and Gaimard, as an extraordinary occurrence, that, on one occasion, he extracted fifty pounds from a single animal. We remember seeing it stated on good authority, that a single piece of precisely the same weight was found by some sailors on the coast of the Bermudas, who, calculating that they had made their fortune, lost no time in escaping to England. Still larger masses sometimes, though rarely, have been found; the largest we have seen mentioned weighed two hundred pounds. ( Fr Curier's Hist. 303.) Ambergris is found in considerable quantity on the coasts of the Indian Archipelago. It is highly esteemed by the Malays, as by most orientalists; some of whom reserve it ex- 
clusively for the use of the rajahs. The coasts of Formusa, of the Molluccas, of Brazil, the Antilles, and Madagascar are also famous for it. It occurs also, but in much smaller quantities, in the Baltic and other European shores. Its use is almost wholly confined to the perfumer.

Among many of the South Sea islanders a most extraordinary value is attached to the teeth of this animal. They offer them as gifts to their idols, or adorn with them their queens. In their estimation, they form the ne plus ultra of what is valuable; and thus they become the most precious subjects of barter, by which most of the whale captains purchase fresh provisions for their crews, or what else of value can be obtained on the islands. It has been mentioned that the inhabitants of the Marquisas consider a good one equal to great riches; and the same is the estimate made by the inhabitants of Fidjis, Rotouma, and by many others of this singular and simple race. 


\section{1}

THE HETERODONS.

Leaving the large headed whales, we come now to the second subdivision, which has been proposed by Blainville, and adopted by Lesson and other systematists. Besides having the head of the ordinary proportion which, with other characters, distinguishes it from the first subdivision, it is distinguished from the third and last chiefly by the teeth. Whilst this third is almost uniformly supplied with a great number of teeth in both jaws, amounting sometimes to hundreds, this second subdivision has generally a very small number indeed, which are moreover very heterogeneous, confined sometimes to the one jaw, and sometimes, in other genera, to the other. Sometimes, as in the narwhal, they are not within the mouth at all; and several genera are believed to be even still more destitute of teeth. From this great paucity, and also from their variety, Blainville has denominated this subdivision heterodon (from érsgos and $0 \delta \delta_{5}$ ). It will be perceived that the character is not a very striking, or perhaps even a very natural and positive one : but, as we presume not to introduce a new classification ourselves, we take it as we find it, and follow it as far as it goes, because we regard it useful. It includes the Narnhal or Sea Unicorn, the Diodons or two-teethed whales, the Hyperoodon of Cuvier, the Aodon or toothless whale; and the Ziphius, which includes some of the most important fossiles which have been discovered. 


\section{Fourth Genus.-NARWHALUS.}

Distinguishing Characters.-This genus has no teeth, properly so called, but only two tusks, long and pointed, usually called horns, springing from the intermaxillary bones, and directed forwards in the axis of the body; it has no dorsal fin.

THE NARWHAL, OR SEA UNICORN.

\section{PLATE XI.}

N. Microchephalus, Bon. Lacépède, Desm.-Monodon Monoceros, Lin., Fab.; popularly known as The Sea Unicorn.

Tris long established genus had been very much the creation of fancy ; and as, from the peculiarity of its singular horn, it excited much interest, so the errors connected with it have been very widely spread. Both Lacépède and Desmaret have three species; the first of which, the large headed, was represented as a great oval animal sixty feet long, with a murderous horn of sixteen feet in length, with which, in troops, it waged deadly warfare with the mightiest inhabitants of the ocean, and made them an easy prey. This species, however, is a mere figment, the product of ignorance and exaggeration. The third species, Narwhalue Andersonii, does not rest on any more solid foundation, so that the genus really comprehends only one species. 


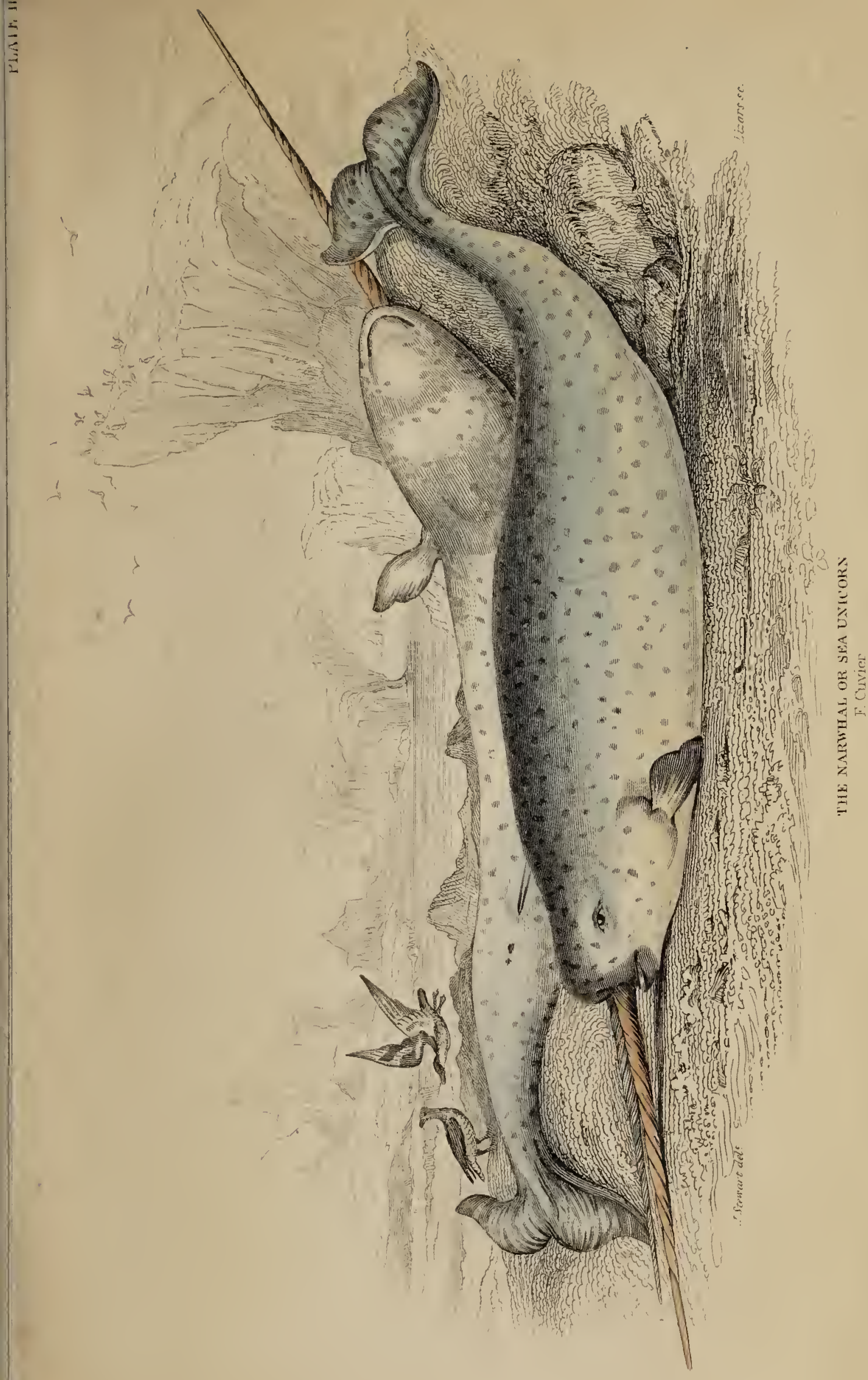



A considerable number of notices have now been collected of this curious animal, from which a tolerably accurate account may be given of its appearance and habits; one of the most accurate of these, with an excellent drawing, was published by Dr. Fleming in 1808, in vol. i. of the Trans. of the Wernerian Soc. The length of the Narwhal is now usually stated, in our more popular works, to be about fifteen or sixteen feet, which is to be understood exclusive of the tusk; so that with this striking appendage, it reaches to from twenty to twenty-six feet. The animal which was stranded at Boston in Lincolnshire, and of which a drawing was sent by Sir J. Banks to Lacépède, and from which he took the characters of his Microcephalus, was stated to be twenty-five feet long. This perfectly agrees with Mr. Sowerby's account of the same specimen, which was published one year after the Count's. Sir J. Banks, in a letter to Dr. Fleming, states, that this animal, when found, had buried the whole of its body in the mud of which the beach was composed, and seemed safely and securely waiting the return of the tide (Brit. Mis. i. 17). Mr. Sowerby moreover reports, that this individual, which was exhibited both in London and Cambridge, was wholly covered with a black and horny substance, like some kinds of tortoise-shell, composed of lamina an inch or more in thickness. Tulpius also states the size of another, supposed to have been caught near the Island of May, to have been twenty-two feet. The head comprehends about one-seventh 
part of the whole length; and behind it there is a slight depression, which points out the line of separation between the head and body. The forehead rises suddenly, almost perpendicular from the mouth, and then proceeds for a few inches in a horizontal direction, when it becomes slightly elevated. On this point the spiracle is situated; it is directly over the eye, and measures about four inches, by one and a half. From the neck, the back swells gradually to a few inches behind the pectoral fins, where it is thickest. On the upper and lower parts, and on each side, slight ridges may be seen, which give to the body, especially towards the tail, somewhat of a quadrangular form. The pectorals are remarkably small for the size of the animal, elliptical and somewhat curved, with their thickest edge forwards. The tail is about twenty inches long and about four feet broad. It has no dorsal fin; but in place of it, there is an irregular, sharp, fatty ridge, two inches in height, extending between two and three feet along the back, nearly mid-way between the snout and tail.

The prevailing colour of the Narwhal is blackishgrey on the back, variegated with numerous darker spots running into each other, and forming a duskyblack surface; with paler and more open spots of grey on a white ground at the sides, which spots disappear altogether on the belly. In old animals the ground is wholly white or yellowish-white, with dark-grey or blackish spots of different degrees of intensity; on the belly extremely faint and few, and 
in considerable surfaces, none at all are to be seen. In sucklings the colour is wholly a bluish-grey or slate colour. In one which was stranded in the Elbe in 1736, Anderson states the skin was white as snow, and marked with many dark spots to a considerable depth; the abdomen was every where white and glistening, and soft to the touch like velvet.

The Narwhal has no true teeth in either jaw; but in the upper are found the most distinguishing characters of the genus, two long straight and pointed tusks, like spears, spirally twisted, and implanted into the bones of the upper jaw-the intermaxillaries; their direction is forwards, somewhat downwards, parallel to the palate bones. There is literally no trace of any other teeth. When very young, the germ of the teeth can be discovered on each side of the mesial line, the subsequent elongation of which produces the sharp tusk of the adult. Sometimes both germs are developed, and produce two horizontal and diverging spears. Among a considerable number of instances which might be adduced, we mention only one beautiful exhibition of this more perfect developement, which is preserved in the museum of Roeding at Hamburgh. In this specimen, when they start from the bone, the tusks are only two inches apart, but they steadily diverge and their points are thirteen inches asunder. The left tusk is seven feet five inches, and the right seven feet long. It much more frequently happens, however, that only une of these germs grows; and that 
the other, somehow strangled, is almost obliterated and remains shut up in the bone, like an inert osseous nut. From this appearance, which is by much most frequently seen, has resulted the many names which the Narwhal has received, such as Monadon, Monoceros, and Unicorn; although the early authors, previous to Linnæus, were not ignorant that the rudiments of two existed. It is curious that the tusk is usually found on the left side, and we do not know that any sufficient reason has been assigned for this circumstance. At one time it was stated that the tusks were peculiar to the males; this is now however found to be incorrect, and it seems doubtful whether they are not as common in the one sex as the other. Fabricius' account is probably the correct one:- "Ceterum tam fominae, quam mares, dentatoe." This naturalist, alike distinguished for his elegance and accuracy, seems to have anticipated those who would put in a claim to originality as to the internal structure of the tooth; we again quote his words, "Radice cavus, quoe cavitas, ut medulla totum fere dentem transit." It consists of a very fine compact kind of ivory.

The use of this tusk is somewhat doubtful, and many purposes sufficiently absurd have been assigned for it. Several hints, however, have been thrown out by the ingenuity of Mr. Scorseby, which, upon the whole, we regard as satisfactorily explaining its use. Thus, in his "Arctic Regions," he remarks, from the extremity of the tusk being 
smooth and clean, whilst all the rest is rough and dirty, and especially from a broken tusk being found rubbed down and rounded, it is not improbable it may be used in piercing thin ice, for the convenience of respiring, preventing the neccssity of retreat into open water." (491). And again in his "Journal of a Voyage," \&c. we find the following interesting statement :- " My father sent me the contents of the stomach of a Narwhal killed a few leagues to the westward of us, which were very extraordinary. They consisted of several half-di gested fishes, with others of which only the bones remained. These were remains of a cuttle fish, part of the spine of a flat fish, probably a small turbot, and a skate almost entire. The last was two feet three inches in length, and one foot eight inches in breadth. It comprised the bones of the head, back, and tail, the side fins, and considerable portions of the muscular substance. It appears remarkable that the Narwhal, an animal without teeth, a small mouth, and with stiff lips, should be able to catch and swallow so large a fish as a skate, the breadth of which is nearly three times as great as the width of its own mouth. As the animal in which these remains were found had a horn of seven feet, I apprehend that this instrument had been employed in the capture of the fishes on which it had recently fed. It seerns probable that the skates had been pierced with the horn and killed before they were devoured; otherwise it is difficult to inagiile how the Narwhal could hare swallowed 
them, or how a fish of any activity would have permitted itself to be taken, and sucked down the throat of a smooth-mouthed animal, without teeth to detain and compress it."

The eyes are small; the orbit is oval, the iris chestnut colour, the sclerotic white. According to Scorseby, there are seven cervical, twelve dorsal, and thirty-five lumbar and caudal vertebræ, in all fiftyfour.

The Narwhal is regarded a migrating animal by the Greenlanders; its favourite resorts seem to be amongst the ice of the Northern Pole, in the creeks and bays of Greenland, Davis Straits, and Iceland. In these localities it is occasionally very abundant, while, when seen further south, it appears as if it had gone astray. Solitary and separated from its kind, it may be found wandering near the shores of Britain, or of Northern Europe. We believe it is scarcely ever found in southern latitudes, and its home seems to be between the $70^{\circ}$ and $80^{\circ}$ of north latitude.

A pleasing account is given of this animal in the following quotation from Mr. Scorseby:- " A great many Narwhals were often sporting about us, sometimes in bands of fifteen or twenty together: in several of them each animal had a long horn; they were extremely playful, frequently elevating their horns, and crossing them with each other as in fencing. In the sporting of these animals they frequently emitted a very unusual sound, resembling the gurgling of water in the throat, which it probably 
was, as it only occurred when they reared their horns, with the front part of the head and mouth out of the water. Several of them followed the ship, and seemed to be attracted by the principle of curiosity, at the sight of so unusual a body. The water being perfectly transparent, they could be scen descending to the keel, and playing about the rudder for a considerable time."

Narwhals are quick, active, inoffensive animals. They swim with considerable velocity. When respiring on the surface, after blowing repeatedly with much force, they frequently lie motionless for several minutes with their back and heads just appearing above water. When harpooned, they dive in the same manner, and with almost the same velocity as the mysticetus, but not to the sime extent. They generally descend about two hundred fathoms, then return to the surface, and ire despatched with the lance in a few minutes. Near the coast, according to Giesecki, they are always seen in flocks, in the severest winter, amidst the fissures of the fixed ice, in the bays from $70^{\circ}$ north latitude to the extremest north. The Greeninnders drive them with their sledges to fissures of the ice, where the animals generally come up to take air, and there kill them with their harpoons and guns.

By the Greenlanders the Unicorn is regarded as the precursor of the mysticetus, and as soon as it is noticed, they prepare in right earnest for the fishing, having learned by experience that wherever the 
Narwhal is, there, or in the immediate neighbourhood, will be found the whale. This probably arises from their using the same kind of food.

The blubber, encompassing the whole body from two to four inches in thickness, supplies about balf a ton of oil, which is regarded of very superior quality. The Greenlanders regard both the oil and the flesh as very delightful nourishment. At a time when the origin of the horns of these animals was less known, and when they were more rare than in the present day, they were considered as invaluable, and brought a high price. The physician, and still more the charlatan, employed them, and superstition converted them to its own use; for it is stated that the monks in various convents procured the true horn of the unicorn, endowed with unheard of powers, and far and near obtained for them the credit of curing the most inveterate diseases. The ivory is esteemed superior to that of the elephant: in the words of Giesecki, it far surpasses it in all its qualities ; it possesses extreme density and hardness, has a dazzling whiteness, which does not pass into yellow, and easily receives a very high polish. It is said that the kings of Denmark possess a magnificent throne made of this precious material, which is preserved with great care in the Castle of Rosenberg; and, at the present day, the horns are highly valued as an article of trade. 


\section{Fifth Genus.-DIODONS.}

The general characters may be stated to be, their having two teeth only in the lower jaw, none in the upper; forehead depressed; lower jaw much larger than upper, and convex.

DIODONS, OR TWO-TEETHED WHALES.

Several species are said to belong to this genus; different, of course, from Hunter's, subsequently discussed. The first we mention is, according to Lesson, the

\section{DIODON DESMARESTL}

Delphinus Desmaresti, Risso.

Risso (Hist. Nat. Nice. t. iii. pl. 2. fig. 3.) describes this cetaceous animal as having a very thick body, especially in the middle, diminishing towards the extremities, and becoming lank in the abdomen. forehead not prominent, but depressed, terminating yy a long muzzle; upper jaw short and without teeth; lower jaw much larger, convex below, and having near its extremity two large conical teeth, three inches long and one broad; the eye small and oval, with blue iris; spiracle large, semi-lunar; pectorals short, dorsal nearly over the vent; tail 
large and festooned. The upper portion of the head and body of the colour of polished steel, with a number of lines and white streaks, occurring without regularity; belly white; inside of the mouth bluish black. Length of the specimen fifteen feet. According to Risso, this species frequents the depths of the Mediterranean, where it is rare: he supplies no information regarding its habits.

We are glad we can present to the reader a representation of the second species, according to Lesson. It is the

\section{DIODON SOWERBI.}

\section{PLATE XII.}

Delphinus Sowerbi.-Desmaret, Blainville.

Our Plate of this beautiful animal was taken from an individual cast ashore near Brodie-House, Elginshire, and was described by Mr Sowerby in his British Miscellany. We have not been able to procure a sight of Risso's plate of the preceding species, but no one can fail to remark a very striking resemblance between Risso's description and the animal now under review; so much so, that notwithstanding Lesson's authority, we are almost tempted to think they must be identical. Their habitat can Bcarcely have been the same 
ت

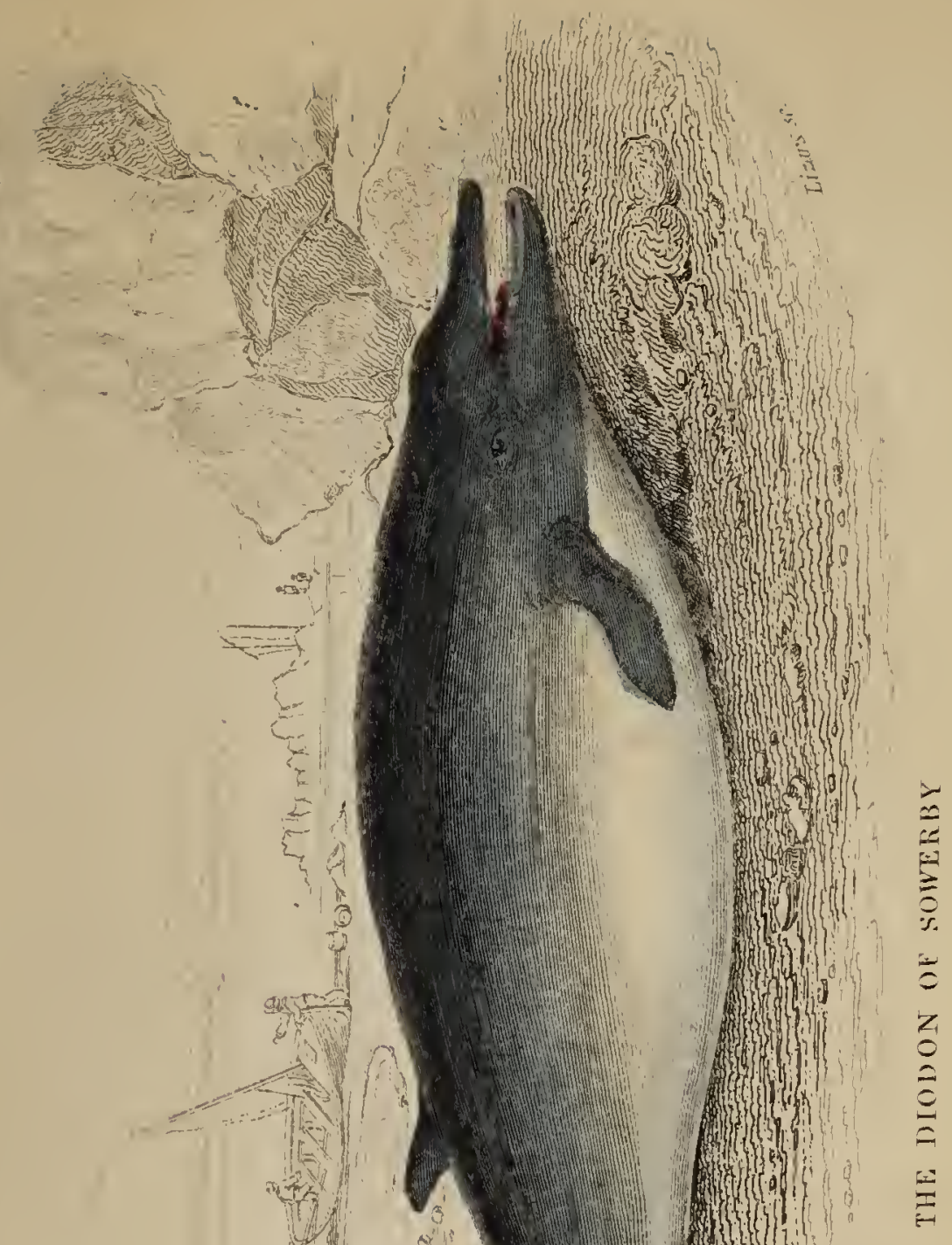



By looking at our plate, and perusing the description of Sowerby, we learn that the body of this beautiful animal is thick, especially in the middle, diminishing towards the extremities; the forehead is not prominent but much depressed, and terminates in a long muzzle. Mr. Sowerby states that the lower jaw is blunt, longer than the upper, with two short lateral teeth, constituting the distinguisliing characteristic of the species; the upper jaw, wholly without teeth, is sharp, let into the lower one, and has two depressions corresponding to the teeth; the eye is very small and oval, the spiracle is stated to be lunated, with its horns pointing forwards; the pectorals are small; the dorsal is over the vent; the tail large and festooned. The colour is black above and nearly white below, and satiny all over. Immediately under the cuticle the sides were observed to be completely covered with white vermicular streaks in every direction, which at a little distance appeared like irregular cuts of a small sharp instrument. The length was sixteen feet, and the circumference eleven at the broadest part. The habitat and habits of this species are wholly unknown. In fact, this is the only specimen which nas hitherto been noticed and described. 


\section{Sixth Genus.-HYPEROODONTES*}

\section{Lacépède, Cuvier.}

Characters.-Three enormous maxillary crests rise over the cranium and are separated by deep furrows; these occasion the remarkably rounded and prominent forehead, with the short and strong beak; pulate supplied with small false tisberculous teeth? The horns of the crescent-shaped spiracle turned backwards.

\section{HYPEROODON HONFLORIENSIS.}

\section{PLATE XIII.}

Hyperoodon of Honfleur, Less.-H. Butskopf, Lacépède.-Delphinus Butskopf, Bon._-D. Hunterii, Desmaret.-D. Bidentatus, Hunter.-Bottle-head of Dale? called Bottle-nosed Whale by Hunter in his Plate xix.

IT may be observed that we avoid every thing like critical disquisition concerning classification and nomenclature, though these are most important as it regards the progress of the science. We do so from the conviction that such discussions are unsuited for a popular work of this nature. It may, however, interest our readers, for once, to have a specimen of the manner in which in these inquiries error slips in, and confusion results ; and we shall, therefore, here adduce a few particulars concerning the important genus under consideration, premising,

* From uxiguy and ojovs, teeth in the palate. 


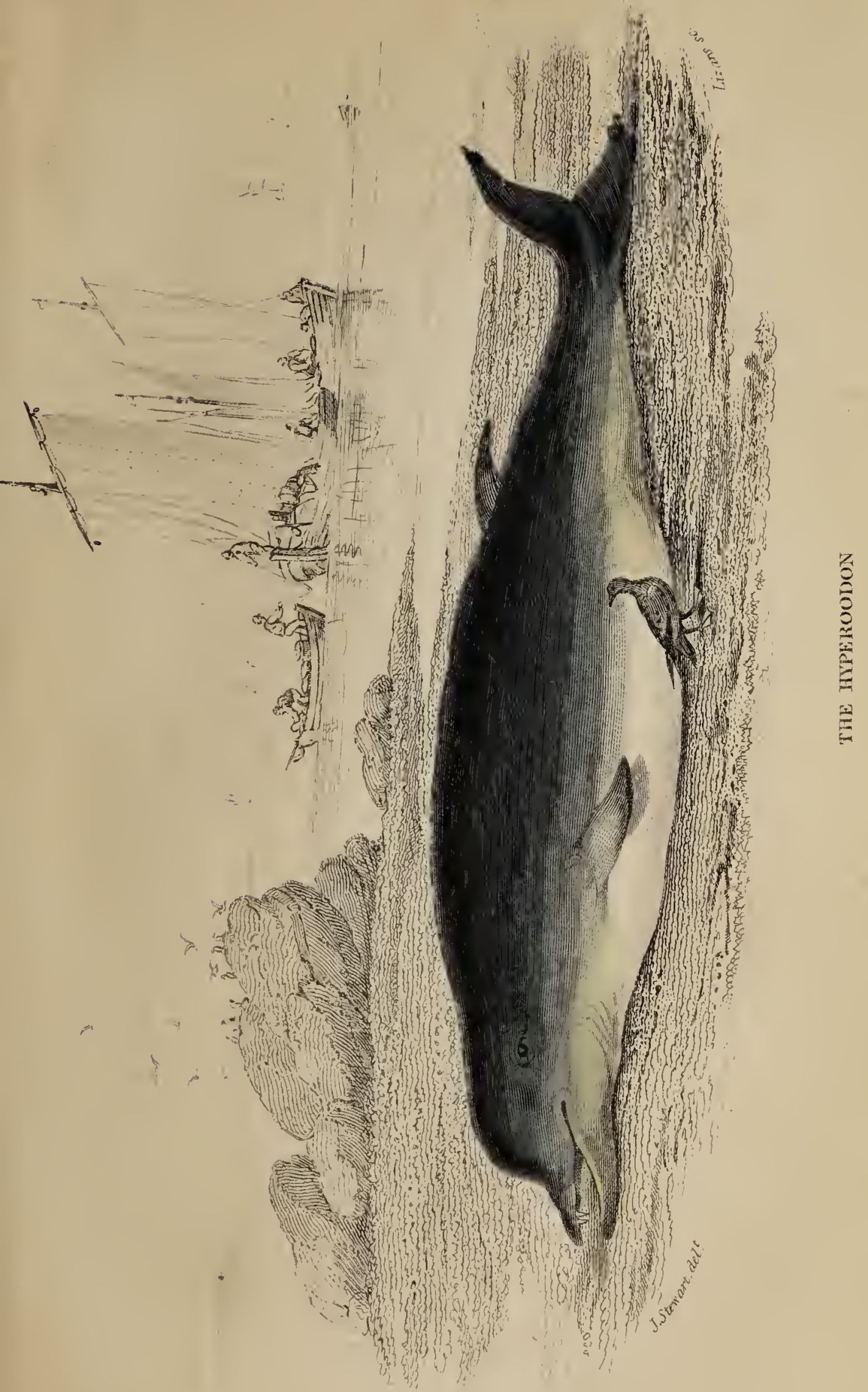



that we select this instance rather because the confusion is confined within narrow limits, than because it exhibits an average degree of the entanglement in which every department of this subject is involved.

This genus was admitted upon the authority of M. Baussard, an officer of marine, who examined two individuals, mother and cub, which were stranded near the small village of Honfleur, and who with laudable zeal published an account of them in the Journ. de Physique, 1789. The circumstances on which the claim of these specimens to be considered generic rests, are the total want of teeth in either jaw, and their having the upper jaw and palate furnished with small unequal and hard points, which were about half an inch long in the cub, and somewhat longer in the mother.

Baussard's memoir appeared subsequent to Hunter's description (Phil. Trans. 1787) of his Delphinus Bidentatus, which was admitted as distinct by Bonnaterre, Lacépède, \&c. Hunter says nothing of false teeth in the palate, and mentions that two strong and robust teeth existed at the extremity of the lower jaw.

These then were long regarded as two species. Bonnaterre, in describing the individuals examined by Baussard, very unaccountably assigned to them two teeth in the lower jaw, and he thus very naturally misled Lacépède, Illiger, and, for a time, Cuvier (Reg. Ani. 1817, i. 281). It was probably when holding this opinion that Cuvier, on visiting Mr. Hunter's museum in London, and examining 
the head of his Bidentatus, came to the conclusion that Baussard's and Hunter's specimens were one and the same species ; belonging, however, to a genus perfectly distinct from all others. He attached the name Hyperoodon to both, and in this has been followed by Desmaret, Lesson, and others to the present time.

But this is not all. Bonnaterre had applied the specific name Butskopf to Baussard's specimens. Butskopf by others, again, was considered the same as Flounder's-head; but this last appellation was applied by Dale to the animal described by him under the name of Bottle-lend; and Cuvier remarking (Oss. Foss. v. 325) that Dale's figure and Baussard's very much corresponded, conjoined this Bottle-head to the Hyperoodons; in this following Hunter, who expressly says (Phil. Trans. 1787, 447) that his second Bottle-nosed Whale is the same as that described by Dale. Once more we have to add, that the Bottle-head of Dale is by Blainville identified, as we apprehend incorrectly, with the toothless whale which comes next to be described, and which is a very different animal.

The Hyperoodon is peculiarly characterized by these alleged false teeth in the upper jaw ; but even allowing that these are not to be found in any species, still the name has been affixed to a genus which without doubt exists, and which is made conspicuous by marked peculiarities. The form of the head alone distinguishes it from the aodon, the only one of the Cetacea to which it approaches. More 
over, the snout is flat, and the horns of its spiracle look backwards (Cun. Oss. Foss. 325); while in the aodon the snout is nearly cylindrical, and the horns of the blow-hole look forward. (Lesson. 133). Besides, there are three great occipital and maxillary crests, which go over the head, and are separated by deep furrows. Cuvier remarks concerning it, this cranium differs entirely from the form peculiar to the dolphins, and alone requires that the animal should be placed in a distinct genus. (Oss. Foss. v. 226.)

As characters, then, we adduce the peculiar form of the head and skeleton; the head being higher than it is broad: the forehead, which is very prominent, terminates suddenly in a flat beak, which is oval at its extremity. The pectorals are very small ; and the dorsal, but little developed, is within a fifth of the whole length, from the tail. The colour is a brownish black, verging towards white beneath. Its usual dimensions are upwards of twenty feet. It appears to be a rare variety, and not to live in herds. It has very seldom been met with. Its habits are very little known. Hunter's specimen was caught in the Thames above London Bridge. Besides the skeleton of this one in his museum, Cuvier states there was also the cranium. of another of the same species, which must have belonged to an individual nearly forty feet in length. 


\section{Seventh Genus.-AOUuns.}

Characters.-Body fusiform; distinct appearance of neck; forehead prominent; blow-hole with horns projecting forwards, jaw prolonged in form of a subcylindrical beak, in same continuous line with the head; no baleen; no teeth; no rugosities on the palate.

\section{A. DALEI, Less*.}

PLATE XIV.

\section{THE TOOTHLESS WHALE OF HAVRE.}

Delphinus Dalei, Blainville; Fr. Cuv. Mam.-Delphinus Edentulus, Schreb. Desmaret.-D. Micropterus, Cuv. R. A. 1829 ; Fr. Cuvier, Hist. des Cet.

Tris elegant whale belongs to the genus Aodom, which is characterized by having no baleen and no teeth. It is the only known species of the genus, and is with much hesitation, and we think erroneously, by Fred. Cuvier and Blainville, made to correspond with the dolphin of Dale, which appears to be identical with the genus last discussed.

The specimen of the animal now before us was stranded in 1825, near Havre; was examined by

* Tliough we believe this to be a complete misnomer, yet we retain it, because under this name the species has been satisfactorily described by Blainville and Lesson. 


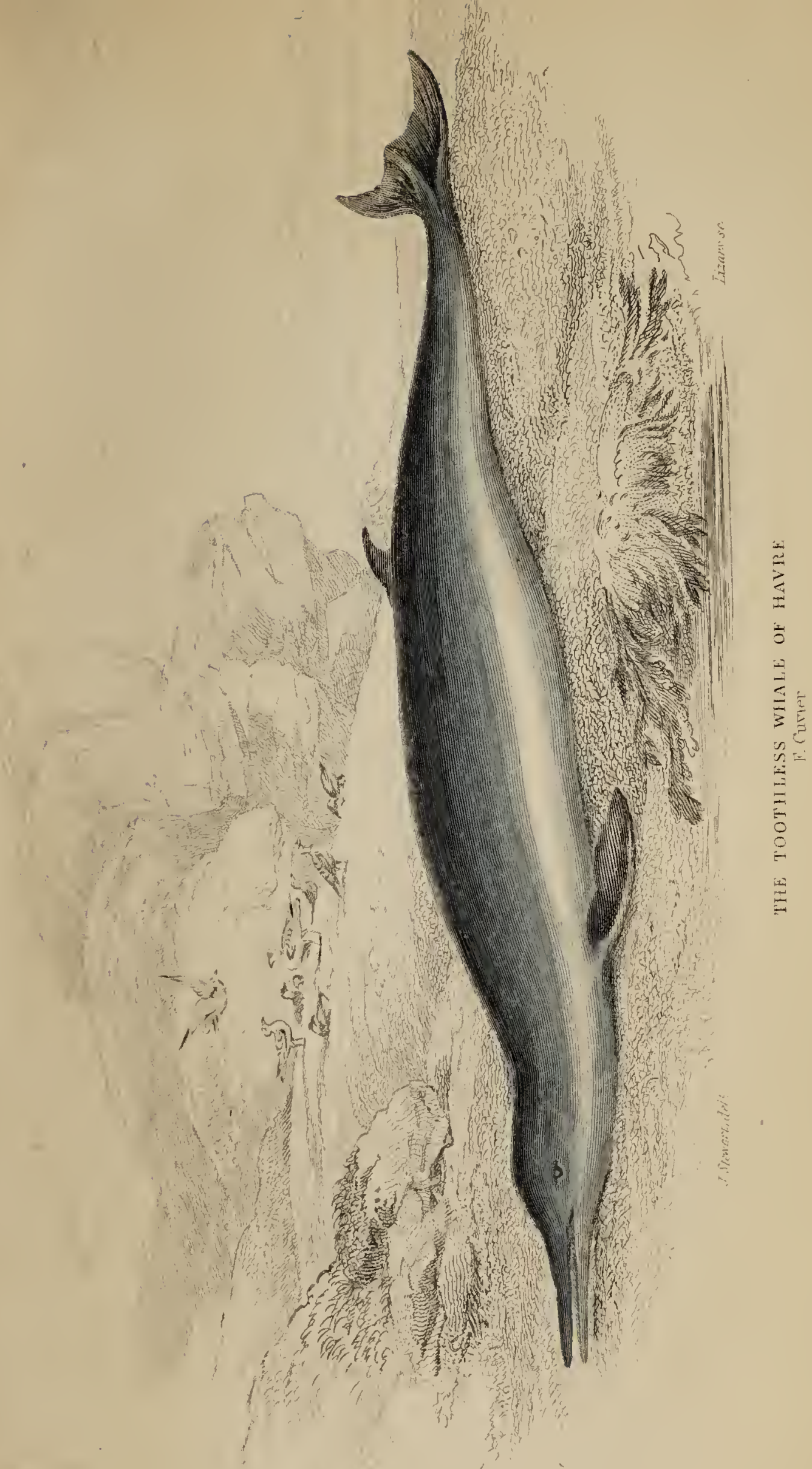



Blainville, Dr. Suriray, and the son of M. F. Cuvier; was delineated by Fred. Cuvier, and its skeleton deposited in the Paris Museum; so that few of the Cetacea are more accurately known. The English name we have applied from the locality in which it was found.

It has been remarked that the Aodon and neighbouring genera form the links of the chain between the larger whales and the dolphins, and we shall perceive presently that there is some ground for this opinion. The length of the specimen now under consideration, which was of a young one, was fifteen feet, and seven feet and a half in circumference. The head, which was distinguishable from the body by a marked neck, was two feet and a half long from the extremity of the beak to the occiput; the body, largest in the middle, became smaller at both extremities. Seen in profile, the dorsal line was curved over the head and over the middle of the body, whilst the under line presented nearly a regular curve. The muzzle was round, long, strait, and perfectly resembled a bird's beak. No teeth were discovered in either jaw in the recent state; but after the gums were removed, a few, in a rudimentary state, as happens in the upper jaw of the cachalots, \&c., were found in the lower jaw. The spiracle was two feet three inches from the extremity of the beak; and its horns were directed forwards. The eye was large, its longitudinal diameter measuring two inches; it had an upper eyelid, but no trace could be discovered of a conduit to the ear, either 
during life or after death. The pectorals were very small in proportion to the size of the animal, being only eighteen inches long and six wide, situated three feet four inches from the front; the dorsal also was very small, a foot high, twelve feet from the anterior extremity. The general colour was grey; dark above, and gradually becoming whitish beneath. It possessed all the brilliancy of tint and softness which characterizes the Cetacea.

These are the characters, drawn by Blainville, of this beautiful and delicate looking animal, of which we know of but one individual, as of one species. They appear quite sufficient to distinguish it from all the other genera. It would appear to be very rare; and of its habitat, disposition, and habits we. know nothing. 


\section{Eighth Genus.-ZIPHIUS.}

OF the next genus, Ziphius, introduced by Cuvier, we shall, in this place, allude but to one of the three species he has established, and this for the purpose of satisfying the reader of the accuracy of those general statements we have formerly made concerning this most important, but somewhat dry portion of the order. The genus is fossile. The specimens, or rather fragments, which Cuvier possessed, were found in various parts of Europe. He states that their craniums ally them to the Cachalots, and still more to the Hyperoodons, many of the distinguishing characters of which they possess. They all appear to have been quite destitute of teeth.

ZIPHIUS PLANIROSTRIS (Cuv. Oss. Foss. v. 352).

This species was formed on the examination of many heads which were discovered in 1809 , completely petrified, in excavating the docks at Antwerp, where they occupied the deepest parts. They were lying half a mile from the banks of the Escaut, thirteen feet above the lowest run of the water, and thirty feet under the mean level of the town, below several strata of sand and clay, of various thickness, which contained a great number of shells and teeth of sharks, \&c. It would appear clear that this species never could have had any teeth, and to use Cuvier's words, it is certain that there are none of the Cetre whose osteology is known, which exhibits a structure similar to that which belongs to this tribe. 


\section{THIRD SUBDIVISION.}

Previous to the present century, the whole of the remaining ordinary Cetacea, which go to form the third subdivision, were, with those of the subdivision we have just left, classed by naturalists under the general term Delphinus, or Dolphins. Whenever, in fact, one of the Cetacea was discovered whose head bore the usual proportion to the body, and whose jaws were supplied with teeth, it was ranked as a dolphin. When the number of known species was but small, and the characters but ill defined, this arrangement was perhaps sufficient; but nowa-days, when their number is greatly increased, and when those who know the subject best declare that a small proportion only of those which really exist have hitherto been described, it becomes necessary to multiply generic divisions; and the term dolphin must be restricted to an individual, though very numerous genus. Lacépède led the way in this division, by the introduction of his $\mathrm{Del}$ phinaptera, which was immediately adopted by Cuvier, Scorseby, \&c. Cuvier, again, separated the Porpoises from the dolphins; and Blainville increased the number of genera by adopting the Oxyptera (Cetæ with two dorsal fins) of Rafinesque, and introducing the Delphinorlyncus. Lesson has still further added to this list. To us it appears that the present state of the science requires no fewer than the following divisions, which in this place we shall do no more than enumerate. The first section 
A. Includes those which have no dorsal fin.

Genus $a$. Having the head globe-shaped. Beluga.

b. Having a slender beak. Delphinapterus.

$B$. Includes those which have a dorsal fin.

Genus $c$. Having the liead globe-shaped. Globiceps.

$d$. With a short snout, uniformly rounded. Phocana.

e. With a snout and a distinct beak. Delphinus.

$f$. With a much longer snout and beak. and having no furrow between them. Delphinorhynous.

- g. Without a snout and witl a long beak. Sooson. $h$. Having a long beak bristled with hair, and both incisor and molar teeth. The Inia.

$i$. Having two dorsal fins. Oxypterus.

On this classification we would simply remark, that we have not at all innovated, but only followed what has already been introduced by able and celebrated naturalists. It would be an easy matter to state objections to this arrangement, more particularly perhaps to its nomenclature, and to demonstrate that it is susceptible of improvement. We feel, however, that we are not the parties to attempt this improvement, which moreover should not too hastily be effected. We consider the above a great stretch and improvement upon any that has yet been offered to the British public. The characters, taken from the fascial line, are conspicuous on the slightest inspection, and we believe they are for the most part fixed and certain. The majority of them are exhibited on Plate I. $s$, the Globiceps; $t$, the Porpoise; $u$, the Dolphin; $v$, the Delphinorhyncus; $n$, the Soosoo.

We now proceed to the genus Beluga. 


\section{4}

\section{Ninth Genus.-BELUGA.}

The osteology of the cranium, descrihed by Baron Cuvier, supplies generic characters which distinguish this from the neighbouring genera. It is these peculiarities which give the shape to the head; obtuse, conical, and rounded. It is distinguished from the Globiccps by not having a dorsal fin ; and from the Delphinapterus, by not having, as it.has, a prolonged snout, like a flattened beak.

\section{THE BELUGA, OR WHITE WHALE.}

\section{PLATE XV.}

Beluga, Bon._Beluga Borealis, Less.-Delphinapterus Beluga, Laoep.-Balæna Albicans, Lin._-Delphinus Albicans, Fab. -White Fish, of Whalers.

THE general appearance of this very beautiful ani-. mal will be more readily perceived by an examination of the accompanying highly finished and accurate Plate, than by any words which we can use. The original, by Mr. Syme, was taken from an individual which for nearly three months during the summer of 1815 was observed to inhabit the Frith of Forth, passing upwards almost every day with the tide, and returning with the ebbing of the waters. During this time it was generally known under the name of the White Whale, and was supposed frequently to be in pursuit of salmon. Many fruitless attempts were made to secure it; but at length it was killed by the salmon-fishers, by means of spears and fire-arms. It was purchased by Mr. Bald of Alloa, and transmitted by him to Professor 


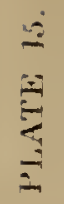

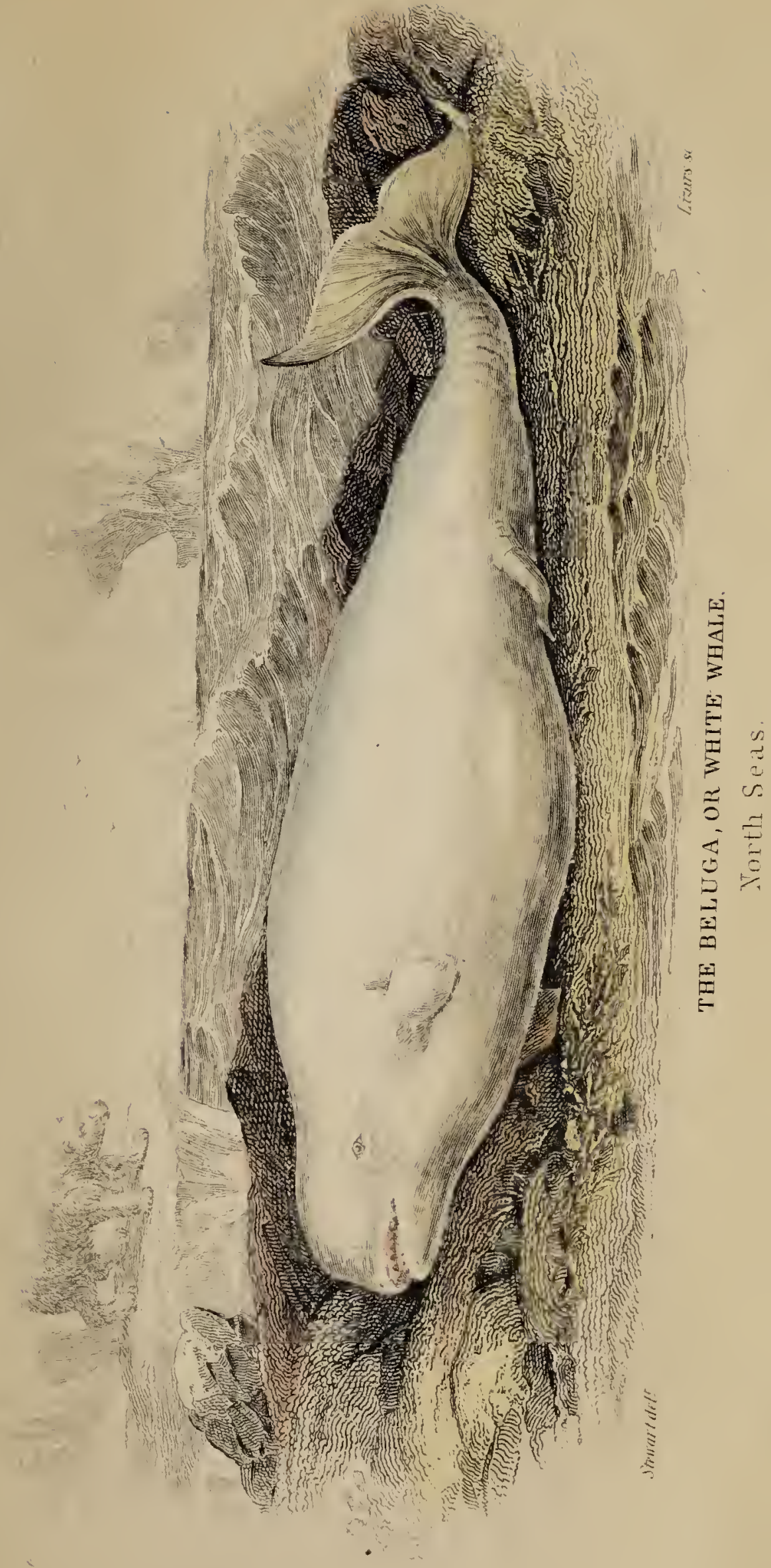



Jameson, and is now in the Royal Museum at Edinburgh. It was examined by Drs. Barclay and Neil, whose observations are published in Trans. Wernerian Soc. vol. iii.

Dr. Neil well observes that the shape of this animal is highly symmetrical, and at once suggests the idea of perfect adaptation to rapid progressive motion in water. It resembles generally a double cone, one end of which is considerably shorter than the other. Its head is small and lengthened, and over the forehead there is a thick round cushion of flesh and fat: the body continues to swell as far as the pectoral fins, and from this point gradually diminishes to the setting on of the tail. Its length varies from twelve to twenty feet. Its pertorals are large, thick, and oval. The tail is also powerful; is bent under the body in swimming, and worked with such force, that it impels the Beluga forward, says Giesecki, with the velocity of an arrow. The colour is usually a uniform and beautiful cream colour, whilst the younger ones are marked with brownish spots, and occasionally are somewhat of a blue or slaty colour. Scorseby remarks that he has seen some of a yellowish colour, approaching to orange; and this agrees with the statement of Fabricius, who says they are white, sometimes tinged with red. Many contradictory accounts are given of the number of teeth, unquestionably arising from the fact that in this whale, as in most of the genera, the teeth have the greatest tendency to drop out as the animal becomes aged; thus clearly showing how objectionable and difficult 
it is to make these parts the ground-work of classification. Anderson states that the Beluga has no teeth in the upper jaw, and that this is the universal opinion of the Greenland fishers (ii. 150), whilst there are eight on each side in the lower $\left(\frac{0}{88}\right)$. Dr. Neil gives the teeth $\frac{99}{66}, i . e$. nine on each side in upper, and six on each side in lower; and Crantz $\frac{89}{66}$. Cuvier, however, states them $\frac{99}{9}$; in all thirtysix ; and this is probably another proof of his great accuracy. In the above enumeration, there is the authority of Neil, and we may add, of Crantz, for nine, nine, in the upper; and Fabricius expressly states that he had counted nine, nine, in the lower; which, he adds, were like the single molares of quadrupeds. If, however, we are so slow in arriving at certainty in the dental apparatus of the Beluga, when are we, by this means, to determine species in many of the other Cetacea?

The spiracle is situated in the vertex, and has its horns turned backwards; the eye is scarcely larger than in man, the iris is blue; Dr. Barclay confirms the statement of Cuvier, that in this and the neighbouring species there is nothing like a true olfactory nerve; there is no external ear, and no appearance even of a meatus auditorius; the mouth is small in proportion to the size of the animal. As the apparatus of the windpipe is different in different genera, we shall here refer the reader to Pallas' interesting description of the valve of the 
blowing canal, which was introduced in our sketch of the Comparative Anatomy of the Order, and which will be found on p. 62 . To this we now add the account given by the late Dr. Barclay of the windpipe itself. "The arytenoid cartilages, as in man, appeared at first view to rest on the margin of the cricoid; but on opening the larynx they were observed to enter more than an inch within the cricoid, and to form the fissure which corresponds with our rima glottidis. From the atlantal margin of the cricoid, they gradually converged till they come into contact, and inclined dorsad; their length was seven inches. The epiglottis was six inches in length, inclining dorsad. These meeting with a membrane interposed, formed a tube, which crossed the pharynx, and was directed to the lower orifice of the breathing tube." We shall subjoin one other observation of this distinguished individual, as it regards an extraordinary structure elsewhere alluded to in these pages. (See page 50.) After observing that in this animal, as in many fishes, the spinal cord may be examined through certain apertures without disturbing the bones, he remarks, that a portion of the cord was found to be covered witli a semi-cylindrical mass on each side, formed of a tough spongy elastic substance, with large vessels running through it, and freely anastomosing. These two cylinders occupied by far the greatest part of the spinal canal; the medullary cord, where examined, not being larger than that of man at the middle of the neck. (Loc. Cit. p. 393.) 
The food of the Beluga is said to be cod, haddocks, flounders, and smaller fish of this description. It seeks them with perseverance, pursues them with ardour, and devours them with avidity.

Its favourite haunts are evidently the higher latitudes of the Arctic Regions. They are plentiful in Hudson's Bay, Davis Straits, and on some parts of the northern coasts of Asia and Americit, where they frequent the large rivers. Steller mentions them as being found at Kamschatka; and according to Charleroix, they are numerous in the Gulf of St. Lawrence, and go with the tide as high as Quebec. There are fisheries both for them and the porpoise in that river. A considerable quantity of oil is obtained, and of their skins is made a sort of Morocco leather, thin, yet strong enough to resist a musket-ball (Pen. Art. Zool. i. 183). They also abound near Disco Island in Greenland, and are not uncommon in Spitzbergen. Mr. Scorseby never observed them lower than Jan Mayen's Land. This navigator also remarks, that he has seldom seen them among the ice, but in those places where the water is clearest and smoothest. They are not at all shy, but often follow the ships, and tumble about the boats in herds of thirty or forty ; bespangling the surface with their splendid whiteness. They are seldom pursued by the whale fishers, not only because it is difficult to strike them, on account of their great activity; but because the harpoon often gives way; and they are, moreover, of comparatively little value when killed $I t$ is only a few stragglers 
that are seen in the southern latitudes, or even on the European shores. Besides the one mentioned above, Coloncl Imrie, in 1793, saw two young ones which had been cast upon the beach in the Pentland Fritli, some miles to the east of Thurso. They were both males, between seven and eight feet long; they were white, mottled with brownish-grey.

Sir Charles Giesecki describes the White Whale as a migrating animal, which visits the west coast of Greenland regularly every year about the end of November. He remarks that, next to the seal, it is the most useful animal captured by the natives, and it comes at a season when their provisions fall very short. It arrives in herds, in stormy weather, with the wind from the south-west. It is captured by the natives with harpoons and strong nets; in the latter case, the nets are extended across the narrow sounds between the islands, and when a shoal is thus interrupted in its course seaward, the individuals are attacked with lances, and great numbers are frequently killed. The flesh is somewhat similar to that of beef, of a bright red colour, though somewhat oily. According to Hans Egede, "His flesh as well as the fat, has no bad taste, and when it is marinated with vinegar and salt, it is as well tasted as any pork whatever; the fins also, and the tail, pickled or sauced, are very good eating; so that he is very good cheer." Its oil is of the best, whitest, and finest quality. Some of the internal membranes are user for windows, and some as bed-curtains; the sinew furnish the best sort of strong thread. 


\section{Tenth Genus._DELPHINAPTERUS.}

The Delphinapterus is distinguished from the Dolphin by having no dorsal fin; and from the Beluga, by having in front of the head a slender beak, flattened transversally, and separated from the head by a deep furrow. The Beluga, moreover, belongs to the northern hemisphere, the Delphinapterus to the southern.

\section{DELPHINAPTERUS PERONII.}

\section{PLATE XVI.}

Delphinapterus Peronii, Cuvier, Lesson._-Delplinus Leucagramphus, Peron.-D. Peronii, Lacépède.

Covier had recognized this whale, first described by Peron, as belonging to this genus; but we are especially indebted to the able author of Zoologie de la Loquille for an accurate account of it. We extract our description from this interesting writer.

High southern latitudes are the resort of the Delphinapterus of Peron. The historian of the voyage of Baudin met with them to the south of Van Diemen's Land, Dr. Quoy saw them near New Guinea, and we have seen them off Magellan's Straits, and among the Falkland Islands. Many hundreds of them surrounded the corvette, in January 1823, on our entering the Southern Ocean, 


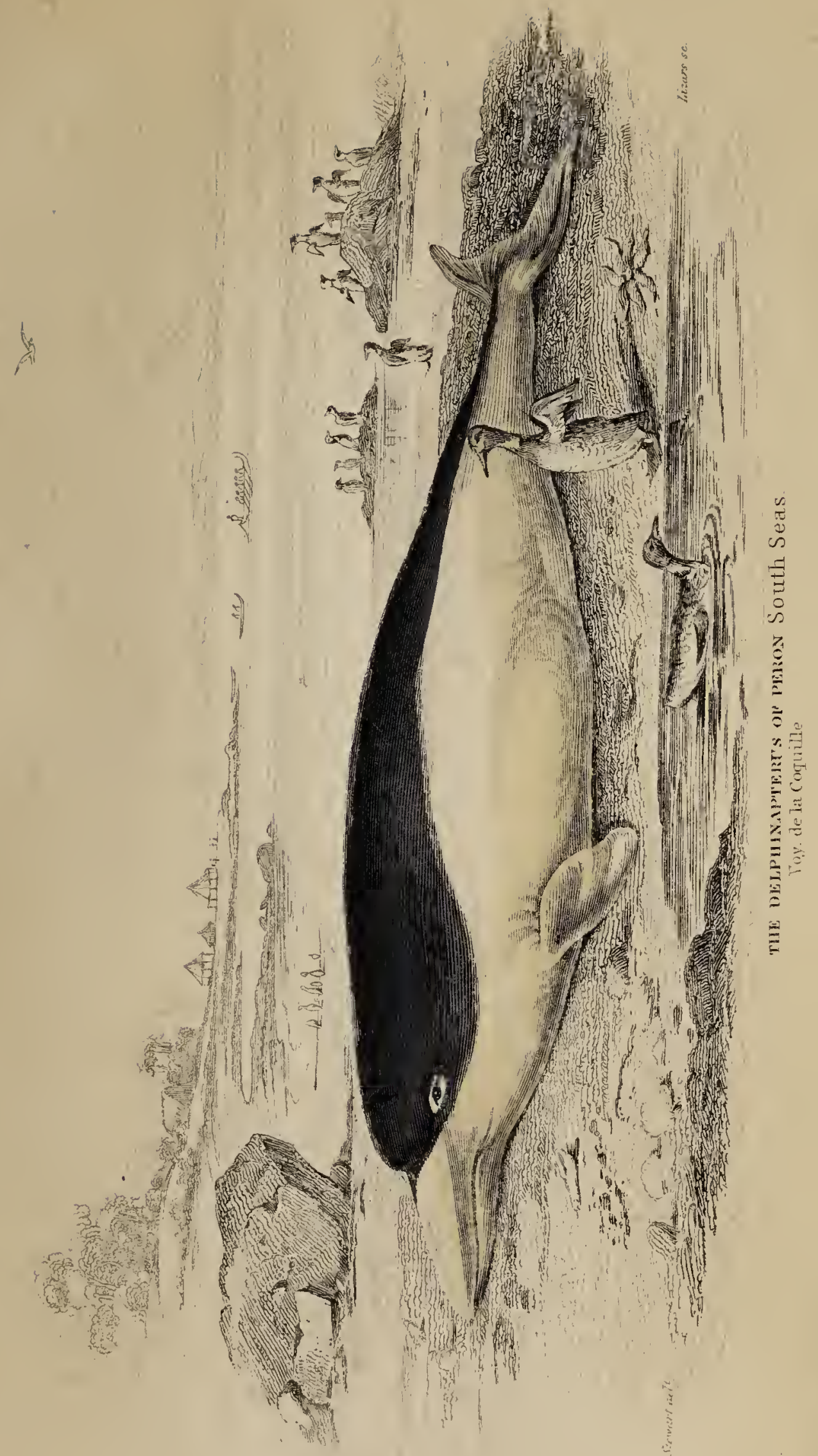



and one of them was harpooned by the sailors, which enables me to give a more accurate account than any previously supplied. It is alluded to in Kotzebue's Voyage, under the name of Dolphin of Chili, and by Lacépède and Desmaret (771) as the Dolphin of Peron.

The individual taken was six feet long. It is elegant in its form, regular in its proportions, sleek, and especially remarkable, in that it appears to be covered with a black cloak. Its snout as far as the eye is of a silky and silvery whiteness, so are the sides, the pectoral fins, the abdomen, and a part of the tail. A large scapulary of a decp bluish-black colour, rising at the eyes where the white appears like a cross, is painted and bent on the flanks, so as to cover the upper part of the back only. The anterior edge of the pectoral fins and tail is brown, the muzzle is prolonged, and separated from the cranium by a deep furrow. The iris is of an eme-. rald-green colour. Teeth $\frac{3939}{3939}$, in all 156 : ther are slender, pointed, and somewhat curved at the summit.

Our space will not permit us to introduce the D. of Commerson, or any other species belonging to this genus. 


\section{2}

\section{Eleventa Genus.-GLOBICEPHALUS.}

This genus is characterized by having no visible snout; the head is entircly globular, and the mouth is not so much at its anterior extremity as at its under part. In this it ro seinlles the Beluga, but differs from it in having a dorsal fin, as well as by many other marked distinctions.

\section{THE DEDUCTOR, OR CA'ING WHALE.}

\section{PLATE XVII.}

Globicephalus Deductor, Lesson.-Delphinus Globiceps, Cuvier, Desm.-D. Deductor, Scorseby.-D. Melas, Dr. Trail.

Earde is perhaps the first author who makes mention of the Deductor, under the name of Butshead (Descrip. of Greenland, 75) ; and he was soon followed by Duhamel, who gave a figure of one taken at Havre, under the name of " the porpoise with the round snout." In 1806, Dr. Neil, in an appendix to his " Tour through some of the Islands of Orkney and Shetland," gives a more extended and interesting account of them, under the name of Uyea-Sound or Caing Whales, than any which had previousty appeared ; and three years after, Dr. Trail published in Nicolson's Journal (1809) the first accurate description of this species, giving it the appellation of Delphinus Melas, with a drawing from his friend James Watson, Esq., which was 


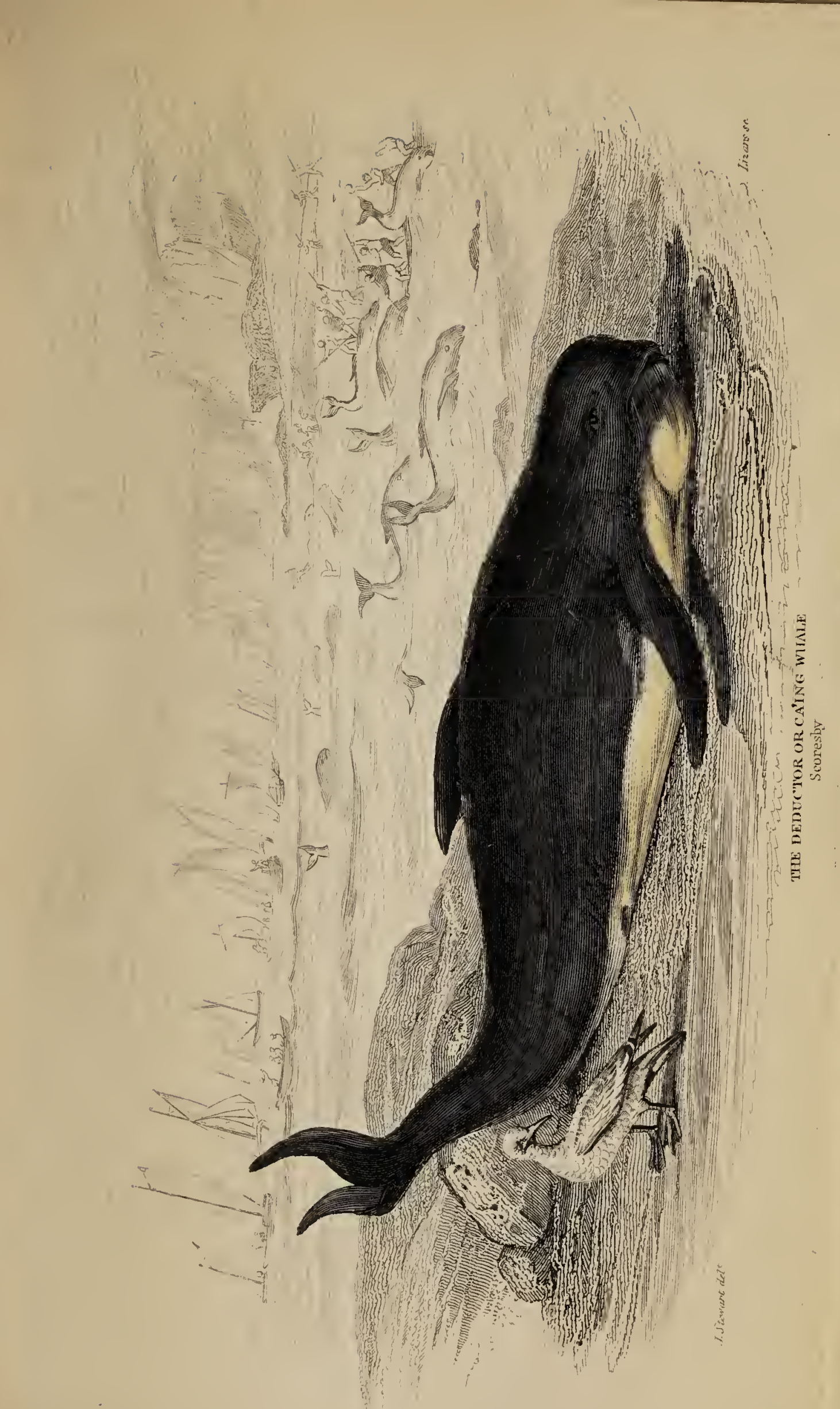

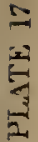

$=$
$\frac{3}{2}$
2

$\frac{1}{2}$
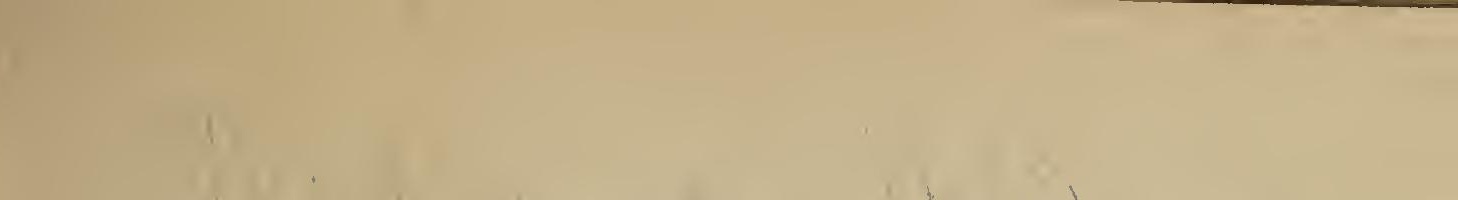

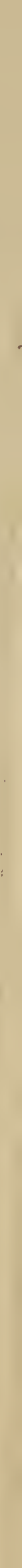

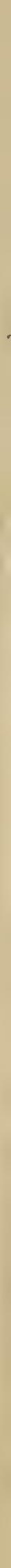



republished, with additional details, by Scorseby in his " Arctic Regions, 1830." In 1812, an interesting memoir concerning this variety, named by him Globiceps, appeared from the pen of Cuvier, in vol. xix. Ann. du Musenem. From these sources, some interesting circumstances may be detailed of this species.

'The Globicephalus, as its name implies, has a head very prominent, short and round, with something like a pad over its mouth, which gives it a very peculiar appearance. Its length is from sixteen to twenty-four feet; its circumference about ten or eleven. Almost the whole body is black, smonth and shining like oiled-silk; the back and sides are jetty-black; the breast and belly of a somewhat lighter colour. The dorsal fin, which is nearly in the centre of the body, is about two feet long at the base, takes a curve backward, and is crescent-shaped at its extremity; it is cartilaginous and immovable; the pectorals arise almost from the side of the neck, are from six to eight feet long, narrow and tapering at their extremity; the tail is large, extending to about five feet. The spiracle is single, and placed in a small hollow towards the back of the head. The upper jaw projects somewhat over the lower; the teeth are not apparent in the young, and begin to fall out before they attain any great age. The normal number is not ascertained, but appears to be from twenty to twenty-eight in each jaw ; they are conical, sharp, and somewhat curved at their summit. When the mouth is shut the 
214 THE DEDUCTOR, OR CA'ING WHALE.

teeth lock into each other, like those of a rat-trap. In the females giving suck, the teats have been observed to be somewhat larger than those of a cow, and when pressed, milk very readily issues from them. Their food is sand-lances and other smaller fish. They are generally very fat, their blubber being about three inches thick, and affording a large quantity of excellent and pale oil.

It would appear that the Northern Ocean, from the $56^{\circ}$ to the $66^{\circ}$, is the farourite resort of the Deductor. Sometimes it has been witnessed in lower latitudes; but not frequently, nor in large numbers: it would also seem to have been seen in the Mediterranean, but whether as a mere straggler or a permanent residenter, we cannot decidedly affirm.

Of all the Cetacea, this would appear to be the most sociable, often herding together in innumerable flocks. We shall here supply a few facts which establish this point. From an old history of the Feroe Islands, quoted by Scorseby, it would appear that the inhabitants are in the habit of hunting these animals, which they designate Grind Whales, and oapture them in great numbers. In the year 1664, on two excursions only, they killed about one thousand. In the year 1748 , forty individuals of this species were seen in Tor Bay, and one seventeen feet long was captured; in 1799, about two hundred ran ashore in Fetlar, one of the Shetland Isles; and in 1805, as mentioned by Dr. Neil, in February, one hundred and ninety, and in March, 
one hundred and twenty more, out of a herd of about five hundred, were forced ashore on the same spot in Uyea-Sound in Unst. In 1806, ninety-two were stranded in Scalpa Bay, Orkney : in the winter of 1809 and 1810, eleven hundred and ten of these whales approached the shore of Hvalfiord, Iceland, and were captured : in 1812, seventy were chased ashore near the village of Bloubalzbance, on the coast of Bretagne; and in 1814, one hundred and fifty were driven into Balta Sound, Shetland, and were there despatched. These are only a few of the instances, in which, in modern times, an extensive slaughter of the Deductor has taken place.

As exhibiting the nature of these occurrences, we subjoin an account of the capture of ninety-eight, which was effected in 1832 in the island of Lewis. "The little town of Stornaway was lately enlivened by a scene of the most animating and striking description. An immense shoal of whales was, early in the morning, chased to the mouth of the harbour by two fishing boats, which had met them in the offing. This circumstance was immediately descried from the shore, and a host of boats, about thirty or forty in number, armed with every species of weapon, set off to join the others in pursuit, and engage in the combat with these giants of the deep. The chase soon became one of bustle and anxiety on the part both of man and whale. The boats were arranged by their crews in the form of a crescent, in the fold of which the whales were collected, and where they had to encounter tremendous 
showers of stones, splashings of oars, frequent gashes with harpoon and spears, whilst the din created by the shouts of the boats'-crews, and the multitude on shore, was in itself sufficient to stupify and stun the bottle-nosed foe to a surrender. On more than one occasion, however, the floating phalanx was broken, and it required the greatest activity and tact ere the breach could be repaired and the fugitives regained. The shore was neared by degrees, the boats advancing and retreating by turns, till at length they succeeded in driving the captive monsters on the beach opposite the town, and within a few yards of it. The movements of the whales were now violent, but except when one became unmanageable and enraged when harpooned, or his tail fixed in a noose, they were not dangerous to approach. One young sailor, however, received a stroke from the tail of one of the largest of them, which promised to be fatal. In a few hours the whales were captured : the shore was strewed with the dead carcases, whilst the sea presented a bloody and troubled aspect, giving evident proofs that it was with no small effort that they were subdued, and made the property of man. On the present occasion, the whole inhabitants of the place, male and female, were interested spectators of the scene." (Caledonian Mercury.) One might almost fancy that old Waller, two hundred years ago, was one of the witnesses of this identical scene.

They man the boats, and all the young men arm

Witl whatsoever may the monsters harm 
Spikes, halberts, spits, and darts that wound so far ;

The tools of peace, the implements of war.

Now was the time for vigorous lads to show What love or honour could invite them to: A goodly theatre! where rocks are round With rever'nd age, and lovely lasses, eromed.

Battle of the Summer Isles.

It would be interesting to ascertain from what mental peculiarity it springs that this animal is so frequently stranded, so easily hunted, and so readily made a prey to the convenience or cupidity of man. It can scarcely, as has been alleged, be the result of their stupidity, by which they lose their way, and do not know the difference between land and water We have seen enough to demonstrate that they are most sociable in their habits; and we may now remark, that they seem moreover to be endowed with an interesting instinct, very useful, doubtless, on the whole, whereby they are strongly induced to follow the guidance of the oldest and most experienced of their number. In the words of Dr. Trail, they seem generally to follow one as a leader with blind confidence; and Dr. Neil remarks, the main body of the drove follows the leading whales, as a flock of sheep follows the wedders. Hence the natives of Shetland well know, that if they are able to guide the leaders, they are sure of likewise entangling multitudes of their followers. This trait is strikingly illustrated by a circumstance of which Dr. Trail was a witness. "I once," says he, "was in a boat when an attempt was made to drive a shoal of them ashore; but when they had approached 
very near the land, the foremost turned round with a sudden leap, and the whole rushed past the boat." It is from this peculiarity of their mental constitution, that Mr. Scorseby, it would appear, applied to them the appellation Deductor.

They appear wholly inoffensive and very timid animals. Thus, in all the instances on record of their being discovered at sea, and hunted to land, the chase has been free from danger, and a few frail boats and most ineffective weapons, with shouts and noise in the water, were sufficient to drive them from their native element to their destruction.

They likewise manifest in a very striking manner that trait for which all the Cetacea seem remarkable; we mean maternal, and, in this case, we must add mutual affection. This is not only inferred from their associating in troops, but especially from their manifestation of a disposition, as we have seen in some of the Sperm Whales, to help and assist one another in their difficulties. Thus, in the case of the stranding of a shoal at Bloubalzbance, there were only twelve men, in half a dozen of frail boats, engaged in the pursuit. At first they succeeded in stranding only one of the young cubs; it immediately set up loud cries, which were heard by the rest, and an old one, which was considered its mother, speedily came to its relief; but she came not alone, the whole flock followed, and were thus made an easy prey. Upon this point we find it stated in Dr. Neil's account, that when any one strikes the ground it sets up a howling cry, and immediately 


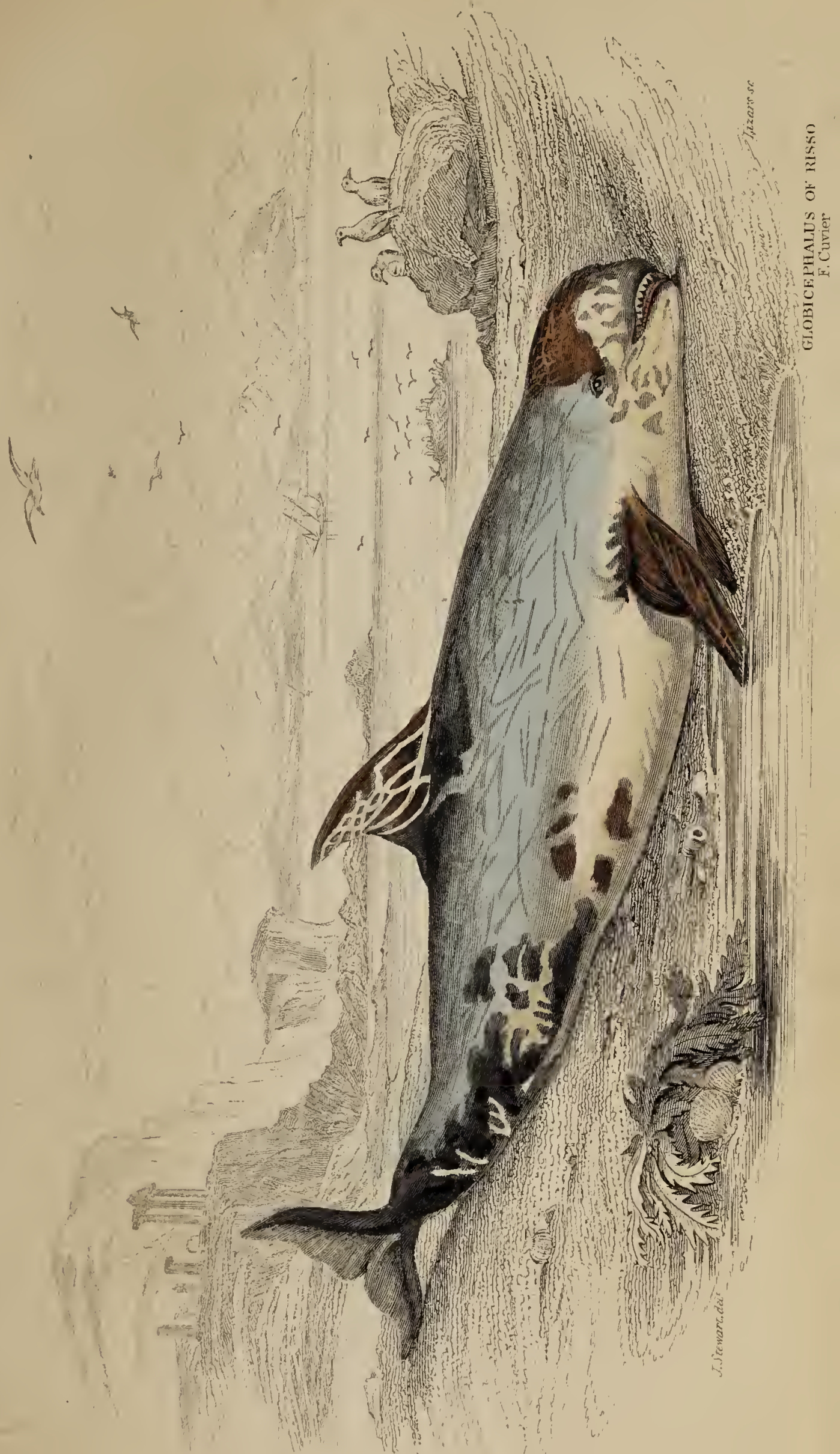



others crowd to the spot as if for its relief. We believe it is this circumstance which has procured for it the name of Caing, that is, Calling Whale.

Cuvier mentions, respecting those captured in Bretagne in 1812, that the flesh was soft, but that it was used as food by the poor in the neighbourhood, for about a fortnight, and was used without any inconvenience.

Risso states that individuals of this species annually visit the neighbourhood of Nice in the months of May and June. Upon the whole they rarely approach the shore, and after a short time they appear to migrate. His description, though generally agreeing, does not perfectly correspond with that which we have given above. (Hist. Nat. \&c. t. iii. p. 33.)

\section{THE GLOBICEPHALUS RISSII.}

\section{PLATE XVIII.}

Globicephalus of Risso, Lesson.-Delphinus Rissii, Cuv.

THE accompanying plate exhibits a specimen of the only other ascertained species belonging to this ge-nus. M. Risso sent an account of it from Nice, with a drawing, in 1811, to Paris; when Cuvier, satisfied it was distinct, affixed to it the name of this modest and devoted naturalist. In addition to the generic characters, which we need not repeat, we remark that the shape, the colour, the appearance of the head and snout, and fins, may be perceived by 
examining the plate, first published by Fr. Cuvier. The spiracle is situated far back in the head; the mouth is large ; in this individual the upper jaw alone had teeth, five on each side, which were large, conical, and soncwhat curved, distant from each other, and strongly fixed in the jaw; the interior of the mouth was covered with soft tubercles; the eye was oval and very small; the iris golden-coloured.

Besides these two species here delineated and described, two other living ones have been named, though their existence is not quite established, the G. Leucacephalus and G. Fuscus. We must now, however, pass on to the

\section{FOSSILE GLOBICEPS.}

Globiceplalus Cortesi, Cuvier_Delphinus Cortesi, Fossile.

WE shall here shortly allude to a fossile species which was discovered by Cortesi, and arranged in this genus by Cuvier. This was the first of the magnificent discoveries made by $M$. Cortesi of Plaisance, on the Appennine hills to the south of Fiorenzuola. In 1800, this enthusiastic naturalist procured the fossile bones of an elephant and rhinoceros on the top of Mount Pulgnasco, one of the hills which descends from the Appennines to the $\mathbf{P o}_{\text {, }}$ they were almost on the surface. Parallel to Mount Pulgnasco on the east, and separated by the streamlet 
ealled Stramonte, there descends another hill, called Torazza, which is lower, and, like the base of Pulgnasco, is composed of blue clay filled with marine shells. It was in this hill, at about one hundred and twenty feet above the Stramonte, that. M. Cortesi, attracted by one of the vertebræe which had been brought him, made search, and discovered the almost entre skeleton of this globiceps, a circumstance which prompted him to all his subsequent researches, of which we have seen so many happy results.

We must not enter into many details, but may state that the head was almost entire, as also the lower jaw ; even the bones of the ear were in situ. Each jaw had twenty-eight teeth: but supposing that it was ascertained, that some of the living species had this precise number, yet this specimen would still differ in certain essential and specific characters. It had thirteen dorsal vertebræ. After considering all the data, M. Cortesi inferred, with much appearance of truth, that this animal must have been about thirteen feet long. We conclude the notice of this wonderful animal of stone in the words of Cuvier,-_" From all these considerations I cannot but conclude, that this fossile Cetacea is of a species different from all those of this genus, which, up to the present time, are distinctly known."

We now proceed to the fourth genus into which we divided these lesser Ceta, viz. the Phoooma or Porpoise Genus. 


\section{2}

\section{Twelfth Gends.-PHOCANA.}

Distinguishing Characters.-The Porpoises have a short spow uniformly rounded to the extremity.

We shall introduce first,

\section{THE COMMON PORPOISE.}

PLATE XIX. Fig. 1.

Phocæna Communis.-Delphinus Phocæna, Lin. Bonn., \&c. Popular names, Maris Sus._Marsouin._Sea Pork._Springwhal._Tumbler._-Porpess.

The Common Porpoise is, of all the Cetacea, that which is best known in this part of the world. It lives on our coasts, frequents our estuaries, ascends our fresh-water rivers, frequently exhibiting itself in numerous groups.

Like the proper dolphin, it is amongst the smallest of the order; and between these two there is much general resemblance in colour, shape, and dispositions, - so far as these dispositions are known. The shape of the head constitutes a distinction. The porpoise has no beak, the muzzle is gently curved at its termination, and possesses in breadth what it wants in length. 


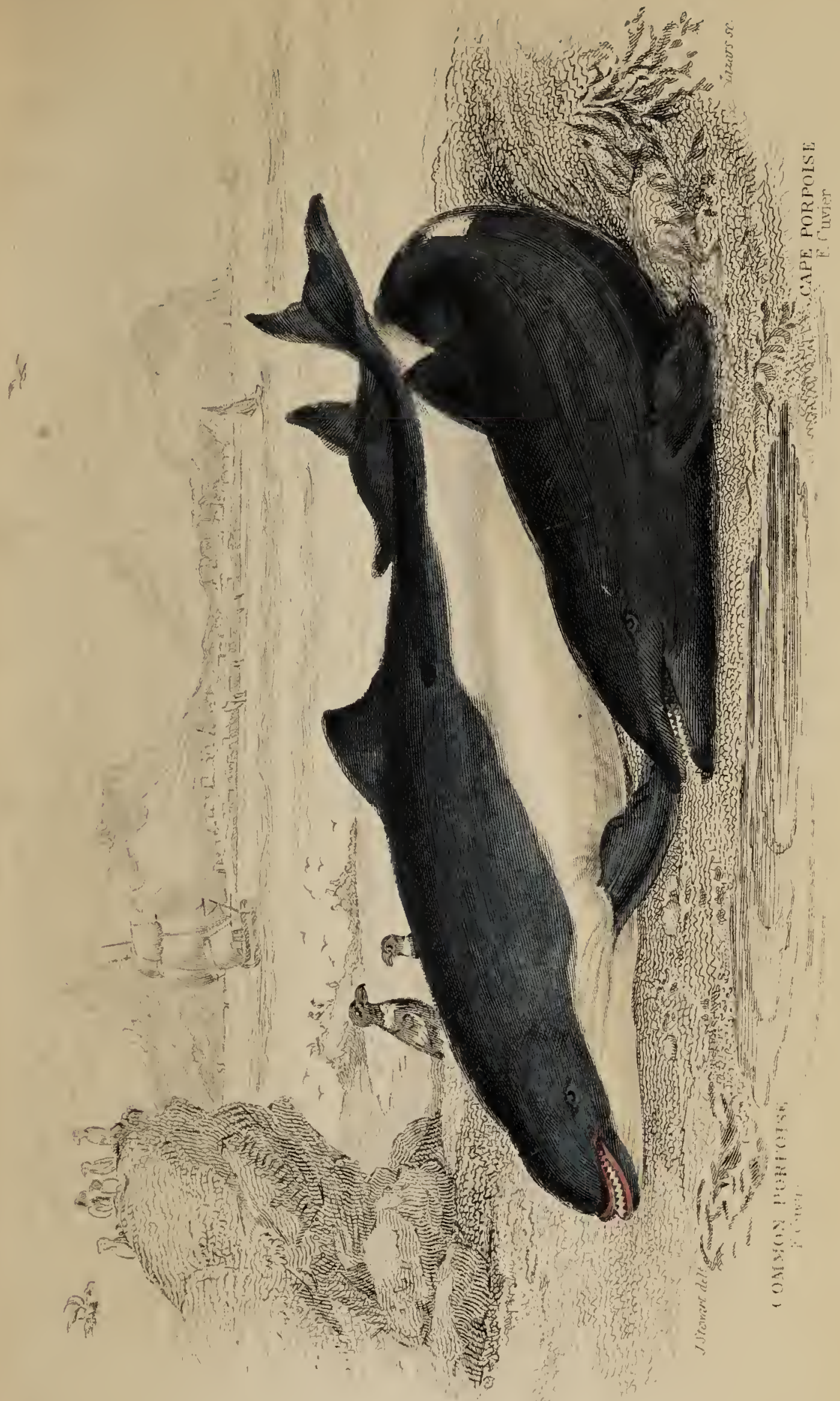


$s$

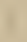


The Porpoise is usually four or five feet long, though sometimes, as much as six or eight. We shall give the general descriptions in the words of Cuvier. It has absolutely no hair, not even eyelashes. Its skin is perfectly smooth, and its scarfskin is very soft to the touch and easily detached. It has no lips properly so called; but the skin, always sleek and black, is somewhat strengthened at its union with the gums. The eye is small, and situated nearly in the line of the opening of the mouth; the eyelids are soft, and have very little play; their internal surface is moistened with mucus, but there are no puncta lacrymalia, and consequently no tears. The iris is yellowish; the pupil in form of a $\mathrm{v}$, reversed. The opening to the ear is not larger than the prick of a pin ; that of the blowhole is placed on the top of the head, precisely between the eyes, and resembles a crescent with its horns looking forward. Neither the dorsal fin nor the tail have any osseous parts in the interior, and the former is incapable of any separate movement, and is composed almost wholly of fat.

The general shape and appearance of the porpoise may be seen in the accompanying Plate, fig. 1. Its flesh is dark-coloured and gorged with blood, and covered with a fatty membrane about an inch thick, which is quite white, and on heating is reduced almost entirely to an oil similar to that of the other Cetre, but very fine and much esteemed. The colour on the upper part of the body is a deep bluish black, fading away on the sides till it acquires a silvery whiteness on 
the ahdomen. The pectorals are brownish, though they nise from a white ground. The teeth, according to Fr. Cuvier, are $\frac{2323}{2323}$, in all ninety-two; they are all equally flat and cutting, straight, and somewi at rounded at the edge. The brain is large and connex, and formed of numerous and deep convolutions lying over the cerebellum. Of all animals, the only other groups which in this respect resemble man, are the dolphins and the monkeys.

The Porpoise is found in all the seas of Europe, in the Atlantic Ocean, and in the Mediterranean. In a late report of a committee of the House of Commons on the public works of Ireland, it is stated " that Porpoises abound in almost innumerable shoals on the western shores of Ireland;" localities certainly pre-eminently suited to their tastes. It is to be regretted that they are not there made the objects of regular pursuit, for it could not fail to be highly useful to poor and unfortunate Ireland to convert these shoals to an economic purpose, not only for the sake of the oil, which is of the purest kind, but also for the skins, as alluded to at the conclusion of this article. The porpoises form themselves into considerable shoals, the individuals of which frequently swim in a line one before another, never showing at the surface more than the upper part of their body, and in such a way that they appear to make a revolving motion on themselves. They appear never to leave the coasts, and are never met with in the high seas. They ascend the 
rivers when led by the pursuit of fish, but do not in general pass the place where the salt and fresh water mix. It does not seem ascertained whether they are migratory in their habits. The inhabitants of Iceland fish them principally in the month of June; according to Fabricius, it is principally in summer they frequent the coasts of Greenland ; and it his been remarked, that it is especially in winter and early spring they are met with on the northern coasts of France: these facts are in favour of the supposition.

When the surface of the sea is smooth, they are often seen to spring out of the water, and to make considerable leaps, as if romping and amusing themselves. This is especially the case in the fine weather of summer, which is supposed to be their rutting season; and then they appear to be very combative and furious, and blind alike to all danger, risk, and snares. At this time they sometimes furiously dash against a vessel, or precipitate themselves upon the shore. According to Anderson, they carry their young six months; the cub at birth is about twenty inches long, and the mother, as in all the other genera, watches over it with the most tender care. In ten years it is stated to have acquired its. full growth.

The food of the Porpoise is chiefly fish, which it pursues with great rapidity and seizes with great address. They are occasionally observed in numbers: to pursue the shoals of herring, mackerel, Sc. which they drive into the bays under great apparent tartor. 
They are also believed to be great enemies to the salmon fisheries, and salmon hunts are frequently witnessed. It is impossible to view without astonishment the rapidity of their movements, and all their turnings and twistings in pursuit of their prey: the salmon are often observed to spring several yards out of the water, but from the quickness of their foes, it seems impossible they should escape.

The Porpoise was at one time, even in these countries, esteemed a voluptuous article of food; Malcolm IV. granted to the monastery of Dunfermline those which were caught in its neighbourhood; and it is said to have been introduced at the tables of the old English nobility as late as the time of Queen Elizabeth. It was eaten with a sauce of bread-crumbs and vinegar. Much later than this, it was a great article of consumption in some countries professing the Roman Catholic faith, especially during the season of Lent; and accordingly, in spring, it was the peculiar object of pursuit. Sailors on long voyages, in lack of fresh provisions, were often happy to have recourse to it. Thus Captain Colnett, in 1793, narrates, that, when off the coast of Mexico in the Pacific, they saw Porpoises in abundance, and took many of them, which they mixed with their salt pork, and so made excellent sausages; they became, he adds, our ordinary food (Loc. Cit. 124). With modern times a change has taken place in the tastes of cultivated society; but in high northern latitudes porpoises are still, as they have ever been, highly esteemed as articles of food. Thus Fgede states, that 
the flesh is by the Greenlander reckoned a great dainty; and in the oil, they find a beverage than which, according to their taste, nothing can be more delicious.

In some parts of North America the skin of the Porpoise, like that of the Beluga, is tanned and dressed with considerable care. At first it is nearly an inch thick, but it is shaved much thinner, till it becomes somewhat transparent, and is then made into articles of wearing apparel: it also supplies excellent coverings for carriages.

In Plate xIx. fig. 2., along with the common Porpoise, will be seen the representation of another variety. This is

THE PORPOISE OF THE CAPE OF GOOD HOPE,

Phocæna Capensis, Dussumier, Cuvier (R. A. 289), Fr. Cuvier (Mam.),

Wirch was first described by Dussumier from an individual taken in the Cape road-stead; where, however, it is not very common. Its length was about four feet; its colour almost wholly black. It did not appear to swim with much velocity; the pectorals are small; the spiracle is somewhat behind the eyes; the teeth appear to be $\frac{2626}{2323}$, in all ninetyeight.

The next species we introduce is by much the largest and most remarkable of the genus. It is 


\section{8}

\section{THE GRAMPUS.}

\section{PLATE XX.}

Phocena Grampus.-Delphinus Grampus, Huntor. DesmPorcus Marinus Major, Crantz, Gesner.

The common Grampus, so well known round the British, and more especially the Scottish shores, under that appellation. As we believe that this remarkable animal is the original of very many of the alleged species of Dolphin, so called, to guard against mistake, it will be necessary to introduce a few words in explanation. We take it to be the Delphinus Orca of Fabricius, Bonnaterre, and Lacépède ; the Butskopf of Anderson, and the second kind of Butskopf of Martens; the Epée de Mer or Sword-fish of Anderson and Crantz, and of which Bonnaterre and Lacépède made their Delphinus Gladiator. We regard it also as the Epaulard of the French, a name which has been very vaguely and generally applied; it is also the second Grampus of Mr. Hunter; which the French naturalists, from a figure sent them, called the Delph. Ventricosus. Finally, it is the fish which the Americans have long been in the habit of denominating the Killer or Thrasher, from its reputed pugnacious and cruel disposition. 


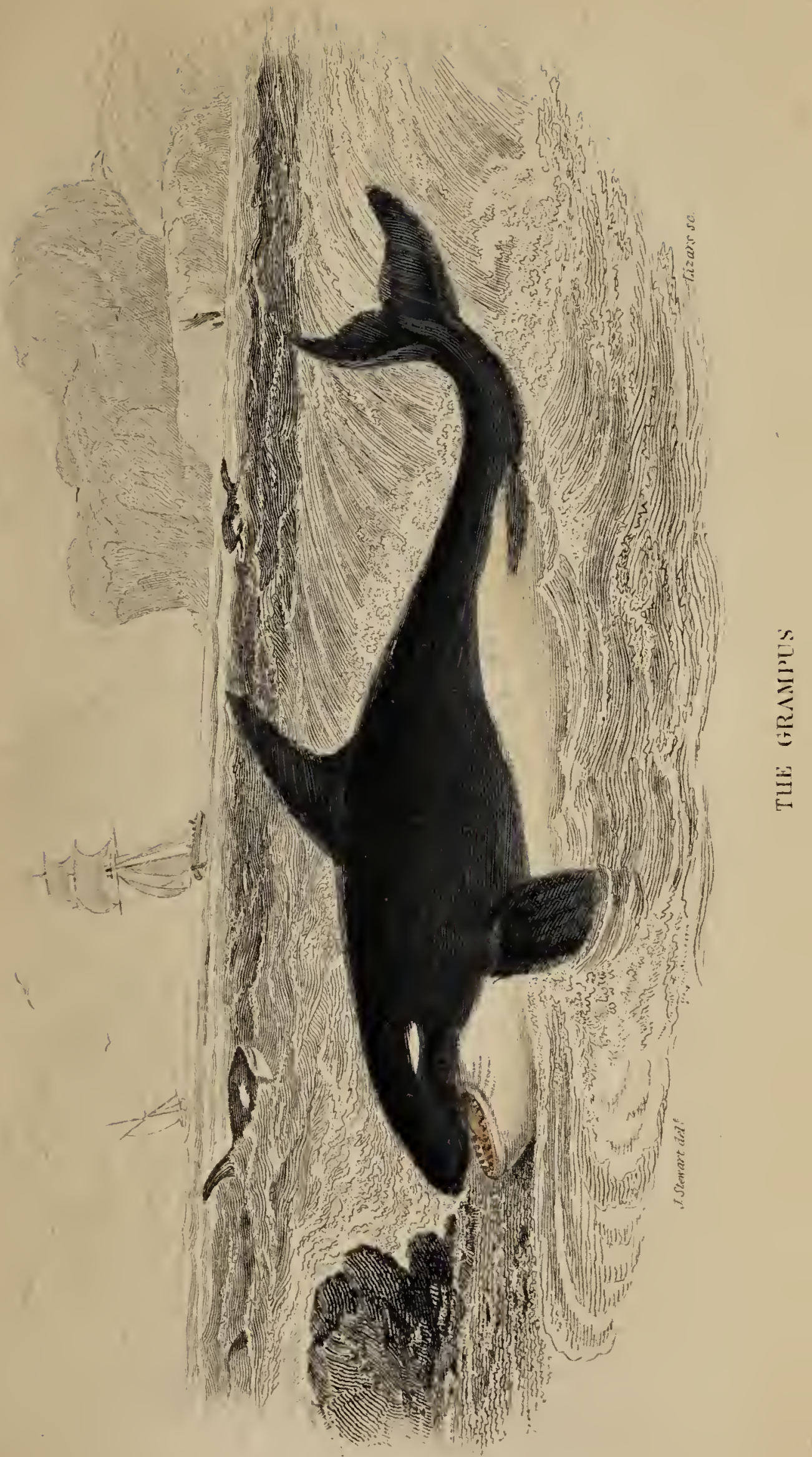



The name Grampus seems to be a corruption of the French : their Grand poison was, by the Normans of the middle age, pronounced Grapois, whence in all probability the English Grampus, to which appellation its dimensions well entitle it. It is remarkable that we are still in want of an accurate description of this species.

An examination of the Plate will render few words necessary regarding its external appearance. It is a great animal, half the size of the Greenland full grown whale, being often seen from twenty-five to thirty feet in length, and ten or twelve in circumference. Its snout is short and roundish; the lower jaw is somewhat bent upwards, broader but not so long as the upper. The teeth are $\frac{1111}{1111}$, forty-four in all; they are strong, large, conical and somewhat hooked; those furthest back being flattened at the summit. The dorsal fin, nearly on the middle of the body, is four feet high and upwards; the pectorals too, are very large and somewhat oval. The tail is very powerful. The colour is black above, suddenly giving place to white on the sides, which is continued over the abdomen. Generally, behind the eye, there is a large white patch, somewhat like an eyelid.

The favourite abode of the Grampus seems to be the northern regions, on the coast of Greenland, Spitzbergen, and Davis Straits. It is also frequently seen in small herds in the British seas and friths, we believe, at all seasons. It often visits the Frith 
of Forth ; and according to Dr. Fleming, it goes up the Frith of Tay nearly as far as the salt water reaches, almost every tide at flood, during the months of July and August, in pursuit of salmon of which it devours immense numbers. Mr. Hunter mentions that one twenty-four feet long was, in 1759 , captured in the Thames; two more were taken in 1772 , one eighteen and the other twentyone feet long; and in 1793 another thirty-one feet long, in the same river; whilst another, that same year, was captured in the Loire, measuring eighteen feet. One was caught in Lynn harbour in 1829. This animal was discovered with its dorsal fin rising above the water. It was immediately driven into the shallows and attacked by the boatmen; but they not being provided with proper weapons, despatched it with much difficulty, by means of great knives and sharpened oars. The groans of the poor animal are described as having been very horrible, and the effusion of blood very great. Being at length deprived of life, it was towed up the river to the town. It was twenty-one feet three inches long, following the curve of the back, and nineteen feet in a straight line; the base of the dorsal fin was about two feet and a half, and the height four feet; the width of the tail was seven feet (Loudon's Mag. iv. 338). Though these animals are cautious as well as daring, yet we believe such notices of capture could easily be multiplied. It is stated that they are not unfrequently seen in the Atlantic Ocean and the Mediterranean Sea; they are even 
said to be occasionally met with in all seas, though with what truth we cannot determine.

From the preceding description it will appear that this is a very powerful animal. Sir Joseph Banks communicated to the Count Jacépède the particulars of the capture of one taken in the Thames in 1772. After being pierced with three harpoons, it pulled the attached boat twice from Blackwall to Greenwich, and once as far as Deptford, against the tide, running at the rate of eight miles an hour; and for a long time unimpeded by the lance-wounds which were inflicted when it came to the surface. So long as it was alive, no boat would venture to approach it; and the dying efforts of this formidable creature were very terrible. It was finally killed opposite Greenwich Hospital.

The Grampus has the character of being exceedingly voracious and warlike. It devours an immense number of fishes of all sizes, and especially large ones, including cod, halibut, skate, and turbot. When pressed with hunger, it is said to throw itself on every thing it meets with, not sparing the smaller porpoises and dolphins: Hunter found a portion of a porpoise in the stomach of one which he examined. It is also said to make war on seals; to espy them on the rocks and ice, when basking or asleep; to drive them if possible with its fins into the sea, where they immediately become an easy prey. They are often seen in small herds of six or eight individuals, apparently chasing and amusing themselves; and when thus in combany, it is alleged that they 
frequently attack the true whale,-not the young and smaller only, but even the greatest giants of the deep. They bite and tear their flesh with their powerful teeth ; oppose their agility to its weight; their number to its size; their address to its power; their audacity to its strength; thus they annoy, torment, and cover with blood and wounds their mighty foe. Nay more, they are stated exactly to resemble so many furious mastiffs fighting with a wild bull. Some seize the tail and endeavour to impede its murderous blows, whilst others attack the head. They seize hold of the lips and tear them away; of the tongue, and devour it; and cease not the contest till they are finally victorious. They have received the appellation of Balcenarum Tyrannus from the accurate Fabricius, and hence their popular name of whale-killers. We apprehend that those bloody fights, recorded with such minute accuracy in all the works on the Cetacea, stand in some need of confirmation.

We shall next notice 


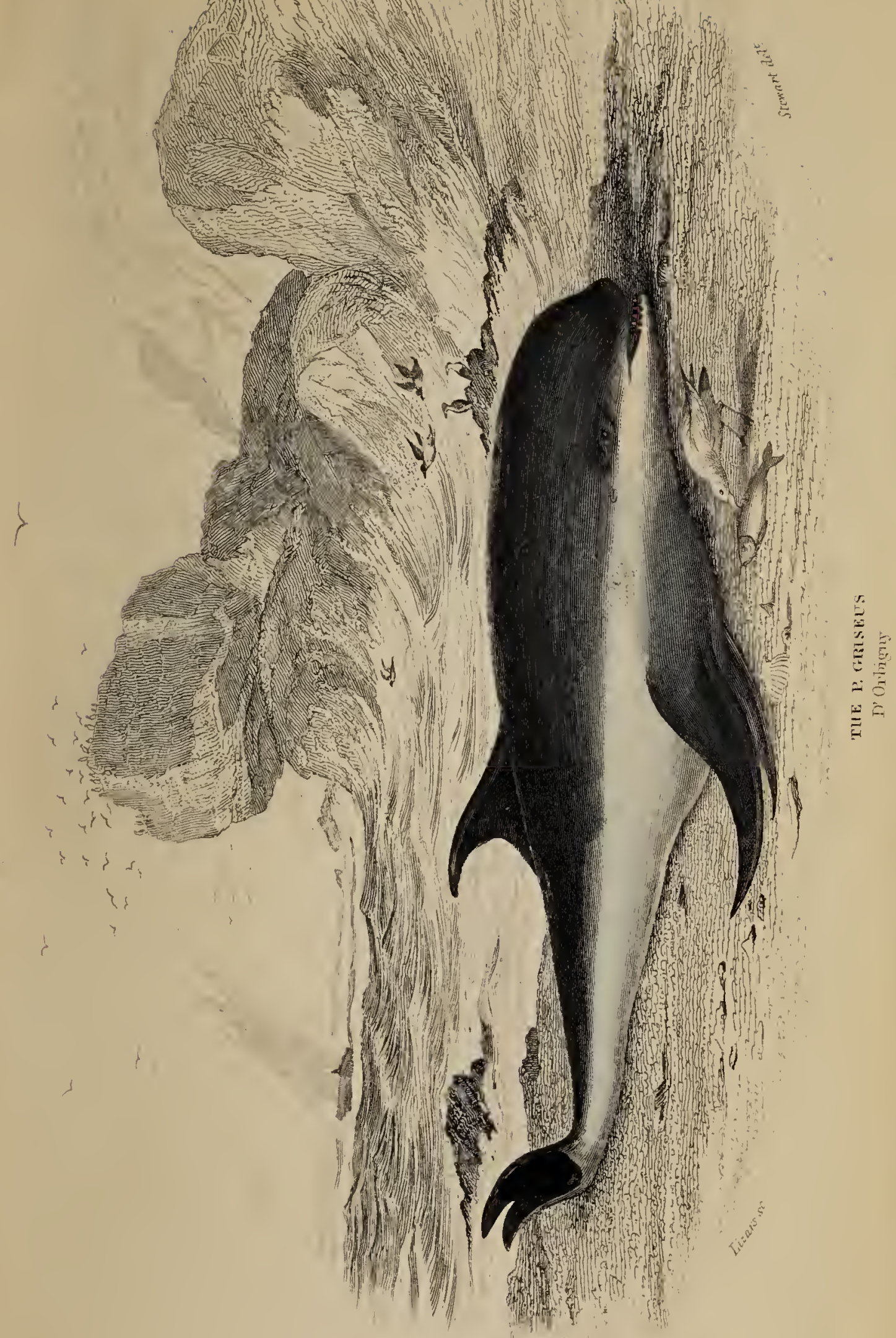





\section{3}

THE P. GRISEUS.

PLATE XXI.

P. Griseus of Cuvier (Ann. Mus. xix. and Reg. Ani. 290), Fr. Cuvier (Mam.).

Trus handsome looking animal has been obtained only on the west coast of France, and it has been after years of labour, and many mistakes, that, through the united efforts of Cuvier, Dumeril, and especially of D'Orbigny, that its true characters have been ascertained. Even externally it will be observed to differ widely from the other species, and the internal differences of the bones of the cranium, \&c. are equally marked. The head is large, obtuse, and somewhat rounded; the upper jaw is several inches larger than the lower; the dorsal fin commences about the middle of the back, and is elevated and pointed; the pectorals are very much developed; the tail also is large. The total length is ten or eleven feet; the colour is a bluish-black above, and a dull white beneath; and these merge into each wther on the flanks. There are no teeth in the upper jaw and only eight in the lower.

At first glance it has some resemblance to the Deductor or Ca'ing Whale, and in some particulars of their history, as their associating in groups and uttering loud cries, they agree. The slightest com- 
parison, however, exhibits many distinctive characters. Their heads are quite differently shaped, and the dental formularies are, of this species $\frac{00}{44}$, originally pointed, but soon blunted ; and of the Deductor $\frac{1414}{1414}$, conical and sharp, and locking into each other like the teeth of a rat-trap. The Deductor is tivice the size of the Griseus; the dorsal fin, in this latter, is much more elevated; the colouring, too, is different. D'Orbigny mentions that two out of the four stranded in 1822 had the dorsal fin destroyed, but whether from disease or the attacks of other animals could not be determined. That it was violently removed was however apparent.

Individuals of this species have usually been brought to the coast by the violent tempests which sweep into the Bay of Biscay and agitate its troubled waters. They are famous for uttering loud cries, and thus attracted the attention of Baron Cuvier; but as we have already alluded to this circumstance (see p. 55, 56), we shall not dwell upon it in this place.

\section{THE STRIPED PORPOISE.}

PLATE XXII. Fig. 1.

P. Bivittatus.-Delphinus Bivittatus, Less.

TrEe only other species of this extensive and well known genus, which we shall submit to the attention of our readers, is remarkable as being one of the 


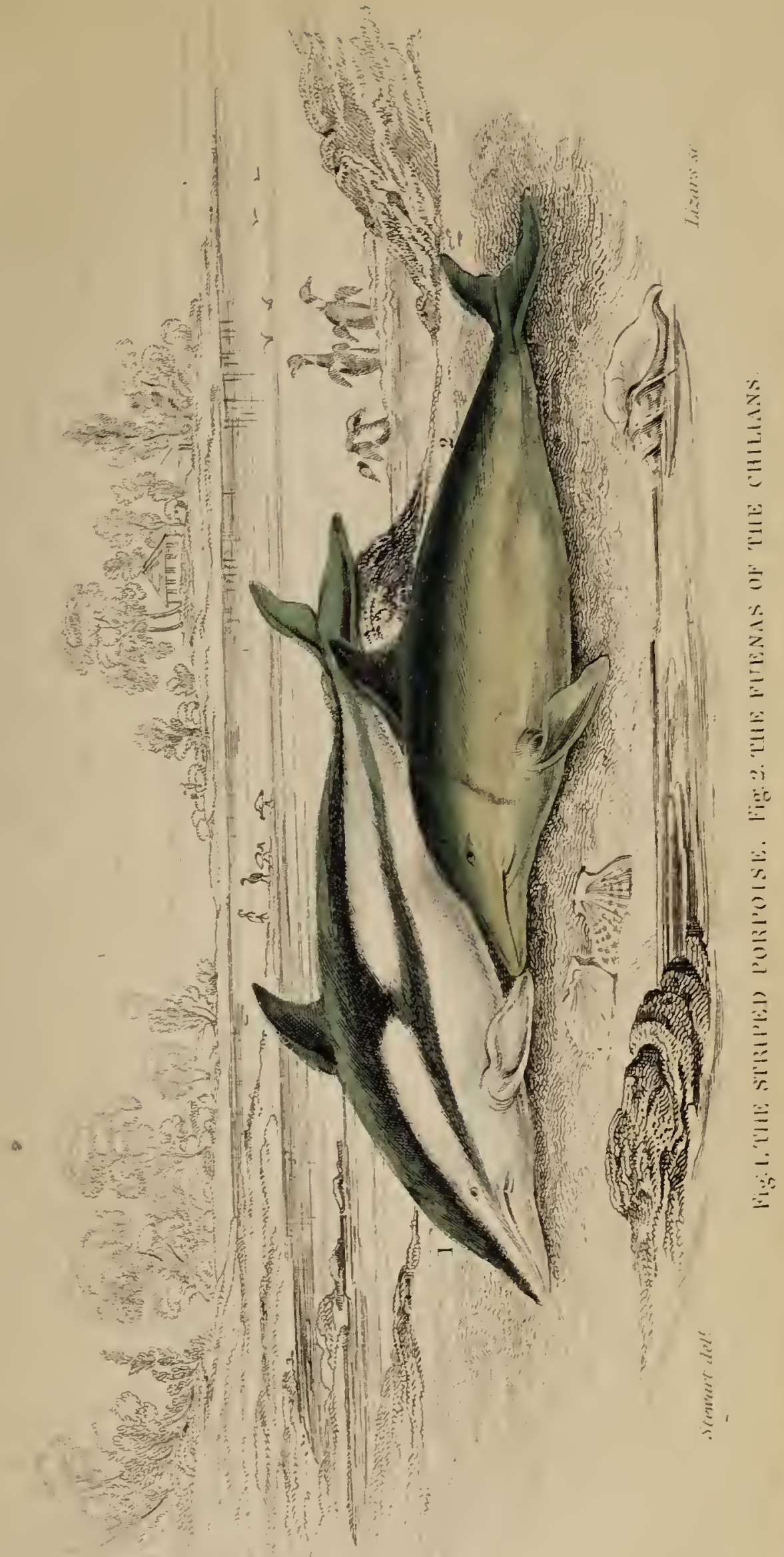



smallest of the whole group, and scarcely equalling one-fiftieth part of the length of the largest genus, -the rorqual. It is interesting as exhibiting a fair specimen of those many beautifully coloured varieties, which abound more especially in the southern seas, and excite the admiration of those who have had the good fortune to behold them. Though placed by Lesson among the Dolphins, yet as the shape of the head differs from them and corresponds with the Porpoises, we shall, as he himself advises (p. 338), arrange them with these latter.

This species was seen not far from the Falkland Islands. For a time it followed the vessel in a high sea, frequently springing over the billows, and apparently enjoyed the resistance experienced from its agitated waves. It is about two feet and a half long, and ten inches thick. It is short and also slender in its forms. The upper half of its body is of a deep shining black colour, the belly and lower jaw are white. There is a large streak of satinywhite running along each side of its body, but interrupted in the middle, opposite the dorsal fin, where the two portions of the stripe thus separated enlarge. The snout is short and conical, the dorsal fin is moderately high, black, and placed in the middle of the body; the tail is brown and scooped out in the middle; the pectoral fins are thin and white, except at the anterior edge, which is black. 


\section{Thirteenth Genus.-DeLPHINUS.}

Having a convex forehead; the snout, in form of a beak, is distinguished from the forehead by a marked furrow.

$W_{E}$ have already mentioned, that formerly the genus Delphinus included the four preceding genera and the succeeding genus. Lacépède, after separating the Delphinapteræ, introduced eleven species into his history ; and Cuvier, after withdrawing the porpoises likewise, and introducing other improvements into the classification, reduced the number of living species, established in 1823, to five (Oss. Foss. v. 275). Though the old genus Delphinus has now been broken down into no less than nine subdivisions, and there are many species in these; yet in the genus of proper Dolphins the number of species already amounts to nearly twenty, and it is the opinion of those most conversant with the subject, that this forms but a small proportion of the existing varieties. This great increase has been owing principally to the discoveries of recent voyagers, and these chiefly French naturalists, who have been sent out by their government in connexion with national voyages of discovery for scientific and commercial purposes; and who, after being rewarded for their Labours, were also enabled, at the public expense, 
to communicate their discoveries in splendid works, - far beyond the risk of private adventure. Not to go so far back as Peron, we shall only name Quoy and Gaimard, the authors of the Zoologie de L'Uranie; Lesson and Carnot, who published the Zoologie do La Coquille; and along with them M. Dussumier, who, on his own account, made several voyages to China, and, unfortunately for science, died before he had digested and published the vast stock of his materials. It is by these gentlemen that the greatest number has within these few years been added to the list.

The general features which distinguish the $\mathrm{Dol}-$ phins are few and simple. Their snout is considerably elongated, broad at the base, round at the extremity, resembling considerably a goose's-bill, whence they derive their common appellation. The beak is always flattened transversely; largest at its posterior parts, and both jaws are supplied with many and sharp teeth; it is also separated from the forehead by a distinct groove. The dorsal fin is always single.

It used to be held that the Common Dolphin was an inhabitant of every sea throughout the world. This appeared the more credible since the strength of the animals, and the velocity of their swimming, exceeding that of a ship in full sail, would readily account for their appearance in all seas, and even at the opposite poles. A very different opinion, however, is now gaining ground, confirmatory of a sentiment of Buffon's in relation to land animals, 
viz. that every distinct species has its distinct locality, and this circumscribed within rather narrow limits. It is more difficult of course to ascertain the truth of this proposition as it regards the inhabitants of the water than of the land, and yet many facts go to establish its truth with regard to the Cetacea. Much, however, remains to be done on this and other points, ere we arrive at a perfect natural history of the order. All that we can attempt in this place, is to offer some remarks on the species which we have exhibited in the plates.

\section{THE COMMON DOLPHIN.}

PLATE XXIII.

Delphinus Delphis, Linn., Bon., Lacépède, Cuvier, \&cc-OOie de Mer, Goose of the Sea.

Thrs animal is perhaps better known as the fictitious creature of unrestrained imagination and of heroic poetry, than the sober Goose of the Sea. It is uniformly considered as the Dolphin of antiquity; the original whence were produced those fantastic beings, endowed with all those extraordinary attributes and charms with which it was clothed. It is the Hieros Ichtllys, or Sacred Fish of the Greeks, to which they originally paid divine honours, and which they afterwards embellished with all the illusions of unbridled fancy. It was also sacred to their god Apollo; the reason assigned for which is, that when Apollo appeared to the Cretans, and obliged them to settle on the coast of Delphis, 


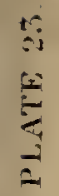



where he founded that oracle so famous throughout untiquity, he did so under the form of a Dolphin. Apollo was thus, according to Visconti, adored not only in connexion with the Delphine province, but the Delphinus fish. He was worshipped at Delphi with Dolphins for his symbols. The ancients respected the Dolphin as a benefactor of mankind; they cherished the tale of Phalantus, the founder of Tarentum, being carried on shore by a Dolphin when wrecked on the coast of Italy; and the story of the musician Arion, who, when about to be thrown overboard by the sailors that they might possess themselves of his wealth, begged that he might be permitted to play some melodious tune, and then threw himself into the sea; upon which one of the many Dolphins, which had been attracted by the music, carried him on its back safe to Tænarus; or rather, perhaps, according to Ovid,

Secure he sits, and with harmonious strains Requites his bearer for his friendly pains.

It is also recorded that the shield and sword of Ulysses bore an image of the Dolphin, and it is certain it is seen in very ancient medals and coins. It very early appeared on the shield of some of the princes of France; it gave a name to a fair province of that empire, and hence a title to the heir-apparent of the crown.

Scarcely less fabulous are those other narratives which have been transmitted on the testimony of the early naturalists. They tell us that the Dolphin 
made itself familiar with man, and conceived a warm attachment for him. Pliny narrates that in Barbary, near the town of Hippo, a Dolphin used to frequent the shore, and accept of food from any hand which supplied it; it would mix among those who were bathing, would allow them to mount its back, would consign itself with docility to their direction, and obey them with as much celerity as precision (lib. ix. chap. 48). Still more extraordinary is that other tale the ancients relate in illustration of the assertion that the Dolphin was yet more partial to children than to adults. Thus, according to Pliny, in several chronicles it was recorded that a Dolphin which had penetrated the lake of Lucrinus, in Campania, every day received bread from the hand of a child, answering to his call, and transporting him on its back to school to the other side of the lake. This intimacy continued for several years, when the boy dying, the affectionate Dolphin, overwhelmed with grief, soon sunk under its bereavement. For such stories as these, which might be easily multiplied from Herodotus, Plutarch, \&c. we apprehend that most of our readers will have but little patience; and we therefore dismiss them with the well known apophthegm,

Sed quid non Grecia mendax Audet in historia?

The Common Dolphin is usually six or seven feet long, sometimes nine or ten. Its proportions on the whole are pleasing, and admirably adapted 
for swimming, as may be seen in the Plate, to which we refer in lieu of many dry details. The pectoral is oval and placed very low; the tail is large and powerful. Its tints, thong' not gay, are attractive. It is black on the back, gregish on the flanks, and white underneath, with a peculiar and satiny glistening when in, or newly taken out of the water, which is striking and beautiful. [t may be well, however, here to remark, that " the Dolphin with its many dying colours" mentioned in many books, and sung by modern poets, is not this but quite onother animal, belonging to a different class of the animal kingdom; it is a true fish, the beautifully coloured Coryphana Hippuris, the Dorado of the Poruguese, and it would be well if its popular name were altogether dropped. The eyes of the true Dolphin are rather small, and supplied with eye-lids. The pupil is in the form of a heart. Mr. Rapp has carefully described the lachrymal gland, which Mr. Ifunter had previously pointed out. 'The smell noust be very imperfect, since the same anatomist could find no vestiges of the olfactory nerve, and there was only one small foramen in the ethmoidal plate. The meatus auditorius is apparent, though very smail. The jaws are equal, and the teeth mount up to $\frac{47}{47} 47=$ one hundred and eighty-eight; ihey are pointed, slender, and somewhat curved, at equal distances from each other, and when the mouth is shut they lock into one another. There are seren cerrical, twelve d.rsal, and fifty-two lumbar 
vertebræ. Finally, the brain of the Dolphin, as of the porpoise, is very large, and developed to an extent which is quite extraordinary among the lower animals. Its weight, in relation to that of the whole body has been stated as one to twenty-fire, which is the same as that in man; the average of four accounts stated in Cuvier's Comparative Anatomy, is one-fiftieth of the whole weight: in the castor the proportion is as one to two hundred and ninety, and in the elephant as one to five hundred. This would lead to the supposition that the intelligence and mental capacity of the Dolphin are considerable; little direct proof indeed exists, owing to the difficulty of observing the habits of the animal; but any indications which have been noticed are favourable to the supposition.

Few if any of the order appear to be more ravenous than the Dolphins. They live upon the medusa and fishes, especially upon flat fish, cod, mullets, pilchards, and herrings. They are so bold as to approach the nets, and have thus sometimes been supposed to be the auxiliaries of the fishermen.

The Common Dolphin is an inhabitant of the European Seas, of the Atlantic, and Mediterranean. It is more common in the temperate zone than in places that are further south. It is true that other species of this genus frequent the seas of Africa, Asia, and America; but it is by no means satisfactorily ascertained that the species now under consideration has this extensive range. The opposite opinion seems to be much more probable. They 
navigate the waters of the ocean in more or less numerous troops, and their vigorous springs and rapid natation, which is daily observed by voyagers, has long made them famous. The Common Dolphin has long been peculiarly signalized for these qualities, which however it enjoys only in common with the larger number of its congeners, and on these points it does not merit any particular distinction. To swim with the rapidity of an arrow, to shoot ahead of ressels which are scudding before the breeze, to spring out of the water, and over the waves, are qualifications possessed alike by all the smaller Cetacea which live in troops in the ocean.

It may serve to exhibit the change of tastes produced by modern refinement, to mention, that Dr. Caius, the celebrated founder of the College at Cambridge which bears his name, records that a Dolphin taken in his time was thought a fit and worthy present to the Duke of Norfolk, who again distributed part of it among his friends; it was roasted and eaten with porpoise sauce.

The next Dolphin we present to the notice of the reader is that of the Benedictin Pernetty 


\section{4}

\section{PERNETTY'S DOLPHIN.}

\section{PLATE XXIV.}

Delphinus Pernettii, Desm. Blainville, Lesson.

ON the 30th of October the vessel of Bougainville, in which Pernetty sailed, being near the Capede-Verd Islands, was surrounded by about a hundred Dolphins, which approached very near them. "They appeared," says Pernetty, " to have come only for the purpose of amusing us; they made extraordinary leaps out of the water; many of these in their capering vaulted four feet high, and turned over two or three times in the air."

One of these Dolphins which was taken, weighed a hundred pounds; its beak was slender, and covered with a thick and greyish skin. "I think," says the author, "it was of that species which is named the Monk of the Sea, for the anterior part of the head terminated in a hood near the root of the muzzle, and there presented something like the edge of a cloak; the back was black, and the abdomen of a pearly-grey colour, verging to yellowish, dappled with spots, some black and others of an iron-grey colour : the teeth were sharp, white, and in the form of those of the pike." To these peculiar characters, Pernetty adds those which are common to all the genus, and subjoins one which, we believe, 


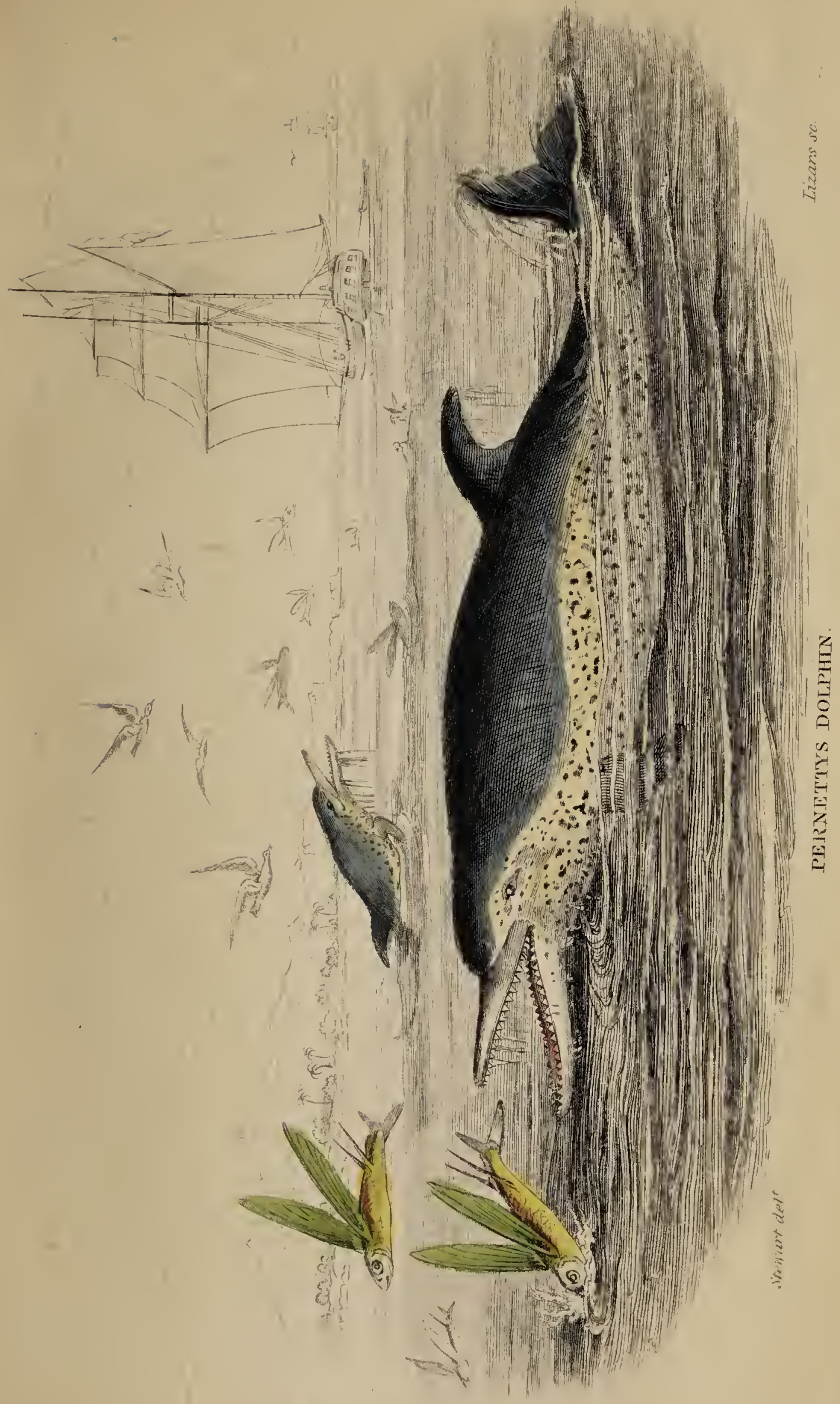



is often referred to many of them, viz. that they exhale an odour which is so strong and penetrating: that whatever substance is impregnated with it: retains it for many days, in spite of all that can be done to overeome it.

Pernetty's figure is well drawn; the beak is longer than in the common variety, and the general proportions are smaller; the lower jaw is curved and longer than the upper; the dorsal fin is more pointed and placed further back.

As furnishing a lively sketch of the habits of the whole genus, we subjoin an account of a hunt of flying-fish, as narrated by an eye-witness, a fair and interesting journalist. "The other morning a large Dolphin which had been following the ship for some distance, and was sparkling most gloriously in the sun, suddenly detected a shoal of flying-fish rising from the sea at some distance: With the rapidity of lightning, he wheeled round,-made one tremendous leap, and so timed his fall as to arrive fairly at the place where our little friends, the flying-fish, were forced to drop into the sea to refresh their weary wing. A flight of sea-gulls now joined in the pursuit; we gave up our protegês for lost, when to our great joy we beheld them rising again, for they had merely skimmed the wave, and thus recruited continued their flight. Their restless foe pursued them with giant strides, now cutting the wave, which flashed and sparkled with the reflection of his brilliant coat, and then giving one huge leap, which brought him up with his prey; they seemed 
conscious that escape was impossible; their flight became shorter and more flurried, whilst the Dolphin, animated by the certain prospect of success, grew more vigorous in his bounds : exhausted, they dropped their wings, and fell one by one into the jaws of the Dolphin, or were snapt up by the vigilant gulls. (Sketches of Bermuda by Miss S. H. Lloyd, Lond. 1835.)

\section{THE LEAD-COLOURED DOLPHIN.}

PLATE XXV. Fig. 1.

Delphinus Plumbeus, Dussumier, Fr. Cuvier.

A Reference to the plate will supersede the necessity of giving a long description of this species. The length is about eight feet; perpendicular height, where largest, one-sixth of the whole length; greatest thickness scarcely so much. The whole body is of a uniform leaden greyish tint, except the extremity and under part of the lower jaw which are whitish. Teeth $\frac{3636}{3232}$, one hundred and thirty-six.

This species was found on the Malabar coast, where it is abundant. "They frequent," says M. Dussumier," the shores and pursue the shoals of pilchards. Its movements are much less rapid than those which are found in the midst of the ocean. The natives capture them in nets, but with much difficulty, because they seem to suspect the intentions of the fishermen, and very cautiously avoid the snare. The noise of a musket makes them fly in all direc- 
$\stackrel{8}{=1}$

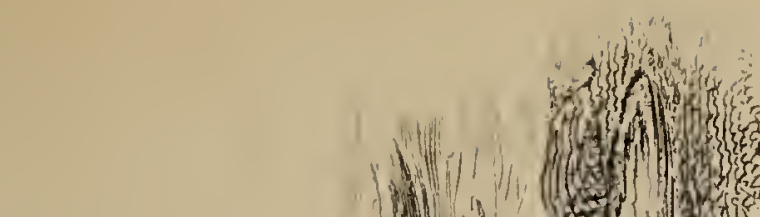

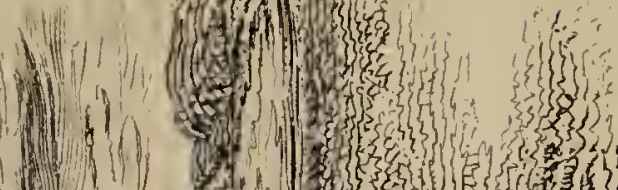

WIN

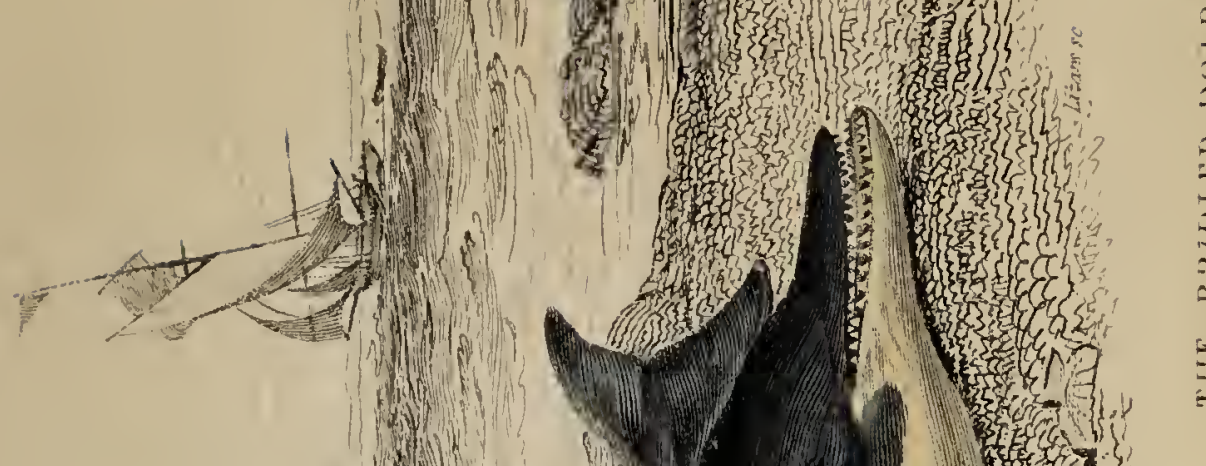

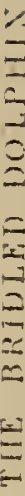

(1)

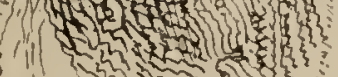
दरते की 

tions, and after having sunk under water, they take a direction different from that which their plunge would have indicated." These circumstances manifest something of that mental capacity, with which it is generally supposed the Dolphin is endowed, but which, from the veil which covers their habits, it is not easy to establish.

\section{THE BRIDLED DOLPHIN.}

\section{PLATE XXV. Fig. 2.}

\section{Delphinus Frænatus, Duss., Fr. Cuvier.}

Trie length of this specimen was four feet and a half long; the height and thickness of its body form one-sixth of the length. The spiracle is in the perpendicular over the eyes. The dorsal fin is nearly in the middle of the body; its length more than one-fifth of the whole body; its form triangular; its anterior margin straight, and equal to the base; it is very pointed. The tail has an acuminated edge, fine and cutting; its breadth is about a foot. The pectoral is long and slender. It is black on the back; this colour grows pale on the flanks; the belly is white : its head is black above; its sides are of an ash colour, and a band of a deeper shade forms a moustache on the cheek, which extends from the angle of the mouth underneath the eyes. The number of teeth has not yet been ascertained.

This Dolphin, a male, was harpooned thirty leagues to the south of Cape-de-Verd. It formed 
one of a very numerous troop, which immediately took to flight on this one being captured. The dark coloured band on the chops of this Dolphin, is the character which induced M. Dussumier to give it the name of Frænatus.

\section{DELPHINUS SUPERCILIOSUS, LESSON.}

\section{PLATE XXVI.}

THE next species we shall adduce of this genus is a very beautiful small variety, for the account of which we are indebted to M. Lesson.

M. Lesson observed this species after doubling Cape Horn in south latitude $45^{\circ}$. M. Garnot when returning to France from Port Jackson, in the Castle-Forbes, subsequently killed one and described it as follows:-Its length was four feet two inches. The snout was tolerably long, and distinguished from the forehead by a deep furrow. The dorsal fin was placed somewhat behind the middle of the body, and terminated in an acute point. All the upper parts of the body are of a brilliant blackish-blue colour, and the sides and under part shine with a silvery whiteness. The pectorals are brown, though placed on the white ground of the sides. What especially characterises this Dolphin is a large white streak over the eye, reaching to the front; and another mark like a white ribbon running along the sides of the body near the tail. Teeth $\frac{3030}{2929}$. 

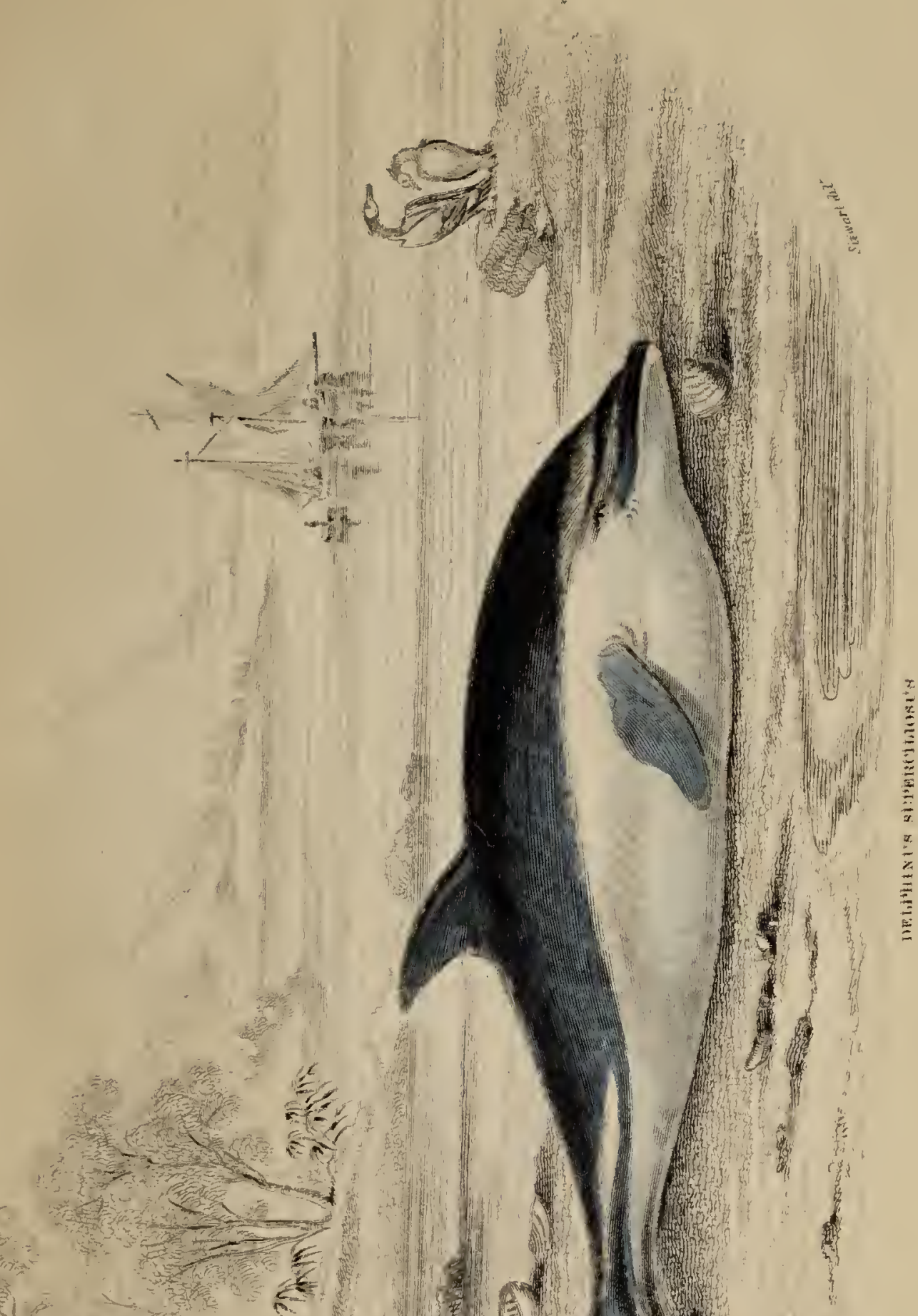

- 40 -

.
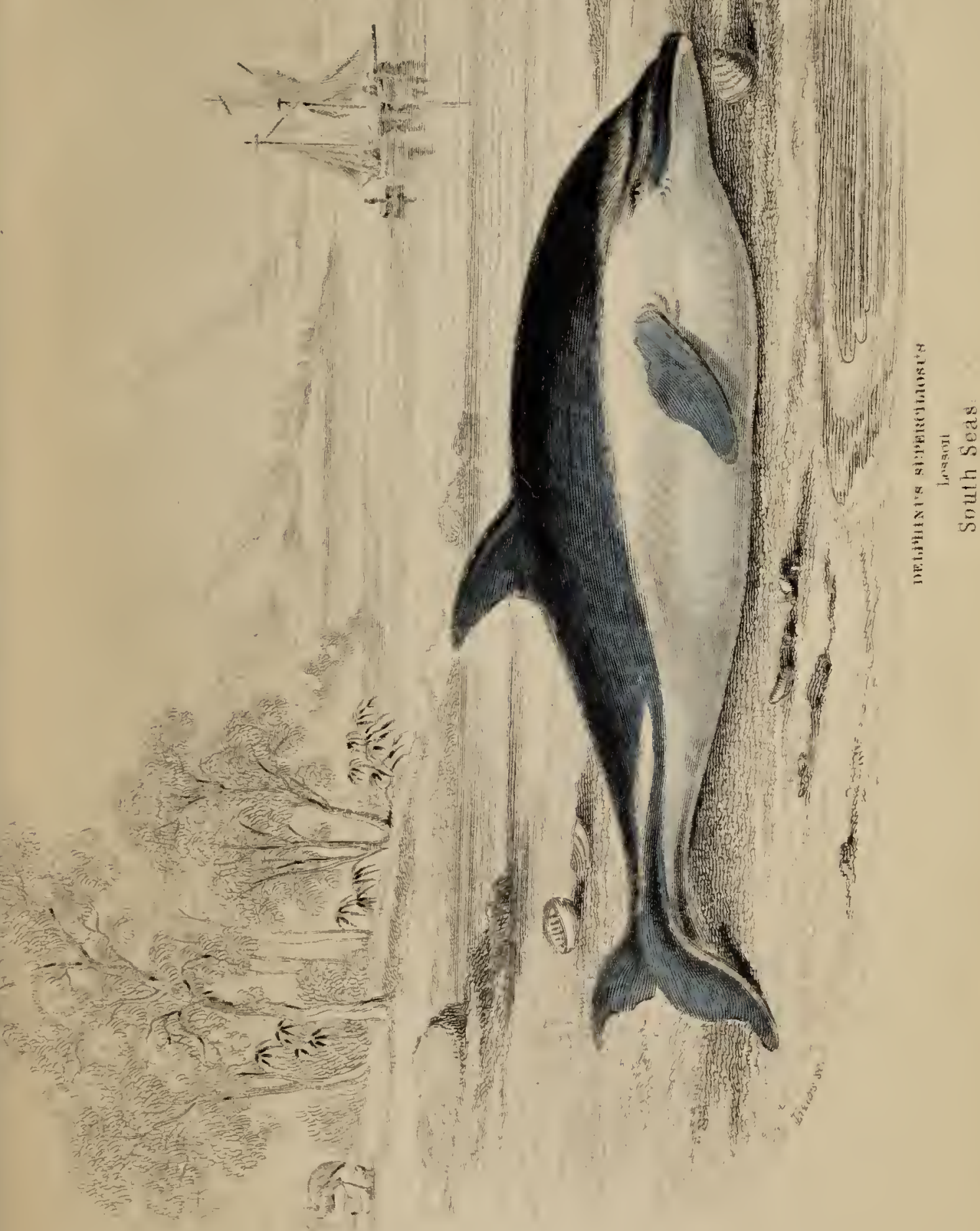

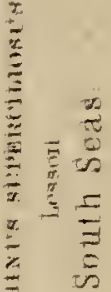

E

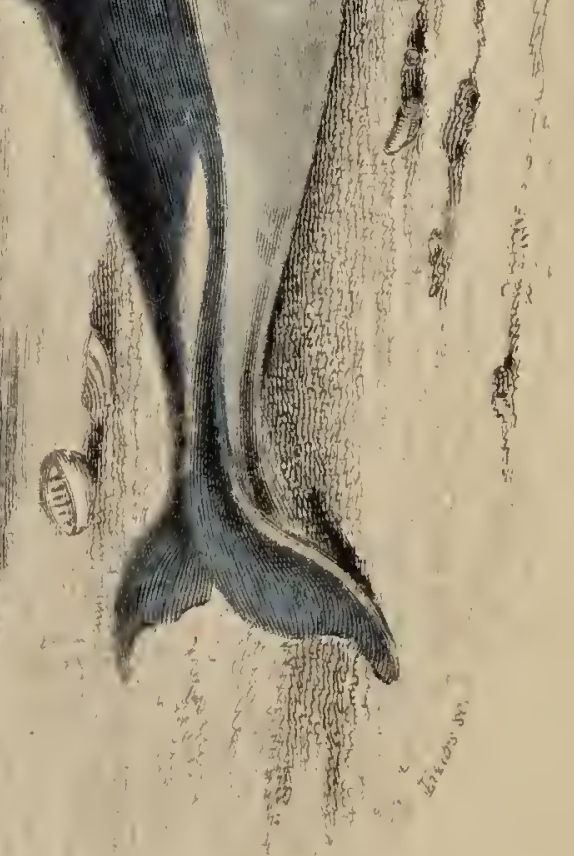

巽

is

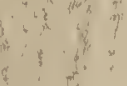




$$
=
$$


Though the markings of this sjecies are beautifu!, yet we are free to confess that we considur it next to impossible to convey, by any pictorial representation, an adequate idea of the brilliancy and variety of the colouring of many of these dolphins, which inhabit the southern and equatorial seas : they rival the hues even of the feathered tribes of the tropics. Thus, we believe, it will generally be allowed that it would be difficult, with our most highly finished colouring, to approach the appearance presented by the original of the New Zealand species, thus minutely described by Quoy and Gaimard. "Colour darkbrown above, dull white on the lower part of beak and body; a large yellow stripe commences at the eye and terminates, growing narrower on the flanks, under the dorsal fin; the tail is of a slate-colour. pale underneath; the pectorals of the colour of white lead, and also the dorsal, tipt round with black : there is a black line over the snout, becomeing larger towards the eye, which it surrounds : this line is accompanied, on either side, with a white margin; the whole body shines brilliantly.

But we must bid adieu to these numerous delphins, with a short notice of 


\section{0}

THE FUNENAS OF THE CHILIANS.

See PLATE XXII. Fig. 2.

D. Lunatus, Less., Fr. Cuv.

ThIs species is massive in its form ; it is about three feet in length; its beak is slender; its dorsal fon round at the top; its colour above, a clear fawn colour, gradually passing into white beneath; a dark-brown and accurately defined cross is seen on the back on a line with the pectorals, and anterior to the dorsal fin.

"This small dolphin," says Lesson, " destroyed an immense quantity of fish, and every morning at sun-rise, we noticed numerous troops of them, which unceasingly were diving, and appeared very busy in hunting their prey. By ten o'clock in the morning, when they had well breakfasted, they devoted themselves to play, and seemed delighted with their leaps, and their striving which should rise the highest." He adds, "we have seen this species only in the Bay of Talcaquana, in the province of Conception, but there it is in very great numbers." 


\section{DELPHINUS YOUNGII (FossIL 2 ).}

As after most of the other genera we have introduced some slight notice of nearly allied fossiles, so we shall here mention that a specimen of a doiphin in a fossile state was discovered in 1819, by Mr. Young of Whitby, in the vast aluminous schistus of the Yorkshire coast. It was embedded in the alum rock, where it is washed by the tide, and is covered at high water, half a mile east of Whitby harbour, and ten yards from the face of the steep cliff which there fronts the German Ocean. The cliff at that place is about a hundred and eighty feet in height, which of course was the depth of this skeleton from the surface, before that part of the cliff which formerly covered it was washed away. Though the skeleton was wonderfully entire, yet we are not surprised that Mr. Young found difficulty in identifying it with any living species: in all probability it belongs to a new one. As there is nothing conclusive concerning this specimen, nor concerning several others which are alluded to, we refer for more ample details to the Wernerian Trans. vol. iii. and to the Geology of the Yorkshire Coast by Messrs. Young and Bird. 


\section{2}

\section{Fodrteenth Genus.-DELPIINORHYNCUS.}

The distinguishing characters of this genus are, a prolonged snout, with a thin and long beak, which is not separated from the forehead by a furrow. The form of the jaws is straight, and they are both supplied with numerous and sharp teeth. The dorsal fin is single.

M. Blatnville introduced this generic distinction, and proposed its designation. The Cuviers, Desmaret, Lesson, and many others have adopted it. The difference is not great, yet it may be found useful in correct classification.

The only representation of this genus we supply is the

\section{DELPHINORHYNCUS OF BREDA.}

\section{PLATE XXVII.}

Delphinorhyncus Bredanensis, Less.-D. Rostratus, Cuv.Delphinus à long bec. Fr. Cuvier.

Cuvier received from $M$. Van Breda, professor of natural history at Gand, a drawing which, with an examination of certain crania, led him to recognise the existence of a new and authentic species of the order (Oss. Foss. v. 400). The specimen of which our Plate is a representation was stranded at Brest and there faithfully delineated. The animal ex- 


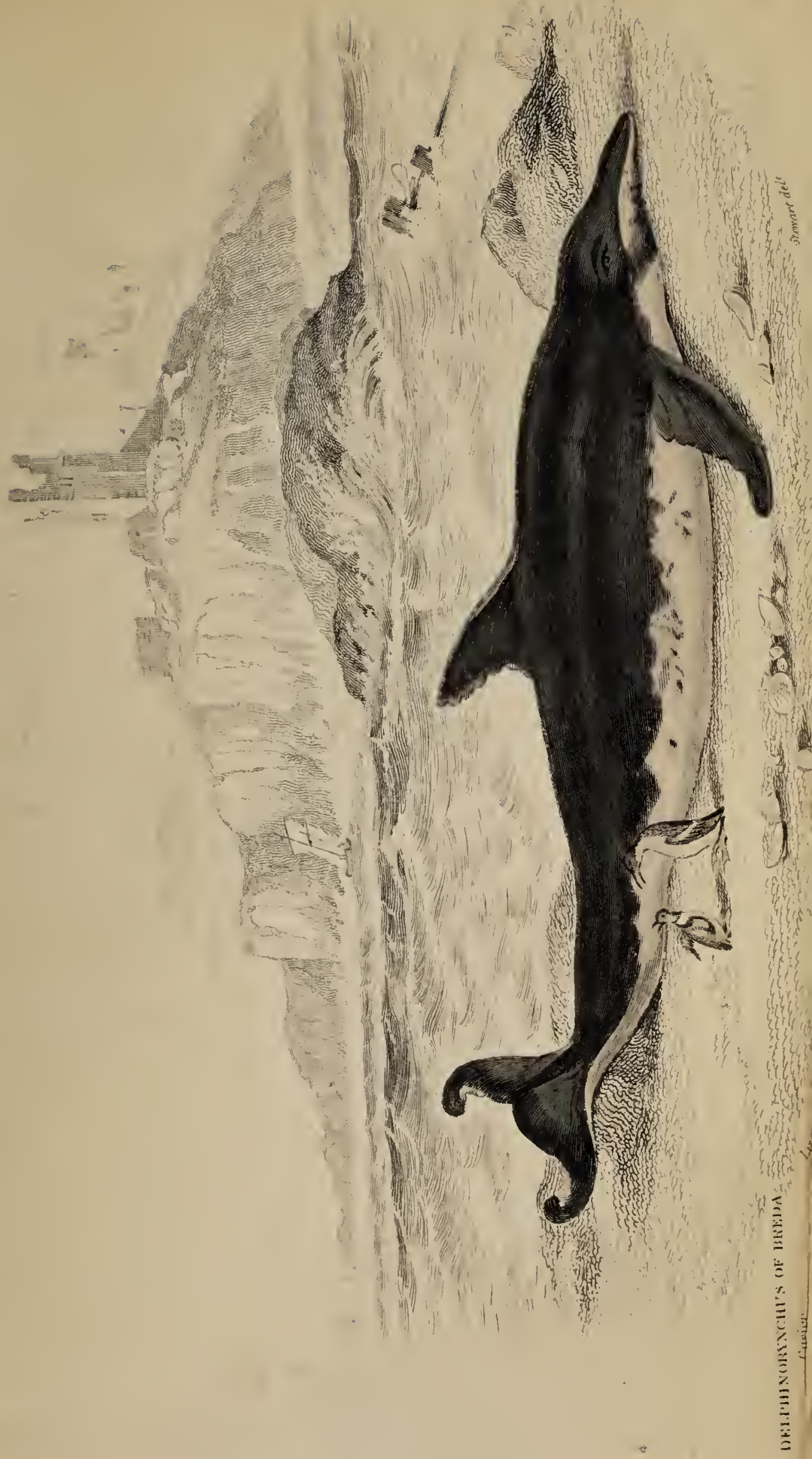



amined by M. Van Breda was eight feet long; its dorsal fin was elevated, and near the middle of the body; its pectorals were scythe-shaped; its tail crescent-shaped and curved in the middle. But what especially characterises it is the profile of the head, which insensibly loses itself in that of the snout, contrary to what is remarked in the Dolphin genus. All the upper parts of this species are of a sootyblack, and the lower of a rich rosy hue. These portions are not separated by a distinct and uniform line; on the contrary, their junction is quite irregular, and many small black patches are figured on the fairer colour. The total number of teeth are from eighty-four to ninety-two. It would appear to inhabit the Atlantic. This appears to be all the information which has been procured regarding this uniunal. 


\section{Fifteente Genus.-SOOSOO.}

The beak is long, slender, compressed at the sides, and expanded at the extremity, so that it is larger at this part than in the middle; it is also somewhat curved at its termination.

THE SOOSOO OF THE GANGES.

PLATE XXVIII.

Soosoo Gangeticus, Lesson.-Delphinus Gangeticus, Roxburgh, Lebeck, \&c.-Platanista of Fr. Cuvier.

OF all the beaked Dolphins, says Cuvier, the most extraorainary, and that perhaps which most merits being formed into a distinct genus is the Soosoo of the Ganges.

This genus at present comprehends but one living species, which is generally described under the name of the Dolphin of the Ganges; the name Soosoo is that given it by the natives in Bengal. Cuvier thinks it is probably the Platanista of Pliny. The bony frame-work proves the peculiarities of this genus more than any other portion of it, and on this Cuvier dwells with his wonted acuteness. (L. C. 279.) Of the manifest characters, the great lateral compression of the lower jaw, which approximates the two rows of teeth, and the great length of the symphysis, are the most remarkable. Accord- 

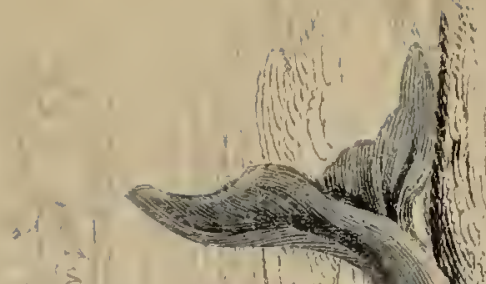

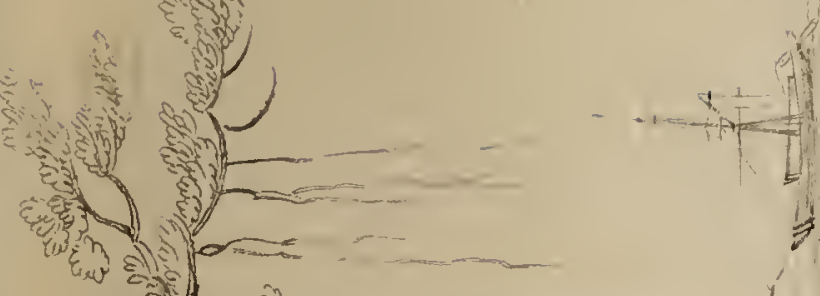
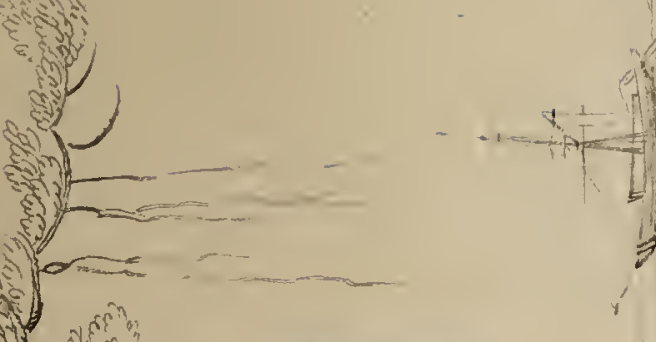

हैंड़ा की हो

हn 5 हो

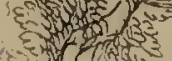

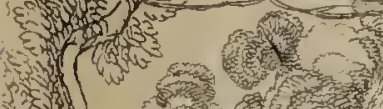

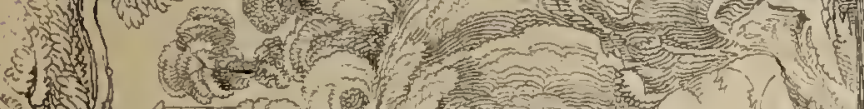

,

3,

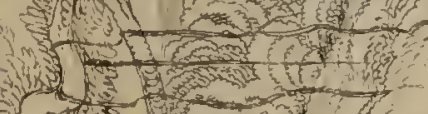

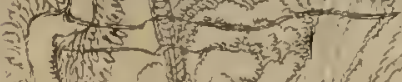

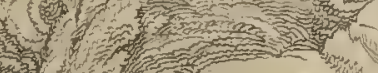

解

(1)

in
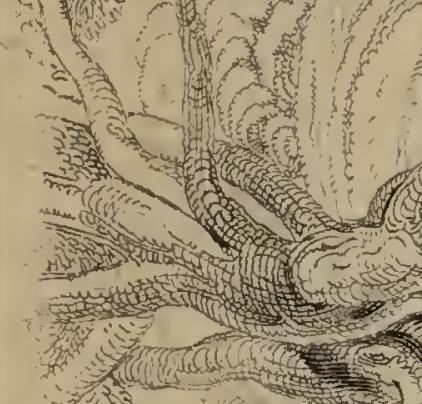

,

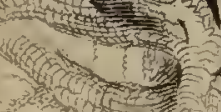

$$
\text { , }
$$



ing to Cuvier, the long symphysis and the maxillary crests approximate it to the Cachalots.

The body of the Soosoo is rather long and slender, thickest about the fore part, and thence tapering to the tail. The head is obtuse, somewhat acuminated at the upper and anterior part, and suddenly tapering to a long and slender, but strong beak. Both jaws are very strong, nearly equal, and almost straight; their length is nearly one-sixth of the whole animal. The pectorals are of an oblique faushape, about a foot and a half long, and a foot broad at the posterior margin, which is scalloped. Instead of a dorsal fin, there is only a projecting angle, somewhat nearer the tail than the snout. The tail is two feet and a half broad, and festooned. The colour is a shining pearly grey, with here and there lighter coloured spots, particularly when the animal is old. Teeth $\frac{3030}{3030}, 120$. Those before are larger, sharper, more approximated, and somewhat curved ; they become gradually smaller, shorter, and more remote from each other, as they approach the throat; and they lock into those of the opposite jaw. The eyes are exceedingly minute, about a line in diameter, of a bright shining black colour, situated four inches above the angle of the mouth, and sunk deep in their small round orbits. The spiracle is situated on the summit of the head; it is linear, and somewhat like the letter $f$, the length running longitudinally along the body. The meatus auditorius is open and observable. There are seven cer- 
vical vertebro, eleven or twolve dorsal an in swentyeight lumbar, in all fifin-ix $m$ fifty-seven.

"They are found in gicat numbers," says Dr. Roxburgh (Asiatic Resurcles, vii. 170), " in the Ganges, even so far up as it is navigable; but seem to delight most in the slow moving labyrinth of rivers and creeks which intersect the delta of that river to the south and east of Calcutta. When in pursuit of the fish on which it feeds, it moves with great velocity and uncommon activity; but at all other times, so far as I have been able to observe, its motions are slow and heavy, often rising to the surface of the water to breathe. Between the skin and flesh is a coat of pale-coloured fat, more or less thick, according to the state of the animal. On this the Hindoos set a high value, as an external remedy of great efficacy in removing pains, \&c. The f.esh is like lean beef, but so far as I can learn, the natives never eat it. In the stomach of the one examined, rice and fragments of shells were found, and many living ascarides, about two inches long." 
THE SOOSOO OF M. IIE BOROA.

Soosoo Bordaii (Fossile), Cuv.

Tris species was discovered by the late M. de Borda at Sort, a village about six miles from Dax, in beds of a species of falun, which are rich in all sorts of shells and other products of the sea. Very considerable fragments of the jaws were procured and sent to Paris, where at first they were considered as belonging to the crocodile of the Ganges. Cuvier, however, speedily demonstrated that this could not be the case, and that they must have belonged to a cetaceous animal. According to him, its head must have been two feet long, and its whole extent about nine feet. From the lower jaw, he inferred it must have been either a dolphin, in the extended signification of that term, or a cachalot; and from the fragments under inspection, it was most likely to be the latter, as none of the dolphins had the lower jaw so formed, except the Gangeticus. An examination, however, of the upper jaw speedily settled this point, in as much as it had teeth, which the cachalot has not. Curier concludes, that it is certain that this Ceté does not belong to any of the species, the osteology of which is known. Th Gangeticus has the symphysis of the lower jaw ex- 
tremely compressed, whilst that of this fossile is broader than it is high. The teeth also are quite of another form. Neither the level above the sea, nor the relation of the specimen to the neighbouring country, are rerorded in the source whence we have extractea tnis truy interesung notice. 


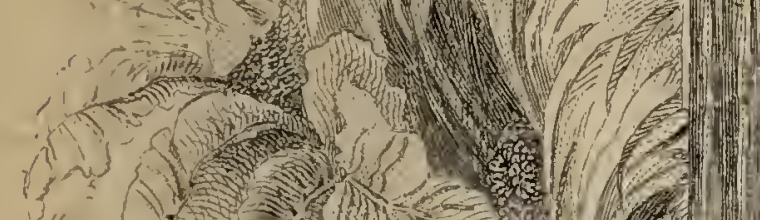

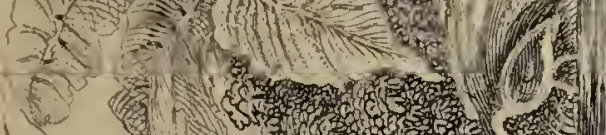

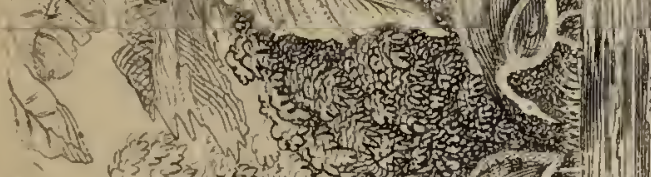

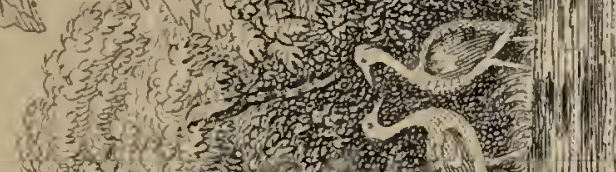

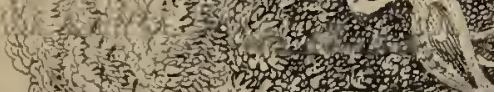
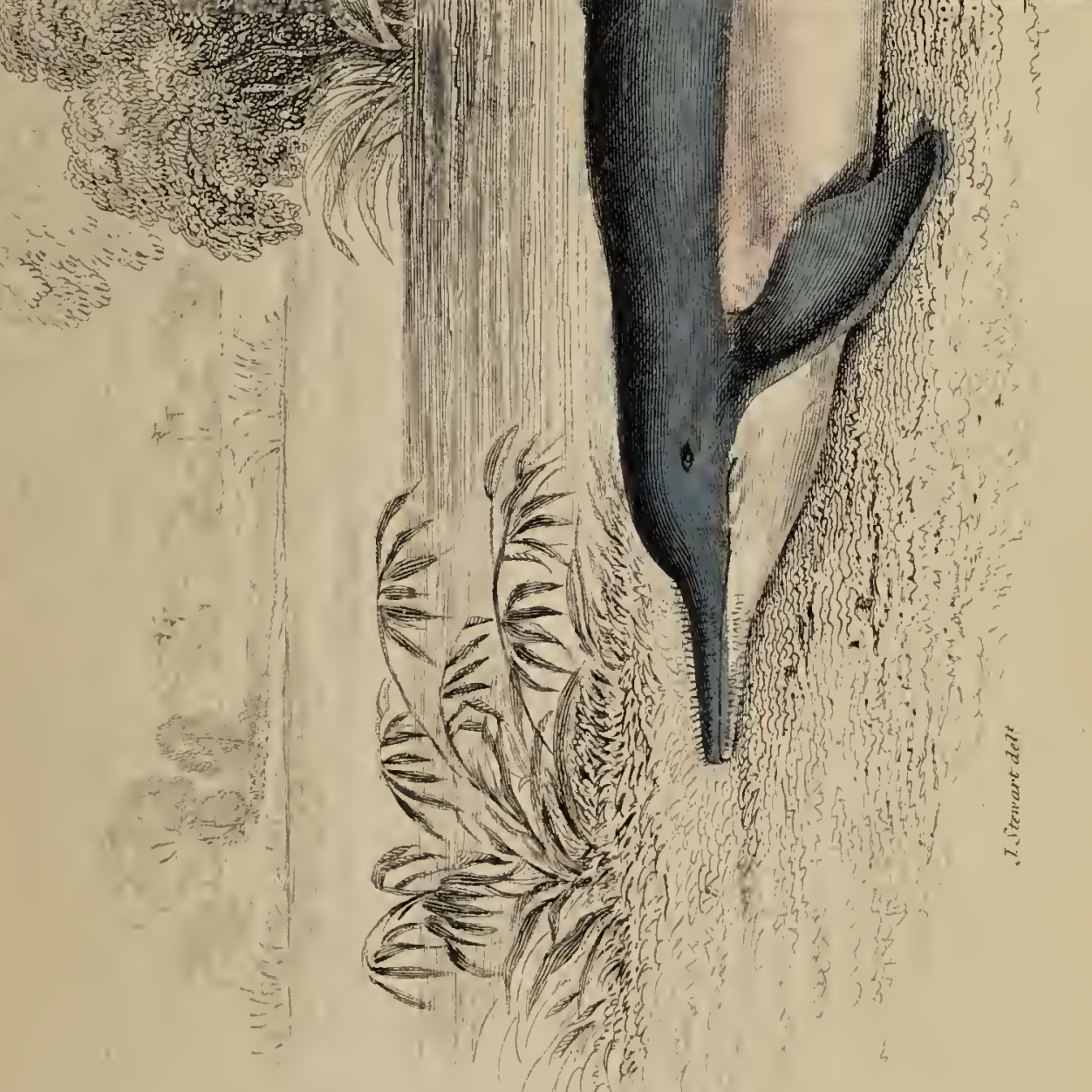



\section{$25 \dot{y}$}

\section{Sixtefenth Gentss.-INIA.}

The Inia has the beak long like that of the Dolphin, but cylindrical, and bristled with strong hairs; it has many teeth, incisors anteriorly, molars posteriorly. The temporal fossa and crest are also peculiar.

I. BOIdVIENSIS, D’Ordigny, Fr. Cuvigr.

\section{PIATE XXIX.}

IT is to M. D'Orbigny we are indebted for our acquaintance with this curious animal, which he has very properly placed in a new genus, thereby establishing a link between the Soosoo and the Stellerus, one of the herbiverous Cetæ. We have found the Soosoo in the water of the Ganges, a hundred miles from the ocean. But the Boliviensis is met with thousands of miles from the sea, and it appears to be an inhabitant solely of rivers and fresh water lakes. It was in the early tributaries of the Amazons, and in the lakes of High Peru, it was found ; and when M. D'Orbigny first heard of it in these regions, he was not a little sceptical that he should encounter one of the whale tribe at the foot of the Cordilleras.

In the principality of Beira, however, where they are in the habit of killing them for their oil, one was harpooned, and brought to the party alive; 
another very young one was also at the same time examined.

In form it resembles the Dolphins, but the body is shorter and more slender. The snout is in the form of a long and very slender beak, almost cylindrical, and obtuse at its extremity. The lips reach as far back as the line of the eye; the blow-hole runs obliquely from before backwards, and opens so far back as to be in the perpendicular over the pectoral fins. The auditory opening is larger than is usual in the Cetæ. The pectorals are large; the dorsal, but little developed, is placed two-thirds down the back; the tail is deeply forked. It has about one hundred and thirty-four teeth $\frac{34}{33} \frac{34}{33}$; all are rough, and marked with deep and interrupted furrows; anteriorly they resemble incisors, posteriorly they have an irregular mammalory shape, which is very peculiar. The skin is fine and smooth; the snout is bristled sparingly with coarse and crisp hair: this was seen also in the cub. The mother was seven feet long; and the males are said to be double that size. Its colour varies : commonly it is a pale blue above, passing into a rose colour beneath; the tail and pectorals are blue. Some are all over of a rosy hue, others are blackish, and some are covered with spots and streaks; the tints are paler when they frequent the rivers, and darker when they retire to the lakes.

This species is found in all the streams which traverse the immense plains of the province of 
Moxos, and which go to form the rivers constituting the Marlieras, one of the earliest branches of the Amazons ; the animal ascends almost to the foot of the Eastern Cordilleras, more than two thousand one hundred miles from the sea: but it is not probable that it goes beyond the cascades of the river Madieras.

This Inia comes more frequently to the surfice of the water than the marine varieties, and does not appear so remarkable for the agility and power of its motions. They habitually unite in little troops of three or four individuals, and they are observed to raise their snouts from the water whilst devouring their prey, which appears to consis entirely of fish. The mother exhibits all the usuat sifection of the order for her young, and is all devotedness to its wall-being and rety. 


\section{2}

\section{Serenteenth Genus._OXYPTERUS.}

With two dorsal fins.

M. Refinesque Sraltz, a naturalist established in Sicily, proposed this name for a dolphin with two dorsal fins, which he affirmed he had seen in the Mediterranean. The evidence he gave of its existence was unsatisfactory, and had not Messrs. Quoy and Gaimard, in their voyage, met with another example of this very singular genus, it would probably have been passed by in this place. This was the

\section{RHINOCEROS WHALE.}

Oxypterus Rhinoceros, Lesson.-Delphinus Rhinoceros, Quoy and Gaimard.

As no individual of this species was captured, we cannot present any plate which could be depended. upon ; we copy, however, from the atlas of Quoy and Gaimard, a cut which will assist the imagination and rivet the peculiarity on the memory.

We shall quote the words of these eminent royagers. "In October 1809, in going from the Sandwich Islands to New South Wales, many Dolphins, in troops, were performing their rapid evolutions about our vessel. Every one on board was 

surprised to perceive that they had a fin on thicir head bent backwards, the same as that on their backs. The size of this animal was about double that of the common Porpoise; and the upper part of its body to the dorsal fin was spotted black and white.

"We did our best to examine them, all the time they accompained us; but although they often passed the prow of the vessel, with the highest part of their back out of the water, yet their heads were so suhmerged, that neither M. Arago nor we could discover whether their snout was long or short; and their habits could not assist us on this point, because they never sprang above the wave, as is common with other species. From their very singular confomation, we have assigned tnem tinen name-Rhinoceros.* 
